\title{
Nanoscale
}

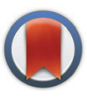

CrossMark

\& click for updates

Cite this: Nanoscale, 2015, 7, 10294

\section{Improving the fracture toughness and the strength of epoxy using nanomaterials - a review of the current status}

\begin{abstract}
N. Domun, ${ }^{a}$ H. Hadavinia, ${ }^{a}{ }^{a}$ T. Zhang, ${ }^{a}$ T. Sainsbury, ${ }^{b}$ G. H. Liaghat ${ }^{a}$ and S. Vahid ${ }^{a}$
The incorporation of nanomaterials in the polymer matrix is considered to be a highly effective technique to improve the mechanical properties of resins. In this paper the effects of the addition of different nanoparticles such as single-walled CNT (SWCNT), double-walled CNT (DWCNT), multi-walled CNT (MWCNT), graphene, nanoclay and nanosilica on fracture toughness, strength and stiffness of the epoxy matrix have been reviewed. The Young's modulus (E), ultimate tensile strength (UTS), mode I ( $\left.G_{1 C}\right)$ and mode II ( $\left.G_{\| C}\right)$ fracture toughness of the various nanocomposites at different nanoparticle loadings are compared. The review shows that, depending on the type of nanoparticles, the integration of the nanoparticles has a substantial effect on mode I and mode II fracture toughness, strength and stiffness. The critical factors such as maintaining a homogeneous dispersion and good adhesion between the matrix and the nanoparticles are highlighted. The effect of surface functionalization, its relevancy and toughening mechanism are also scrutinized and discussed. A large variety of data comprised of the mechanical properties of nanomaterial toughened composites reported to date has thus been compiled to facilitate the evolution of this emerging field, and the results are presented in maps showing the effect of nanoparticle loading on mode I fracture toughness, stiffness and strength.
\end{abstract}

Received 1st March 2015, Accepted 1st May 2015

DOI: $10.1039 / \mathrm{c} 5 \mathrm{nr} 01354 \mathrm{~b}$

www.rsc.org/nanoscale cations, from composite wind turbine blades in the renewable energy sector to the highly complex structural parts of aeroplanes. $^{1-6}$ Developed in $1960,{ }^{7}$ the diglycidyl ether of bisphenol A (DGEBA) is the epoxy resin commonly used by most researchers. They are also extensively being employed as engineering adhesives and the matrix for fibre reinforced plastics (FRP) due to their highly beneficial properties such as high adhesion strength and good process ability. The uncured epoxy resins have only poor mechanical, chemical and heat

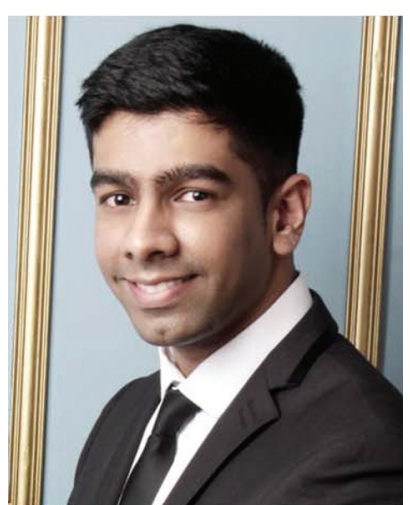

Nadiim Domun
Nadiim Domun is a PhD student in the School of Mechanical \& Automotive Engineering at Kingston University London. $\mathrm{He}$ is currently working on the development of novel nanocomposites using CNT/graphene nanoparticles for the improvement of the ballistic performance of FRP composite structures.

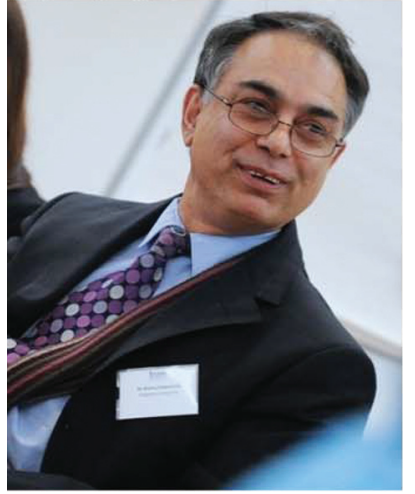

Homayoun Hadavinia is an Associate Professor in Composite Materials at Kingston University London; his background is in fatigue and delamination mechanisms in FRP composite materials. The focus of his work on nanocomposites has been to develop new resins for improved performance of fibre reinforced polymer composites.

Homayoun Hadavinia 
resistance; by reacting the linear epoxy resin with suitable curatives, three-dimensional cross-linked thermoset structures can be obtained. ${ }^{1}$ This is ideal for the mechanical and thermal properties, resulting in high modulus, failure strength and great bonding for many industrial applications. ${ }^{8,9}$

However, there are a few drawbacks which point to highly unsatisfactory properties; a higher cross-link density contributes to lower fracture toughness, which restricts their applications. A number of researchers ${ }^{10-12}$ have concluded that high cross-link density will decrease the fracture toughness of pristine epoxies due to internal stresses induced during curing of the epoxy. Within a high cross-link density epoxy, resistance to crack initiation is very low and the void growth due to plastic deformation is constrained.

These drawbacks can be overcome by modifying epoxy resins with integration of various nanofillers as a second microphase, for advanced composite applications. ${ }^{13-16}$ The blending of epoxy resins with nanofillers is a step towards increasing the fracture toughness of thermosetting polymers. With the existing benefits provided by resins such as good stiffness, specific strength, and low cure shrinkage, the performance of the epoxy can be further improved by the use of fillers and engineered according to a unique application. ${ }^{17}$ The emergence of nanocomposites has attracted great interest amongst researchers and the research studies show that the improvement of mechanical properties and toughness of materials can be achieved by using highly prospective fillers.

The amalgamation of rubber along with other potential nanofillers dispersed in epoxy resins ${ }^{18-23}$ has also been an area of interest for many researchers. It was observed that there is a substantial increase in fracture toughness and ductility but, on the other hand, decreases in the stiffness of the cured polymers. $^{24}$ Low modulus rubber particles usually decrease the stiffness and thermal properties of polymer-based materials. $^{25,26}$

The use of nanorubber as a second phase to reinforce epoxy has also been an area of interest for many researchers. As highlighted by Zhao et al., ${ }^{14}$ carboxylic nitrile-butadiene nanorubber (NR) particles were incorporated in DGEBF epoxy resin to enhance its tensile strength and fracture toughness. A similar study conducted by Dadfar et $a .^{27}$ using carboxyl-terminated butadiene acrylonitrile (CTBN) demonstrated an enhancement in the fracture toughness properties of the resin.

Hydroxyl terminated polybutadiene (HTPB $)^{28-30}$ liquid rubber incorporated into epoxy resin has been used in several studies in an attempt to improve the toughness, strength and stiffness of the nanocomposite. The properties of the resulting nanocomposite were modified, leading to better performances.

The research of Tang et al. ${ }^{31}$ was based on two different types of rubber, namely the phase-separation-formed submicron liquid rubber (LR) and preformed nanoscale powered rubber (PR) particles, opted for the toughening mechanisms of epoxy composites. The introduction of those particles allowed better mechanical properties to be achieved as well for the glass-transition temperature. The work of Chen et al. ${ }^{32}$ focused on the mechanical properties and toughening mechanisms of epoxy using polysiloxane-based core-shell particles (S-CSR). It was found that the mechanical properties of the resulting nanocomposite decrease whilst a significant improvement in the fracture toughness was observed from $117 \mathrm{~J} \mathrm{~m}^{-2}$ to $947 \mathrm{~J} \mathrm{~m}^{-2}$ after the introduction of S-CSR into the epoxy resin. The toughening mechanisms were mainly caused by cavitation of the particles followed by void growth.

Toughness is regarded as a crucial property in determining whether the resulting material is appropriate for a specific application without fracturing. ${ }^{33,34}$ The toughening mechanisms of epoxies ${ }^{35}$ have been investigated with various effective approaches. For this purpose, several types of nanomaterials are currently being used and tested; among the most promising ones are carbon nanotubes (SWCNT, DWCNT, and MWCNT), graphene, nanoclay and nanosilica.

The main aim of this paper is to provide a review on the mechanical properties including fracture toughness performance of the epoxy resin modified by different nanomaterials.

A lot of studies on processing of nanocomposite materials have been carried out by many researchers. ${ }^{36-40}$ Most of the reviewed data in this paper are based on the DGEBA epoxy

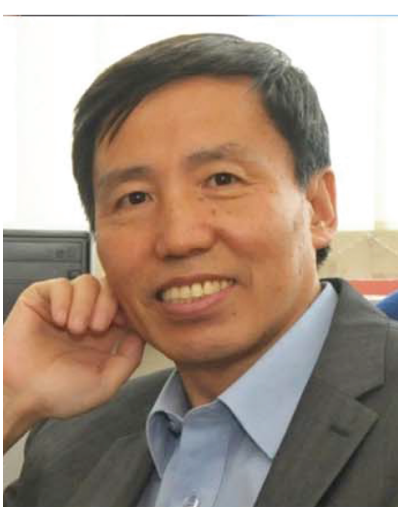

Tao Zhang
Tao Zhang is a Professor in Materials Engineering at Kingston University London. His research interests are: numerical analysis for process optimisation and new process design; thermal spray and other surface coating processes; net shape forming of ceramics; improving the performance of materials using nanomaterials.

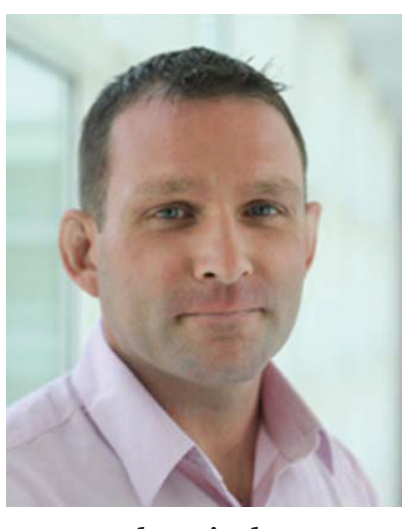

Toby Sainsbury
Toby Sainsbury is a Senior Research Scientist within the Materials Division at National Physical Laboratory (NPL) in the $U K$ and is currently conducting research concerned with packaging and protection of graphene materials and with the development of chemically functionalized graphene and analogous $2 D$ nanosheet materials directed towards band-gap manipulation, sensing, catalysis and composite materials. 
matrix. In this paper the mechanical properties and fracture toughness performance of numerous nanofillers were compiled to facilitate the development of the nanocomposite in this evolving field. The focused approach is based on the classification of incorporating CNTs, graphene, nanoclay and nanosilica as nanofillers in the epoxy resin.

\subsection{Epoxy}

Toughening of epoxy resins ${ }^{41}$ has been at the forefront of many research studies since the early 1980s. Despite the numerous advantages that it offers such as excellent mechanical properties and thermal stability, ${ }^{42-44}$ epoxy is fundamentally brittle due to its high crosslink density. The deficiency in toughness properties is one of the key drawbacks in spreading its use across numerous applications. A governing approach for increasing the toughness of the latter was to add a second phase also known as micro-fillers or nanoparticles, which activates during the curing treatment process, able to trigger toughening mechanisms during crack propagation. These materials exhibit a high specific strength to weight ratio, low density, high stiffness and high fracture toughness. The key objective of reinforcing epoxies is to allow the desired properties to be tailored according to the engineering needs whilst keeping the cost low.

The simplest epoxy is known as alpha epoxy or 1,2-epoxy which consists of three-member ring structure. ${ }^{31}$ It is normally cured from an amine hardener in a range of $5-150{ }^{\circ} \mathrm{C}$. The most common epoxy resins which are currently being used are the diglycidyl ether of bisphenol A (DGEBA), tetraglycidyl diamino diphenyl methane (TGDDM), triglycidyl p-amino phenol (TGAP) and diglycidyl ether of bisphenol F (DGEBF). Fig. 1 shows the synthesis of epoxy monomer from bisphenol A (DGEBA) and epichlorohydrin. Chen et al. ${ }^{45}$ studied the cryogenic mechanical properties of the MWCNT reinforced DGEBF epoxy nanocomposite in an attempt to improve the high requirements of cryogenic engineering applications in various sectors. They concluded that the cryogenic tensile properties as well as the impact strength were all improved by the incorporation of MWCNT nanoparticles. Zhang et al. ${ }^{46}$ investigated
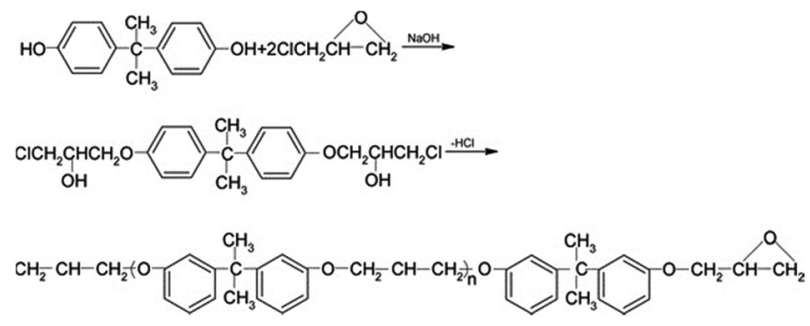

Fig. 1 Synthesis of epoxy monomer from bisphenol A (DGEBA) and epichlorohydrin. ${ }^{7}$ Reprinted with permission from ref. 7 (Copyright (C) 2014 Taylor \& Francis).

the effect of enhancing DGEBF with nanosilica at different temperatures. Testing was carried out at room temperature $\left(23{ }^{\circ} \mathrm{C}\right.$ ) and $80^{\circ} \mathrm{C}$. The improvement in fracture toughness was significantly higher than that observed for the stiffness.

Amongst all the epoxies, the commercial DGEBA epoxies are generally low in molecular weight, consisting of high reactive functional groups and extremely high cross-linkage which increase the glass transition temperature. Superior adhesion acquired after the curing process with hardeners can be achieved due to these resins possessing more hydroxyl groups in their backbones. Several studies conducted on the most common epoxies such as (1) bisphenol A (DGEBA), (2) phenolphthalein (DGEPP), and (3) 9,9-bis(4-hydroxyphenyl)fluorine (DGEBF) were evaluated by Lin et $a l^{47}$ At similar curing settings, the cross-linkage densities were assessed, demonstrating that DGEBA was much better than DGEBP followed by DGEBF.

With the ductility of the epoxy as a critical factor, the modification of epoxy resin is essential in an attempt to enhance the ductility, tensile strength and fracture toughness properties. There are different ways of modifying the epoxy. Those are (1) elastomeric modification, (2) thermoset modification and (3) thermoplastic modification amongst others.

Elastomer modification based on epoxy monomer is normally carried out using soft rubber particles in various forms in an attempt to optimise the epoxy matrix system. Many

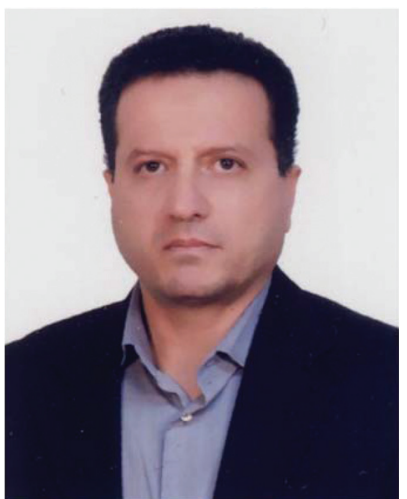

Gholamhossein Liaghat

Gholamhossein Liaghat is a Professor of impact mechanics at Tarbiat Modares University; his research interests are in the penetration and perforation process of ceramic/polymer composite structures by experimental and analytical methods and modifying the resin of fibre reinforced polymer composites to increase their impact and

ballistic performance.

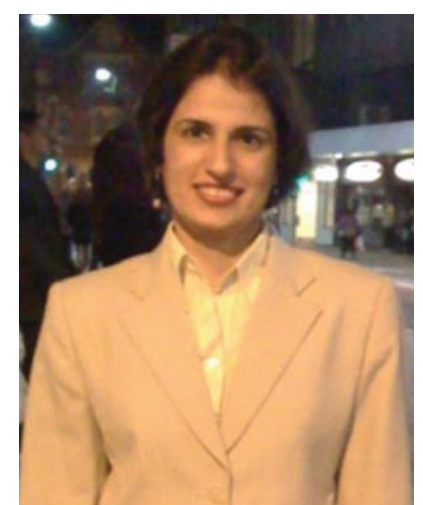

Samireh Vahid
Samireh Vahid is a lecturer at Kingston University London; her research interest is in applied engineering mathematics. In particular, she is interested in rheology for a better understanding of the fluid dynamics of confined nanoparticles in the polymer matrix for application in FRP composite materials. 
researchers ${ }^{48,49}$ have focused their studies essentially on the use of rubber particles as toughening mechanisms to enhance the fracture toughness. Yee and Pearson ${ }^{50}$ used several types of carboxyl-terminated butadiene nitrile liquid rubber to study the toughening mechanisms in elastomer-modified epoxies. The particle-size on the deformation mechanisms was highly critical to reinforce the epoxy system.

Thermoset is generally in liquid or malleable form before curing and cannot be reheated once it has been hardened. Generally carried out using polyester, vinyl ester or polyurethane, thermoset modification has been an area of interest, used as fillers in epoxy due to low manufacturing cost, easy processing and high molecular weight properties. As reported by some researchers, ${ }^{51-53}$ the mechanical and fracture properties of the epoxy resins are enhanced due to low viscosity of the unsaturated polyester. Chinnakkannu et al. ${ }^{54}$ studied the fracture toughness of vinyl esters incorporated into epoxy resins. Higher loading content of 5, 10 and $15 \mathrm{wt} \%$ of vinyl ester oligomer caused an improvement in the mechanical properties due to the formation of a complicated cross-linked network.

Thermoplastic normally has a reversible cycle, changing from the solid state to the liquid state or vice versa. Thermoplastic modification used in an epoxy system has thus major advantages, typically high stiffness and fracture toughness compared to some of the elastomer and thermoset modifications, where there is a decrease in the thermal and mechanical properties. ${ }^{55-58}$ The frequently used thermoplastics are poly(amide-ester), poly(acrylonitrile-co-butadiene-styrene) (ABS), poly(aryl ether ketone), polybutadiene (PB), polybutylene terephthalate (PBT), polycarbonate (PC), poly(ether ketone) (PEEK) and poly(etherimide) (PEI), amongst others.

\subsection{Dispersion of nanomaterials}

The optimal performance of the nanocomposite may be achieved by proper dispersion of nanofillers in the resin. The dispersion of different nanomaterials into the epoxy matrix has been investigated by many researchers e.g. ref. 59-61. There are crucial stages that need to be observed in order to achieve an adequate reinforcement. When homogeneous dispersions are attained, the performance of the nanocomposite increases significantly due to load transfer to the nanomaterials. In addition, higher aspect ratio, alignment and stress transfer will also contribute to a higher performance of the polymer. ${ }^{62}$

Curing behaviour of epoxy is fundamentally affected by the addition of nanomaterials. Incorporation of nanomaterials into the epoxy matrix system often results in viscosity build-up and shear-thinning behaviour of the latter. ${ }^{63}$

Two distinct methods for the dispersion of nanomaterials in the resin are the mechanical and the surface functionalization methods. ${ }^{64}$ Solution mixing, ultra-sonication (Fig. 2), calendering and ball milling are the most common techniques used for dispersion depending on the type of nanomaterial. ${ }^{65-67}$ Solution mixing is the most common technique used for processing $\mathrm{CNT} /$ polymer by mixing with an appropriate solvent. ${ }^{68,69}$ Ultra-sonication is another method of exerting ultrasound energy to the nanomaterials for agitating the particles by using an ultrasonic probe. The sonication process, if not monitored appropriately, can cause serious damage to the CNTs and affect the mechanical and fracture properties of the nanocomposite. ${ }^{70}$

Also known as three roll mills, calender is regarded as an encouraging method to achieve good dispensability as confirmed by some studies. ${ }^{45,46}$ High shear stress is applied to disentangle CNT bundles, allowing a homogeneous dispersion process to take place. However, research carried out by $\mathrm{Fu}$ et $a .^{71}$ was not in agreement with the previous statement. The same approach using the three-roll calendaring technique was used to prepare the CNT based epoxy nanocomposite. After processing the composites, the original length of the CNT was reduced, eventually affecting the mechanical properties resulting in poor performances. Retaining the residual CNT length is very critical in achieving optimal mechanical properties.
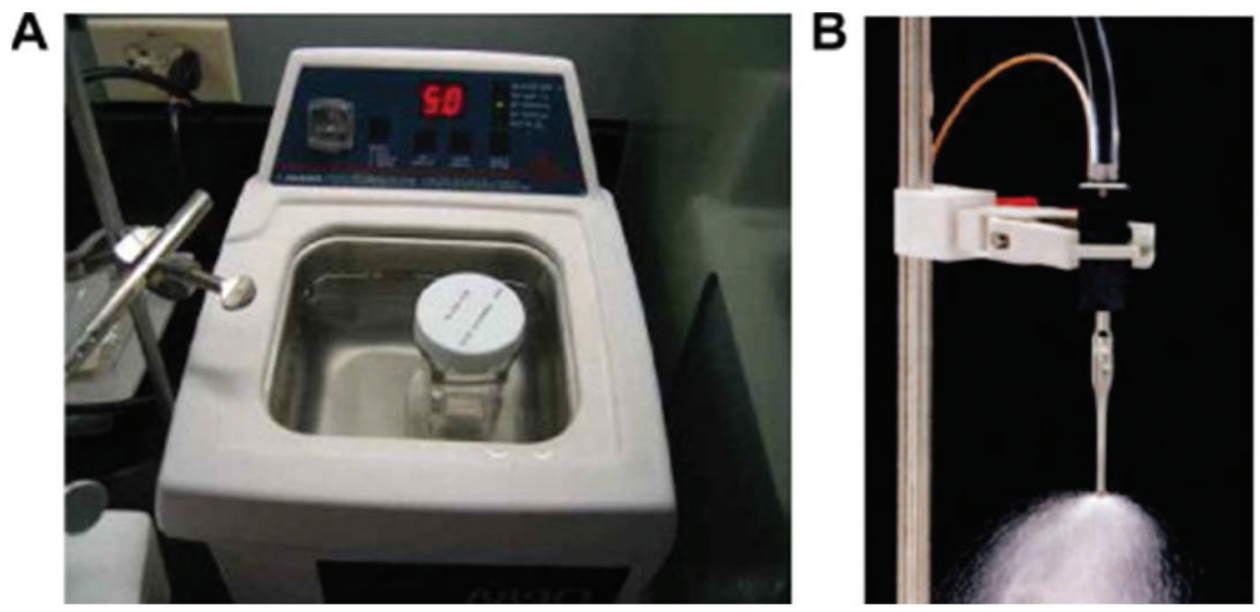

Fig. 2 Water bath sonicator (A); probe/horn sonicator (B). ${ }^{74}$ Reprinted with permission from ref. 74 (Copyright $\odot 2010$ Elsevier). 
(a)

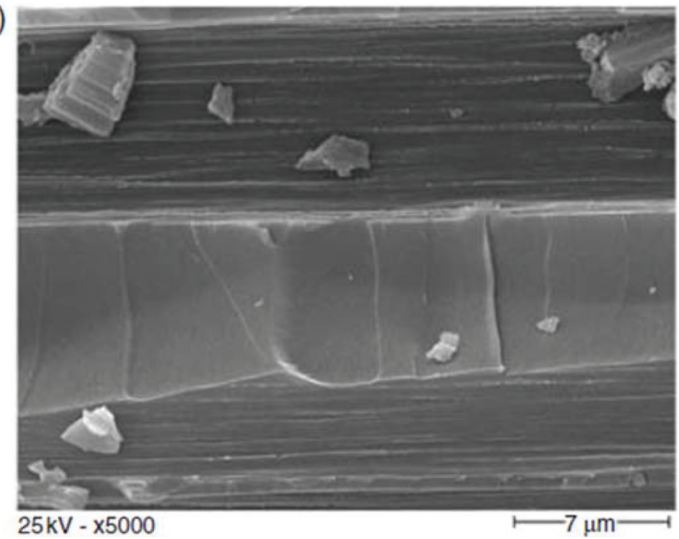

(c)

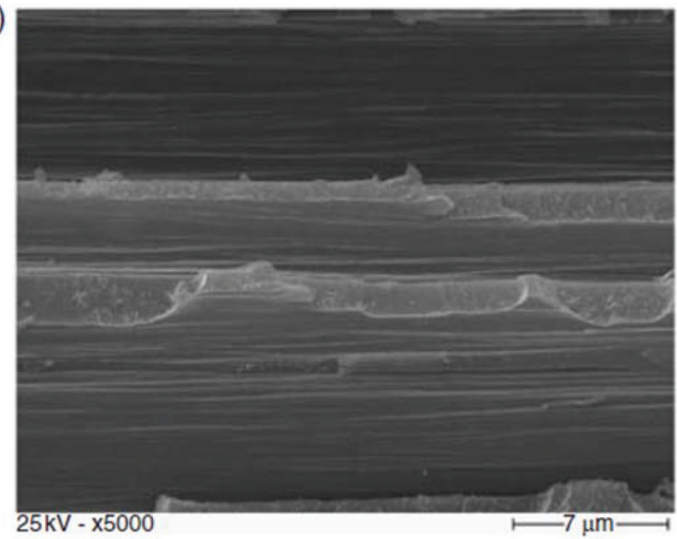

(b)

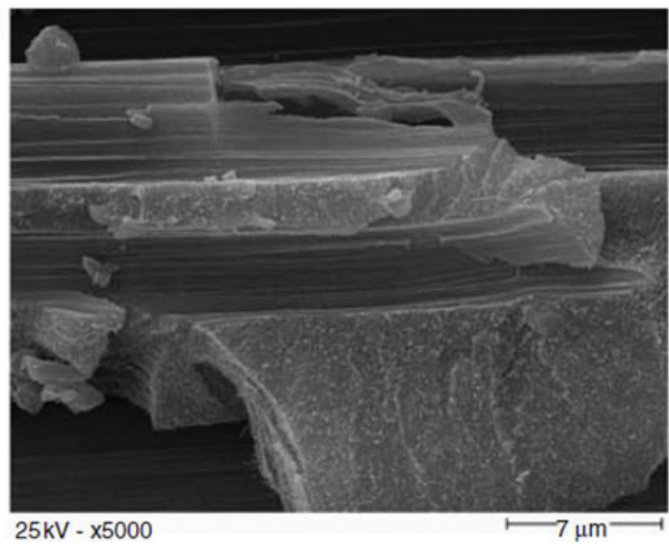

(d)

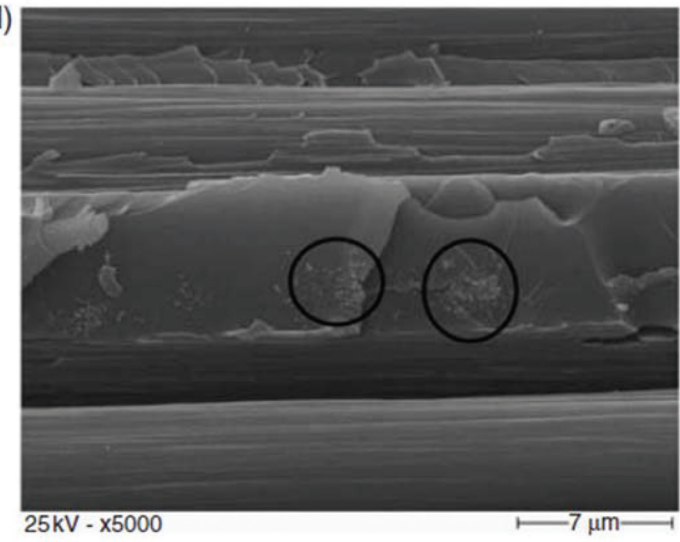

Fig. 3 SEM images for (a) neat epoxy, (b) $1 \%$ of MWCNT, (c) $0.5 \%$ of MWCNT and (d) $0.1 \%$ of MWCNT under mode I loading ${ }^{81}$ Reprinted with permission from ref. 81 (Copyright @ 2009 Sage).

These could be further explained due to the minimum gap between rollers of approximately 1-5 $\mu \mathrm{m}$ in size, which is almost equivalent to the length of CNTs, much larger than the diameter of each CNT. ${ }^{72}$ Suarez et al. $^{73}$ concluded that this technique should be designed taking into account any surface functionalization that would be applied. This was due to ineffective dispersion due to higher agglomerates in the presence of surface functionalization.

High shear stress is very critical in order to extricate CNT bundles, allowing uniform dispersion of the nanofillers in the matrix resin. Lastly, ball milling has been efficiently used for various carbon materials to disperse into epoxy based resin. In the case of chemicals, the dispersibility is highly efficient and the length for CNTs, for instance, can be controlled accordingly by adjusting the milling time.

Allaoui et al. $^{75}$ analysed the effectiveness of the dispersion process when MWCNT was mixed into rubbery epoxy matrix resin. Although the mechanical properties were satisfactory with a substantial increase in Young's modulus, the preparation method did not lead to a satisfactory dispersion. Gojny et $a .^{76}$ concluded that a huge amount of ultrasound energy is required to ensure a consistent dispersion process. Interestingly, the sonication method was classified as non-effective by the latter due to the damage caused to the effective length of the CNT. ${ }^{77,78}$ The calendering method, due to its scalability, is reported as ideal for a high volume production rate. ${ }^{79,80}$

Karapappas et $a .^{81}$ conducted SEM studies on the dispersion process of nanoparticles. Fig. 3 shows SEM images at various nanoparticle loadings. At $1 \mathrm{wt} \%$ of MWCNT loading, evidence of good dispersion was noticed and at $0.5 \mathrm{wt} \%$ of MWCNT loading, no agglomeration was observed. The SEM image at $0.1 \%$ of MWCNT loading revealed the presence of agglomeration due to poor dispersion.

\subsection{Effects of nanofillers on the mechanical properties of epoxy}

To study the effects of nanofillers on the mechanical properties of epoxy, the published data acquired from this developing area were compiled into four different sections, each representing specific nanomaterials and the results are summarized in tables. The structure of the tables are: column 1 represents the materials type which is sub-divided into two columns, (1) nanomaterials (species) and (2) epoxy (type and hardener); column 2 represents the weight fraction of the nanofillers; column 3 shows the particle size in nanometres; 
column 4 shows the unmodified and modified resins denoted with NR and MR, respectively.

Mechanical properties including the Young's modulus, ultimate tensile strength, ductility as well as fracture toughness parameters comprised of $G_{\mathrm{IC}}, G_{\mathrm{IIC}}, K_{\mathrm{IC}}$ and $K_{\mathrm{IIC}}$ are listed in column 5 under several sub-columns. The mechanical testing technique, the dispersion method and the source of references are reported in column 6, 7 and 8, respectively.

\section{Carbon nanotubes (CNTs)}

The first TEM evidence for the tubular nature of some nanosized carbon filaments was published in 1952 by Radushkevich and Lukyanovich. ${ }^{82}$ In 1976, CNTs have been prepared by pyrolysing a mixture of benzene and hydrogen at about $1100{ }^{\circ} \mathrm{C}$ by Oberlin et al. ${ }^{83,84}$ and later by Endo and Kroto. ${ }^{85}$ The work on MWCNTs was boosted in 1991, when Sumio Iijima announced in Nature the preparation of nanometresize, needle-like tubes of carbon. ${ }^{86}$ Iijima's 1991 paper generated unprecedented interest in the carbon nanostructures and has since fuelled intense research in the area of nanotechnology.

Many researchers have worked on CNTs due to their high aspect ratio and unique properties such as high strength, stiffness performance, thermal and electrical conductivity. ${ }^{75,86-90}$ Made of cylindrical rolled up graphene sheets and fullerene structure, CNT consists of three different types: (1) single-walled CNT (SWCNT), (2) double-walled CNT (DWCNT) and (3) multi-walled CNT (MWCNT). Their atomic arrangements can be categorised into three groups, namely zigzag, chiral and armchair (Fig. 4). Numerous techniques such as scanning electron microscopy (SEM), ${ }^{91}$ transmission electron microscopy $(\text { TEM })^{92,93}$ and Raman spectroscopy ${ }^{94}$ were employed to determine the microstructures of CNT due to its dimensions being very small.
CNT offers exceptional mechanical, physical and interface properties. ${ }^{95}$ Many researchers used CNT in the development of a more effective matrix resin. Yu et al. ${ }^{96}$ reported that the Young's modulus and tensile strength were impressively improved with the addition of CNT in the epoxy. To be able to appreciate the impact that CNTs can provide to improve the mechanical and fracture resistance, ${ }^{97}$ the critical factors such as the specific surface area (SSA), preservation of a high aspect ratio $^{98,99}$ and homogeneous dispersion as mentioned earlier have to be understood. ${ }^{76}$ The surface area primarily facilitates the stress transfer, but inadmissibly allowing the generation of strong forces amongst nanotubes which is reliant on the diameter and the amount of sidewalls. ${ }^{100}$ SWCNT has the highest aspect ratio as compared with MWCNT. Made up of numerous layers with a bigger diameter, MWCNT demonstrates an enhancement of dispersion but offers a less significant interface for stress transfer.

\subsection{Importance of functionalization}

Due to the poor dispersion ability and weak interaction between the nanomaterials and the matrix resins, the strengthening effect of nanofillers is still limited. The presence of van der Waals forces causes the dispersion process to be very ineffective. The implementation of surface functionalization $^{101-104}$ is another approach to overcome this difficulty as it will maximise the performance and the benefits of CNTs (Fig. 5). Either physical or chemical functionalization can be applied depending on the interactions between the particles and the matrix. ${ }^{105}$ As highlighted by Zhu et al. ${ }^{106}$, the blending of acid treatment alongside fluorination has provided a major improvement in the mechanical properties of SWCNT. Functionalization of graphene sheets is of equal importance for engineering applications. Chemical functionalization is the most common method employed, often carried out by solventassisted techniques. It eliminates the agglomeration of single layer graphene during the reduction process whilst preserving the properties of the latter.

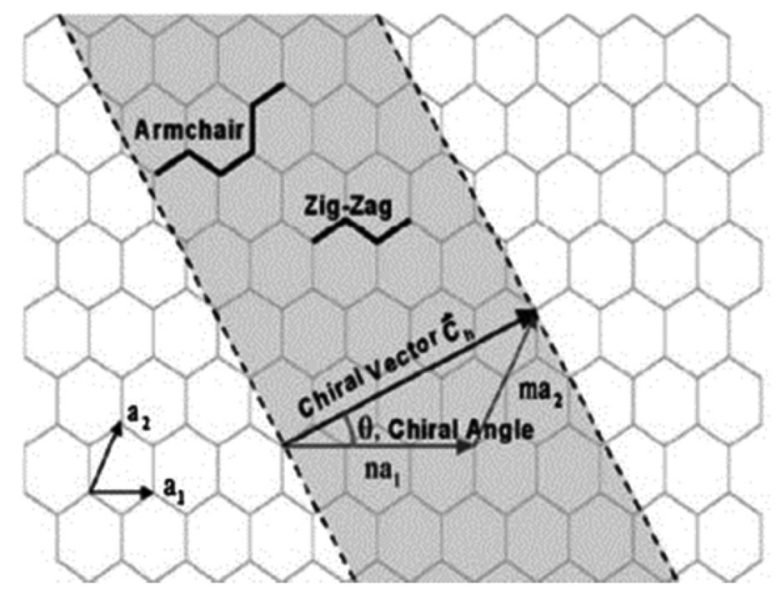

A
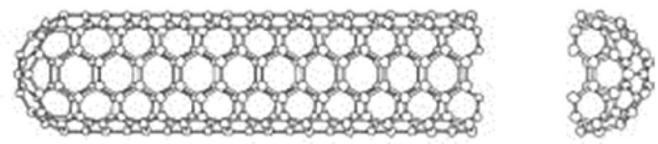

B
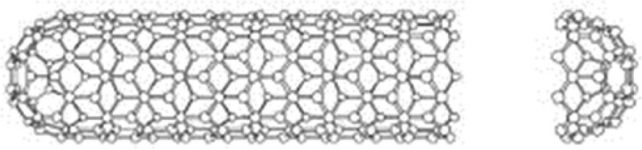

C
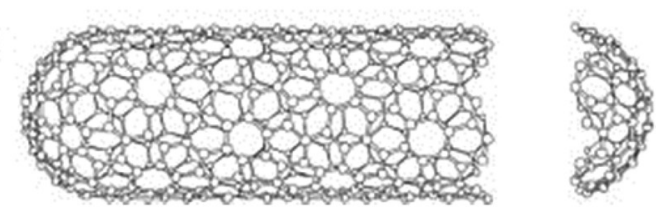

Fig. 4 Schematic diagram showing how a hexagonal sheet of graphene is rolled to form a CNT with different chiralities (A: armchair; B: zigzag; C: chiral).$^{74}$ Reprinted with permission from ref. 74 (Copyright () 2010 Elsevier). 


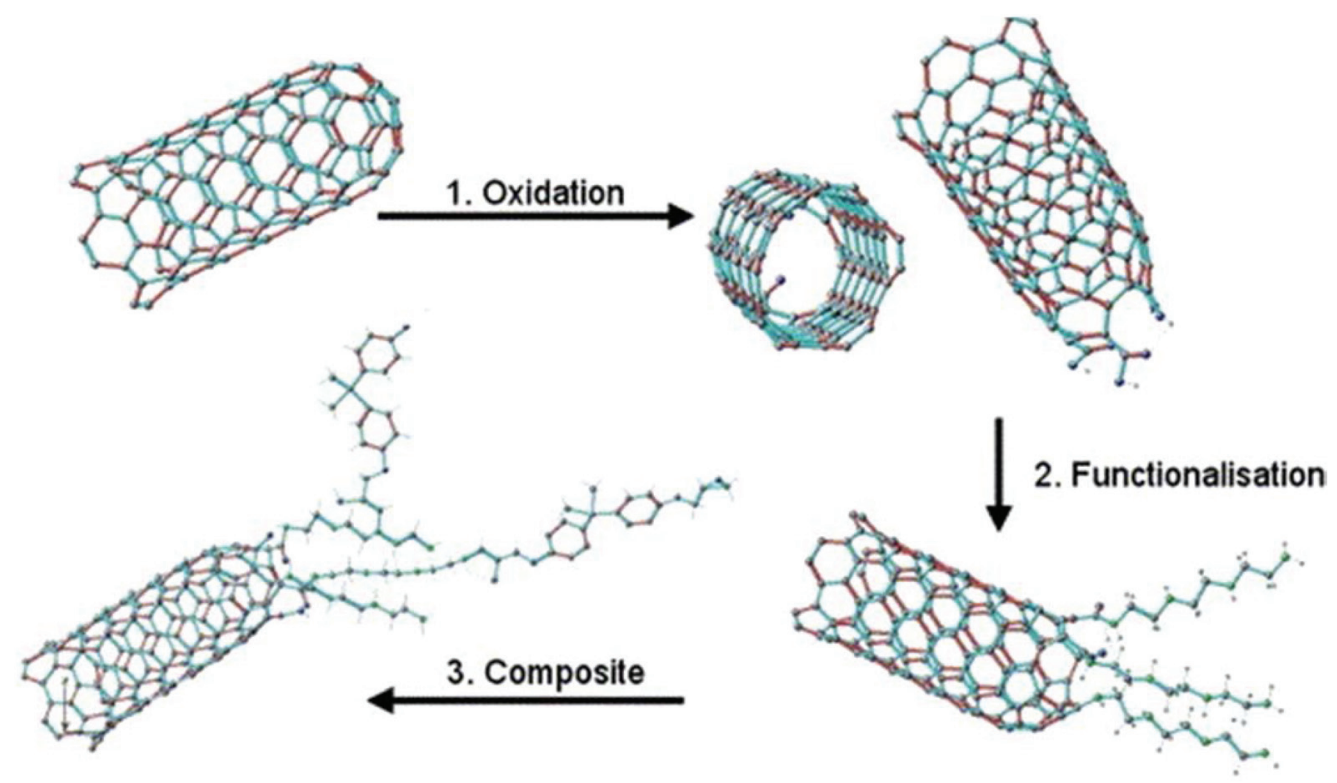

Fig. 5 Scheme of the functionalization process of CNTs showing the whole cycle from the oxidation to the composite manufacturing. In a first step the nanotubes are oxidised and (1) then functionalised (2) and finally processed to the nanocomposite (3). ${ }^{107}$ Reprinted with permission from ref. 107 (Copyright @ 2005 Elsevier).

\subsection{Mechanical properties using CNT nanomaterials}

The outcome of incorporating CNTs into epoxy resins based on the mechanical and fracture properties needs particular attention due to its popularity in recent years. CNT nanomaterial is interestingly a potential candidate due to its exceptional mechanical properties and high aspect ratio as previously mentioned. Normally, CNTs improve the mode (I + II) fracture toughness of the epoxies. ${ }^{108,109}$ A comparative analysis amongst all types of CNTs is carried out to have a better appreciation of their performance.

2.2.1 Comparative analysis of the mechanical properties of nanocomposites using CNTs. The results of the mechanical properties (E, UTS, \%EL) and fracture toughness for mode I and mode II for the neat epoxy and after the introduction of nanofillers are analysed. All the collected data are summarised in Table 1. The incorporation of CNTs into the epoxy resins contributed to an increase in stiffness for all of the 14 studies listed in the table to different extent and also leads to a sensible increase in the Young's modulus.

The effects of non-functionalized DWCNT and aminofunctionalized DWCNT were studied at low CNT content by Gojny et $a l^{79}$ Interestingly, the Young's modulus of DWCNT-NH2 was noted as the highest one and this can be associated with the re-agglomeration. The stiffness of the epoxy toughened by non-functionalized DWCNT was increased slightly as compared to the one toughened by amino-functionalized DWCNT. The modulus of the neat epoxy was increased from $3.28 \mathrm{GPa}$ leading to a further increase to $3.51 \mathrm{GPa}$ by the addition of functionalized DWCNT at $1.0 \mathrm{wt} \%$. The results were explained due to the fact that the dispersion was much homogeneous due to the strong interfacial forces with the amino-groups. The UTS decreased slightly from 63.8 GPa to $62.5 \mathrm{GPa}$ for the nanocomposites with nonfunctionalized DWCNT, but increased slightly by $1.6 \%$ for the nanocomposites with DWCNT-NH2. Gojny et al. ${ }^{76,110}$ concluded that a good impregnation with the resin, along with a tough interfacial bonding, is necessary for an effective reinforcement. According to the same researcher, nano-ropes are formed due to aggregation of bonds and the alignment of CNT tubes, which are challenging to detach and penetrate through. At $1.0 \mathrm{wt} \%$ loading, the neat epoxy had a Young's modulus of 2.5 GPa and an UTS of $63.8 \mathrm{MPa}$, used for benchmarking. An improvement of $3 \%$ and $4 \%$ in the stiffness and UTS, respectively, for the non-functionalized SWCNT was noted. For the non-functionalized DWCNT, the mechanical properties were enhanced leading to $12 \%$ and $6 \%$ increase in Young's modulus and UTS respectively for $0.3 \mathrm{wt} \%$ concentration. This trend confirms that the addition of SWCNT and DWCNT increases the mechanical properties whereas there is a minor decrease in the values in the case of MWCNT. A justification of the findings was provided by Gojny. ${ }^{111} \mathrm{He}$ highlighted that the epoxy with SWCNTs had the highest UTS value due to its high specific surface area (SSA) and high aspect ratio owing to its structural layout. DWCNT displayed a lower SSA due to its two concentric layers, normally a compromise between effective dispersion and reinforcement possibility. The functionalized MWCNT does not have a significant effect on the UTS of epoxies. It was noted that due to the concentric nature of the layers present in MWCNT, the internal layers do not contribute to the stress transmission. Also, the insignificant effect on increasing the concentration of nanotubes can be associ- 
Table 1 Carbon nano-tubes

\begin{tabular}{|c|c|c|c|c|c|c|c|c|c|c|c|c|c|c|c|}
\hline & \multicolumn{2}{|l|}{ Materials } & \multirow{3}{*}{$\begin{array}{l}\text { Particles } \\
\text { loading } \\
\text { (wt } \% \text { ) }\end{array}$} & \multirow{3}{*}{$\begin{array}{l}\text { Particle } \\
\text { Size (nm) }\end{array}$} & & \multicolumn{7}{|c|}{ Effect on the mechanical properties } & \multirow{3}{*}{$\begin{array}{l}\text { Type of } \\
\text { mechanical } \\
\text { testing }\end{array}$} & \multirow[b]{3}{*}{ Production method } & \multirow[b]{3}{*}{ Ref. } \\
\hline & \multirow[b]{2}{*}{ Nanomaterials } & \multirow[b]{2}{*}{ Resin } & & & & & & & $\begin{array}{l}\text { Fractl } \\
G:(\mathrm{J} \mathrm{r}\end{array}$ & $\begin{array}{l}\text { re toug } \\
\left.{ }^{-2}\right) K\end{array}$ & $\begin{array}{l}\text { hness } \\
\text { (MPa } \sqrt{ }\end{array}$ & & & & \\
\hline & & & & & & (GPa) & (MPa) & EL & $G_{\mathrm{IC}}$ & $K_{\mathrm{IC}}$ & $G_{\text {IIC }}$ & $K_{\text {IIC }}$ & & & \\
\hline 1 & SWCNT (Elicarb) & Epoxy (DGEBA + & 0.1 & $d<2$ & $\mathrm{NR}^{a}$ & 2.59 & 63.8 & & 163 & 0.65 & & & Tensile test/ & High shear mixing/ & 76 \\
\hline & & H137i) & & & $\mathrm{MR}^{b}$ & 2.69 & 66.3 & & 237 & 0.80 & & 1.82 & $\begin{array}{l}\text { (SENB)/CT /SEM/ } \\
\text { TEM }\end{array}$ & sonication & \\
\hline 2 & SWCNT (XD Grade) & Epoxy (Epon & 1.0 & & NR & 2.76 & 64.1 & 3.24 & 113 & 0.56 & & & Tensile test/ & Ultra-sonication/ & 120 \\
\hline & & 862) & & & MR & 3.49 & 74.7 & 3.32 & 124 & 0.66 & & & $(\mathrm{DMA}) / 3-\mathrm{PB}$ & degassed & \\
\hline 3 & DWCNT (Nanocyl) & Epoxy (MGS & 0.1 & 2.8 & NR & 3.28 & 63.8 & & 128 & 0.65 & & & TEM/SEM/ & Calenders & 79 \\
\hline & + NH2 & L135i + H 137i) & & & MR & 3.37 & 62.5 & & 171 & 0.76 & & & compact tension & (dispersion). Cured & \\
\hline & & & & & MR & 3.51 & 63.5 & & 174 & 0.78 & & & $(\mathrm{CT})$ & $\begin{array}{l}\text { and post-cured. } \\
\text { Sonication }\end{array}$ & \\
\hline 4 & DWCNT (Elicarb) & Epoxy (DGEBA + & 0.3 & 2.8 & NR & 2.59 & 63.8 & & 163 & 0.65 & & & Tensile test/ & High shear mixing/ & 76 \\
\hline & & H137i) & & & MR & 2.89 & 67.8 & & 250 & 0.85 & & & $\begin{array}{l}\text { (SENB)/CT /SEM/ } \\
\text { TEM }\end{array}$ & sonication & \\
\hline 5 & MWCNT & Epoxy (ML-506 & 0.1 & $15-50$ & NR & 3.15 & 68.4 & & 833 & 1.62 & & 1.49 & Tensile test/ & Sonication/degassed & $121,122,214$ \\
\hline & & $+\mathrm{HA}-11)$ & & & MR & 3.24 & 71.7 & & 1079 & 1.87 & & 1.82 & (SENB) & in vacuum & \\
\hline 6 & MWCNT -NH2 & Epoxy (DGEBA + & 0.1 & $15-50$ & NR & 2.59 & 63.8 & & 163 & 0.65 & & & Tensile test/ & High shear mixing/ & 76 \\
\hline & (Elicarb) & $\mathrm{H} 137 \mathrm{i})$ & & & MR & 2.88 & 64.7 & & 227 & 0.81 & & & $\begin{array}{l}\text { (SENB)/CT /SEM/ } \\
\text { TEM }\end{array}$ & sonication & \\
\hline 7 & MWCNT (ARKEMA) & $\begin{array}{l}\text { Epoxy (Araldite } \\
\text { LY 564) }\end{array}$ & 0.0 & - & NR & 2.6 & 24.0 & & 200 & 0.75 & & & $\begin{array}{l}\text { Tensile test } \\
\text { (SENB)/(DMA) }\end{array}$ & $\begin{array}{l}\text { Sonication } 100 \% \text { at } \\
0.5 \mathrm{wt} \%-1 \mathrm{~h}\end{array}$ & 17 \\
\hline & & & 0.5 & $10-15$ & MR & 2.5 & 30.0 & & 390 & 1.35 & & & & $50 \%$ at $0.5 \mathrm{wt} \%-2 \mathrm{~h}$ & \\
\hline & & & $0.5-\mathrm{OP}$ & $10-15$ & MR & & & & 1300 & 2.6 & & & & & \\
\hline 8 & MWCNT & Epoxy (Araldite) & 1.0 & $10-15$ & NR & & & & 300 & & 1000 & & $(\mathrm{DCB}) /\left(3 \mathrm{ENF}^{d}\right)$ & Torus-mill device/ & 81 \\
\hline & $\left(\right.$ ARKEMA $\left.^{\top}\right)$ & & & & MR & & & & 490 & & 1480 & & & vacuum & \\
\hline 9 & MWCNT (C 150P) & Epoxy & 0.0 & $4-15$ & NR & 2.87 & 73.4 & 2.9 & 64 & 0.46 & & & $\left(\mathrm{DMTA}^{e}\right) /$ Tensile & High speed mixer/ & 112 \\
\hline & & (Bisphenol-A)/ & $0.5-\mathrm{P}^{f}$ & & MR & 2.89 & 72.2 & 3.0 & 110 & 0.59 & & & test/quasi-static/ & three-roll mill/ & \\
\hline & & Albidur HE600 & $0.5-\mathrm{F}^{g}$ & & MR & 2.88 & 89.0 & 5.6 & 135 & 0.64 & & & $\mathrm{CT}$ & $\begin{array}{l}\text { degassed cured in } \\
\text { oven }\end{array}$ & \\
\hline 10 & MWCNT & Epoxy (DGEBA) & 0.0 & 120 & NR & 2.90 & & & 133 & 0.69 & & & Uniaxial tensile & Ultrasonic probe/ & 115 \\
\hline & (Produced) & LY-556 & 0.1 & & MR & 3.01 & & & 162 & 0.85 & & & test/(SENB) & vacuum oven & \\
\hline & & & 0.2 & & MR & 3.11 & & & 188 & 0.88 & & & & & \\
\hline & & & 0.5 & & MR & 3.26 & & & 223 & 0.98 & & & & & \\
\hline 11 & MWCNT + Silica & Epoxy (DGEBA) & 0.0 & - & NR & 2.90 & & & 132 & 0.69 & & & Uniaxial tensile & Ultrasonic bath/ & 116 \\
\hline & (Nanopox F400) & LY-556 & $0.06 / 2.0$ & & MR & 2.95 & & & 176 & 0.75 & & & test/(SENB) & mechanical stirrer/ & \\
\hline & & & $0.00 / 6.0$ & & MR & 3.01 & & & 181 & 0.75 & & & & vacuum oven & \\
\hline & & & $0.06 / 6.0$ & & MR & 3.03 & & & 195 & 0.96 & & & & & \\
\hline 12 & MWCNT (Provided & Epoxy (DGEBA) & 1.0 & $20-30$ & NR & 2.95 & 76.4 & 3.1 & 89 & 0.55 & & & Tensile test/ & High-speed mixer/ & 20 \\
\hline & by Timestub ${ }^{\mathrm{TM}}$ ) & МНHРА & & & MR & 3.06 & 73.5 & 2.5 & 140 & 0.70 & & & compact test & $\begin{array}{l}\text { planetary ball mill/ } \\
\text { degassed/cured }\end{array}$ & \\
\hline 13 & MWCNT (Provided & Epoxy (DGEBA) & $1.0 / 10.0$ & $20-30$ & NR & 2.95 & 76.4 & 3.1 & 89 & 0.55 & & & Tensile test/ & High-speed mixer/ & 20 \\
\hline & $\begin{array}{l}\left.\text { by Timestub }{ }^{\mathrm{TM}}\right)+ \\
\mathbf{L R}^{h}\end{array}$ & МНHРА & & & MR & 2.66 & 70.7 & 5.2 & 455 & 1.17 & & & compact test & $\begin{array}{l}\text { planetary ball mill/ } \\
\text { degassed/cured }\end{array}$ & \\
\hline 14 & MWCNT (CMW) & Epoxy (Epon & 1.0 & 35 & NR & 1.97 & 47.3 & 2.4 & 120 & 2.04 & & & Tensile test/ & Ultrasonic/ & 215 \\
\hline & & $828)$ & & & MR & 1.59 & 46.4 & 3.2 & 270 & 2.8 & & & SENB & mechanical mixing & \\
\hline
\end{tabular}

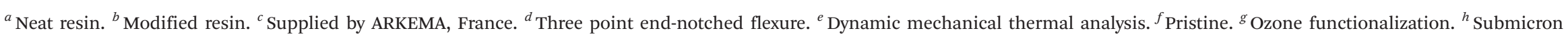
liquid rubber. 
ated with the poor dispersibility and deficiencies in the composite.

Ozone functionalized MWCNT was used to modify the properties of epoxy by Tang et al. ${ }^{112}$ The maximum UTS recorded was $89 \mathrm{MPa}$ using the ozone functionalization MWCNT at $0.5 \mathrm{wt} \%$. The elastic modulus and UTS of the neat epoxy are 2.87 GPa and 73.4 MPa respectively. No considerable changes in the stiffness were found by adding both functionalized and non-functionalized MWCNTs. A small decrease of $1.7 \%$ in UTS for the epoxy with non-functionalized MWCNT was noted whereas the contrary occurred for the one with ozone-functionalized MWCNT with an increase of $21 \%$. With the aid of surface functionalization on the latter, a more effective dispersion and stronger interfacial bonding with the epoxy contributed to the improvement in the UTS while a comparable trend was noticed for the \% elongation to break.

SWCNT used as nanofillers to reinforce the epoxy system was found to have some encouraging outcomes by $\mathrm{Zhu}$ et al. ${ }^{106,113}$ With the addition of $1.0 \mathrm{wt} \%$ of functionalized nanotubes to the resins, an enhancement in the dispersion and mechanical properties has been achieved, resulting in $30 \%$ increase in modulus and $18 \%$ in tensile strength. Feng et $a l .{ }^{114}$ studied the effects of a high SWCNT loading on epoxy resin. The dynamic and tensile properties were enhanced by the incorporation of SWCNT into the matrix system. At $39.1 \mathrm{wt} \%$ loading of SWCNT, the Young's modulus and tensile strength were increased by $408 \%$ and $183 \%$ respectively, compared to the neat epoxy.

Hsieh et al. ${ }^{115}$ investigated the effect of volume content of MWCNT on the fracture toughness and fatigue performance of a thermosetting epoxy polymer. Uniaxial tensile tests were carried out to determine the mechanical properties of the subsequent nanocomposite. Microscopic analysis revealed that the long nanotubes were agglomerated and increasing the wt $\%$ content of the filler had direct consequences on the agglomerate. Increasing the MWCNT content leads to higher stiffness performance and mode I fracture toughness. An increase of $12 \%$ in the elastic modulus at $0.5 \mathrm{wt} \%$ compared to the pristine epoxy was recorded.

In another research study, Hsieh et al. ${ }^{116}$ studied to enhance the mechanical properties including toughness, by adding silica nanoparticles and MWCNT to an epoxy resin. Atomic force microscopy (AFM) and transmission optical microscopy were used to examine the homogeneity of the resulting nanocomposite. The results showed that the nanosilica was uniformly dispersed in the matrix whereas a small agglomeration of MWCNT in the matrix was observed. The unmodified resin recorded a value of 2.9 GPa for the Young's modulus. The addition of $0.06 \%$ of MWCNT and $2.0 \%$ of nanosilica increases the stiffness slightly by $1.7 \%$. With $6.0 \mathrm{wt} \%$ of nanosilica, the Young's modulus was $3.0 \mathrm{GPa}$. The addition of $0.06 \mathrm{wt} \%$ of MWCNT to $6.0 \mathrm{wt} \%$ of nanosilica increases the Young's modulus moderately by only $0.6 \%$ (see Fig. 6).

The mechanical properties and fracture toughness of epoxy filled with CNTs and rubber spherical particles were investigated by Tang and co-workers. ${ }^{20}$ When $1.0 \mathrm{wt} \%$ of MWCNT was added, the stiffness increased by $3.7 \%$ whilst the UTS and the $\%$ elongation at break decreased by $4 \%$ and $18.9 \%$, respectively. Interestingly, the addition of submicron liquid rubber to

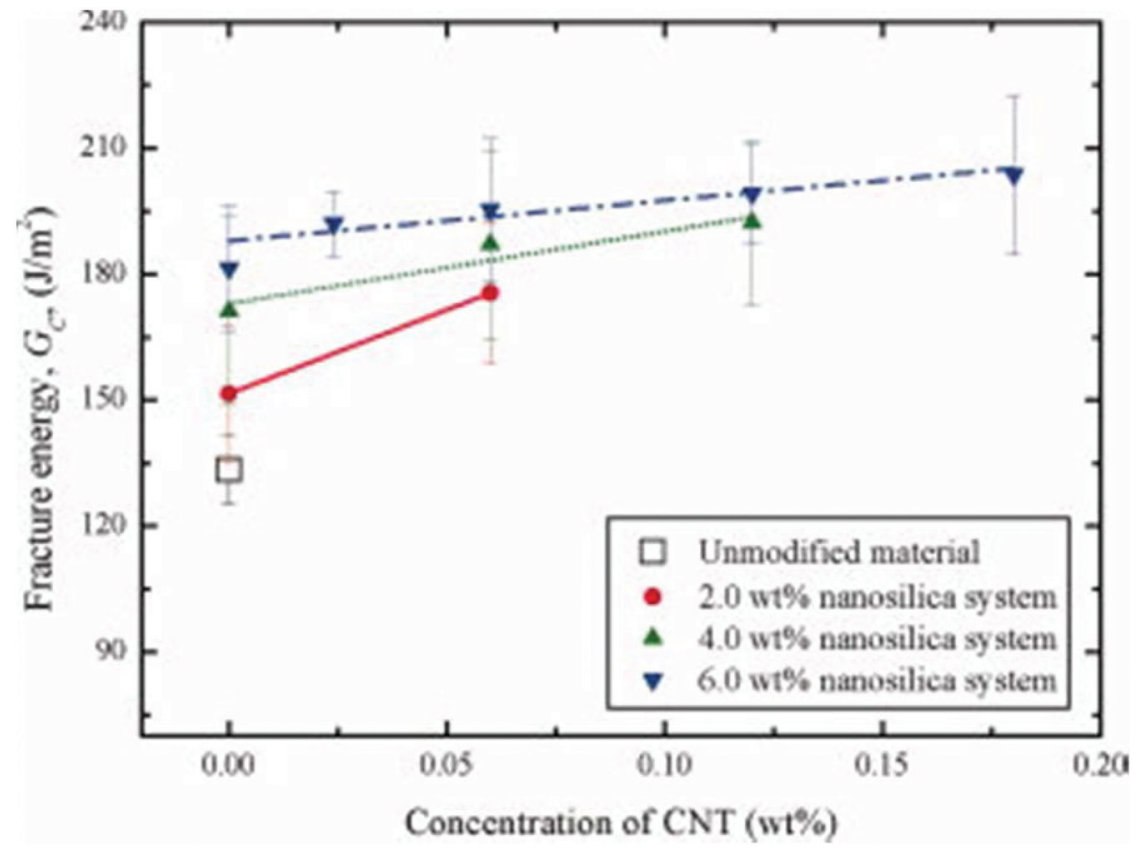

Fig. 6 The fracture energy of the neat epoxy and nanocomposites containing nanosilica and MWCNTs as a function of the concentration of MWCNTs. ${ }^{116}$ Reprinted with permission from ref. 116 (Copyright @ 2011 Wiley). 
the MWCNT (EP/MWCNT/LR), along with the epoxy based resin, had a negative effect on the Young's modulus and UTS with a decrease in value by $9.8 \%$ and $7.5 \%$ correspondingly.

Cryogenic mechanical properties are very important parameters in many cryogenic engineering applications. Yang et $a l .{ }^{117}$ investigated the incorporation of MWCNT to the reinforced DGEBF epoxy system modified by poly(ethersulfone) to improve the cryogenic mechanical properties of the resulting nanocomposite. The three-roll mill calendar technique was employed followed by vacuum degassing for the preparation of the samples. For characterization, a tensile test was carried out under cryogenic temperature conditions by immersing the clamps and the samples in liquid nitrogen. The result shows that at $77 \mathrm{~K}$, the tensile strength and the Young's modulus both increase by $58 \%$ and $12 \%$ at $0.5 \mathrm{wt} \%$ and $2.5 \mathrm{wt} \%$ of MWCNT loading, respectively. The failure strain originally increases up to $0.5 \mathrm{wt} \%$ loading and decreases with further increasing the MWCNT content.

Kim et al. ${ }^{118}$ studied the effect of CNT functionalization on crack resistance of a carbon/epoxy composite at cryogenic temperature. Surface modification in the form of aminofunctionalization was conducted to improve the bonding between CNTs and the epoxy system. An evaporation technique along with sonication was used to prepare the specimen and curing allowed in an autoclave. The tensile properties were evaluated at room temperature. An increase in tensile strength by up to $0.7 \mathrm{wt} \%$ of functionalized CNTs was noted: a $16.7 \%$ increment. In the case of the tensile stiffness, an increase by $0.2 \mathrm{wt} \%$ was noticed where it peaked at $0.7 \%$ loading before experiencing a decrease. At cryogenic temperature, the fracture toughness of the functionalized carbon/epoxy composite increased by $44 \%$ in comparison with the carbon/epoxy composite.

In another study conducted by Lau et al. ${ }^{119}$, polymer-based composites under cryogenic environment conditions were enhanced using tailored CNTs such as coiled carbon nanotubes (CCNTs) and randomly-oriented nanoclay-supported nanotubes (NSCNTs). At $77 \mathrm{~K}$, the mechanical properties of CCNT reinforced epoxy composites were evaluated at different weight loading contents. An increase in the stiffness with increasing CCNT loadings was observed, reaching its maximum value at $3 \mathrm{wt} \%$ concentration with a value of 8.9 , an increment of $20 \%$.

2.2.2 Comparative analysis of the fracture toughness of nanocomposites using CNTs. Regardless of the amount of filler content added to the epoxy, the addition of CNTs undoubtedly has an effect on the increase in mode I and mode II fracture toughness of the resin. The neat epoxy has a fracture toughness $\left(G_{\mathrm{IC}}\right)$ of $163 \mathrm{~J} \mathrm{~m}^{-2}$. By adding only $0.1 \mathrm{wt} \%$ of DWCNT, ${ }^{76}$ the increase in fracture toughness was observed to be $27 \%$, which is the lowest value in the 14 CNT modified epoxies investigated (Table 1).

The mode I fracture toughness of epoxies modified by nonfunctionalized and amino-functionalized DWCNT was examined by Gojny et al. ${ }^{79}$ at low CNT content. They reported an increase in fracture toughness of all the nanocomposites as compared to the neat epoxy $\left(128 \mathrm{~J} \mathrm{~m}^{-2}\right)$. The nanocomposite toughened by DWCNT had an increase of $34 \%$ in fracture toughness whereas the nanocomposite toughened by aminofunctionalized DWCNT had a slightly higher value of $36 \%$. Remarkably, $1 \mathrm{wt} \%$ of DWCNT-NH2 results in a much higher fracture toughness.

As mentioned before, Gojny et al. ${ }^{76}$ studied the effect of SWCNTs, DWCNTs and MWCNTs on the mechanical properties and the benefits of surface functionalization of CNTs. The pristine epoxy had a mode I fracture toughness of $163 \mathrm{~J}$ $\mathrm{m}^{-2}$, which was increased by $45 \%$ to $237 \mathrm{~J} \mathrm{~m}^{-2}$ using non-functionalized SWCNT. It was observed that non-functionalized nanomaterials provide an enhancement in the fracture toughness, generally at low content. Increasing the percentage weight content of SWCNT over $0.3 \%$ showed a decrease in mode I fracture toughness. They explained the reason for this finding by associating it with re-agglomeration. Aminofunctionalization of the CNTs facilitated the dispersion and impregnation process as well as the interfacial forces between the nanoparticles and the matrix resin. It was reported that with $0.5 \%$ of amino-functionalization of DWCNT, the fracture toughness increased significantly by $43 \%$ as compared to pure epoxy. A similar tendency was observed for the functionalized MWCNT, with an increase by $39 \%$ in fracture toughness (see Fig. 7).

Sun et $a l .{ }^{120}$ found that surface-functionalization of SWCNTs increases moderately the fracture toughness of the subsequent nanocomposite. An increase of $9.7 \%$ at $1.0 \mathrm{wt} \%$ loading was noticed for the modified resin. They noted that the enhancement in the fracture toughness was still not substantial and they suggested that de-roping the SWCNTs may contribute to effective dispersion by keeping CNTs straight in the resin matrix system, thereby fulfilling its full potential.

Gkikas et al. ${ }^{17}$ studied the effect of dispersion conditions on the toughness of MWCNT toughened epoxy. Single edge notch 3-point bending (SENB) was used to determine the toughness of the nanocomposite. At $0.5 \mathrm{wt} \% \mathrm{CNT}$ reinforcement and the sonication power at full amplitude $(100 \%)$ for $1 \mathrm{~h}$, the toughness increased by $95 \%$. Further sonication for $2 \mathrm{~h}$ revealed a reduction in the fracture properties of the nanocomposite. The importance of the duration and amplitude of the sonication process for good dispersibility was highlighted. For the nanocomposite with the same CNT loading, reducing the sonication power to half the maximum amplitude (50\%) and increasing the time to $2 \mathrm{~h}$ increased the fracture toughness by $550 \%$ as compared to the neat epoxy.

Ayatollahi et al. ${ }^{121,122}$ also investigated the effects of MWCNT as nanofillers on the epoxy matrix under bending and shear loading conditions. A single-edge notch bend specimen (SENB) was used for this study. The mode I and mode II fracture toughness increased when the MWCNT loading increased from $0.1 \mathrm{wt} \%$ to $0.5 \mathrm{wt} \%$ but a contrasting behaviour was observed when increasing the loading from $0.5 \mathrm{wt} \%$ to $1.0 \mathrm{wt} \%$. MWCNT inevitably provided a much greater fracture toughness performance $\left(G_{\mathrm{IC}}=1079 \mathrm{~J} \mathrm{~m}^{-2}\right), 30 \%$ higher than that of the neat epoxy at a loading of $0.1 \mathrm{wt} \%$. The rise in the 

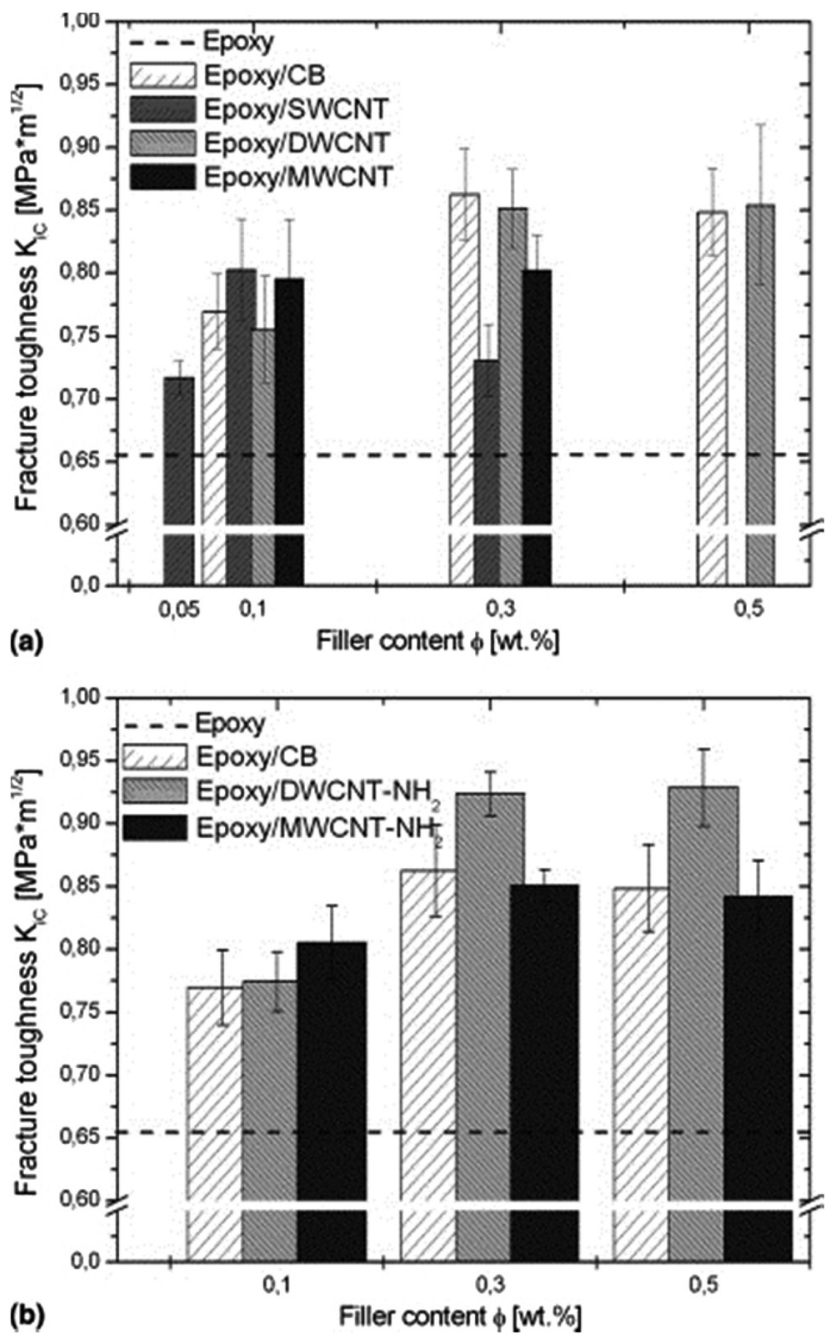

Fig. 7 Fracture toughness of epoxy-based composites containing (a) non-functionalized and (b) functionalized CNTs. ${ }^{76}$ Reprinted with permission from ref. 76 (Copyright @ 2005 Elsevier).

fracture toughness is totally reliant on the type of loading, where shear loading is more effective in comparison with normal loading.

As stated before, functionalization can be important in the improvement of the fracture toughness performance. Tang et al. $^{112}$ investigated the addition of MWCNT to epoxy (Bisphenol-A/Albidur HE600) at $0.5 \mathrm{wt} \%$ content. Microscopic images of SEM revealed some evidence from the fracture surface of the nanocomposite, demonstrating that the dispersion level has been effectively achieved. Several sets of readings were taken for both neat and ozone treated epoxy with MWCNT. The mode I fracture toughness of epoxies with the neat and ozone functionalized MWCNT was found to be $110 \mathrm{~J} \mathrm{~m}^{-2}$ and $135 \mathrm{~J} \mathrm{~m}^{-2}$, an increment of $71 \%$ and $110 \%$, respectively, revealing the effects of surface modification. It was shown that there were substantial enhancements in fracture properties for the functionalized nanocomposite compared to the untreated samples due to its superior dispersion ability and resilient interfacial bonding with the epoxy matrix during the production stage.

Hsieh and co-workers ${ }^{115}$ investigated the fracture toughness of a thermosetting epoxy polymer toughened with CNTs. Using AFM and TOM, the microscopic images revealed that the nanotubes were still agglomerated in the resin after the dispersion process. SEM images clearly demonstrated that CNT debonding and pull-out contributed to the toughening mechanisms. Mode I fracture toughness $G_{\text {IC }}$ increased progressively as the volume content of the CNTs was increased. The neat epoxy had a toughness of $133 \mathrm{~J} \mathrm{~m}^{-2}$ which was increased by $68 \%$ by adding $0.5 \mathrm{wt} \%$ of CNT.

Merging nanosilica and carbon nanotubes to enhance the toughness of an epoxy was investigated by the same researcher. ${ }^{116}$ SEM and SENB were used to analyse the fracture surface and determining the fracture toughness. As stated before, homogeneity occurred in the case of the silica nanoparticles. The incorporation of silica alone with the epoxy points to an increase in mode I fracture toughness. At $6.0 \mathrm{wt} \%$ of silica (EP/S), $G_{\text {IC }}$ increases by $37 \%$ compared to the pristine epoxy. Further addition of $0.06 \mathrm{wt} \%$ of MWCNT to the existing $6.0 \mathrm{wt} \%$ of silica (EP/MWCNT/S) increased the fracture toughness by $47 \%$ in comparison with the benchmarking neat epoxy. The highest value of $G_{\text {IC }}$ noted was $204 \mathrm{~J} \mathrm{~m}^{-2}$.

Tang et $a .^{20}$ studied the influence of spherical rubber particles on the fracture properties when incorporated with CNTs toughened epoxy. MWCNT mixed with epoxy (DGEBA) MHHPA at $1.0 \mathrm{wt} \%$ was first investigated. An increase of $56 \%$ for the value of $G_{\text {IC }}$ was noted. The fracture properties were further enhanced by the addition of $10.0 \mathrm{wt} \%$ of submicron liquid rubber with $1.0 \mathrm{wt} \%$ MWCNT, where a significant improvement of $409 \%$ increase in $G_{\text {IC }}$ was achieved. The presence of rubber (in the epoxy/MWCNT/LR system) contributed to the reinforcement of mode I fracture toughness in contrast to the epoxy/MWCNT system.

Yi et al. ${ }^{123}$ studied the effect of oxidized MWCNTs (O-CNTs) incorporated in epoxy with the reactive oligomer. The incorporation of soft modifiers in an attempt to enhance the fracture toughness is often at the expense of poor mechanical properties. Using the reactive oligomer, a cross linking mechanism is activated between the O-CNTs and the epoxies. At $0.5 \mathrm{wt} \%$ loading of O-CNTs with oligomer modified epoxy, the fracture toughness recorded at both room temperature and cryogenic temperature reported by the latter demonstrated a significant improvement by $23.6 \%$ and $69.5 \%$ respectively. The change in mechanical properties of the modified epoxy was found to be $91.7 \mathrm{MPa}$, which has a negligible decrease when compared to the unmodified epoxy (92.1 MPa).

The cryogenic fracture toughness was also studied by Yang et $a .^{117}$ with the combination of MWCNT based epoxy modified by poly(ethersulfone) (PES). The three-point bend test was used to evaluate the fracture properties of the nanocomposite. At $77 \mathrm{~K}$, it was observed that the fracture toughness increased with increasing the MWCNT content up to $0.5 \mathrm{wt} \%$ loading, recording a value of $2.02 \mathrm{MPa} \sqrt{ } \mathrm{m}$, an increment of $13.5 \%$ compared to the modified PES epoxy resin. A further decrease 
in the fracture toughness up to $2.5 \mathrm{wt} \%$ loading was noted, though it was still a higher value than that for the epoxy matrix resin.

2.2.3 Highlights summary of nanocomposites using CNTs. Based on the results on the mechanical and fracture toughness properties reported by various researchers, the properties of nanocomposites are enhanced at very low CNT loadings. Most of the loading values gathered from the reviewed papers are approximately in the same range. Amongst all the CNTs, DWCNT had produced the highest stiffness nanocomposites when surface functionalization was carried out. The values of Young's modulus presented for most of the MWCNT nanocomposites were much lower in comparison with SWCNT and DWCNT ones. This effect was explained due to the difference in specific surface area (SSA).

Optimizing the sonication power during mixing resulted in the highest value of mode I fracture toughness $\left(1300 \mathrm{~J} \mathrm{~m}^{-2}\right)$ as reported by Gkikas et al. ${ }^{17}$ The outcome of the multiphase study revealed another great potential route that could be explored as established by the presence of liquid rubber. The addition of rubber increased mode I fracture toughness by $409 \%$ in comparison with pristine epoxy, the highest increase amongst the 14 CNTs research reports. MWCNT is still the most interesting candidate with a promising outlook, by choosing an appropriate dispersion and functionalization techniques.

\section{Graphene}

Graphene, known for its single-layered atom-thick flatbed structure, has brought a new dimension to the nanotechnology world. ${ }^{124}$ Considered as a planar sheet of $\mathrm{sp}^{2}$-bonded carbon atoms in a honeycomb crystal lattice, graphene is also considered as the prime element of carbon allotropes, including graphite, fullerenes and carbon nanotubes (Fig. 8). ${ }^{125-127}$ It exhibits very good mechanical and electrical properties as well as fracture toughness performance. ${ }^{128-132}$ Graphene has high thermal conductivity ( $\left.5000 \mathrm{~W} \mathrm{~m}^{-1} \mathrm{~K}^{-1}\right)$, electrical conductivity (6000 $\mathrm{S} \mathrm{cm}^{-1}$ ) and mechanical stiffness (130 GPa), an optical transmittance of $\sim 98 \%$ and a large specific surface area $\left(2675 \mathrm{~m}^{2} \mathrm{~g}^{-1}\right)$. The graphene surface-to-volume ratio is higher than SWNTs as the inner nanotube surface is inaccessible to polymer molecules. This makes graphene potentially more promising for changing the matrix properties. Most of the reported studies until the mid-1990s were focused on graphite

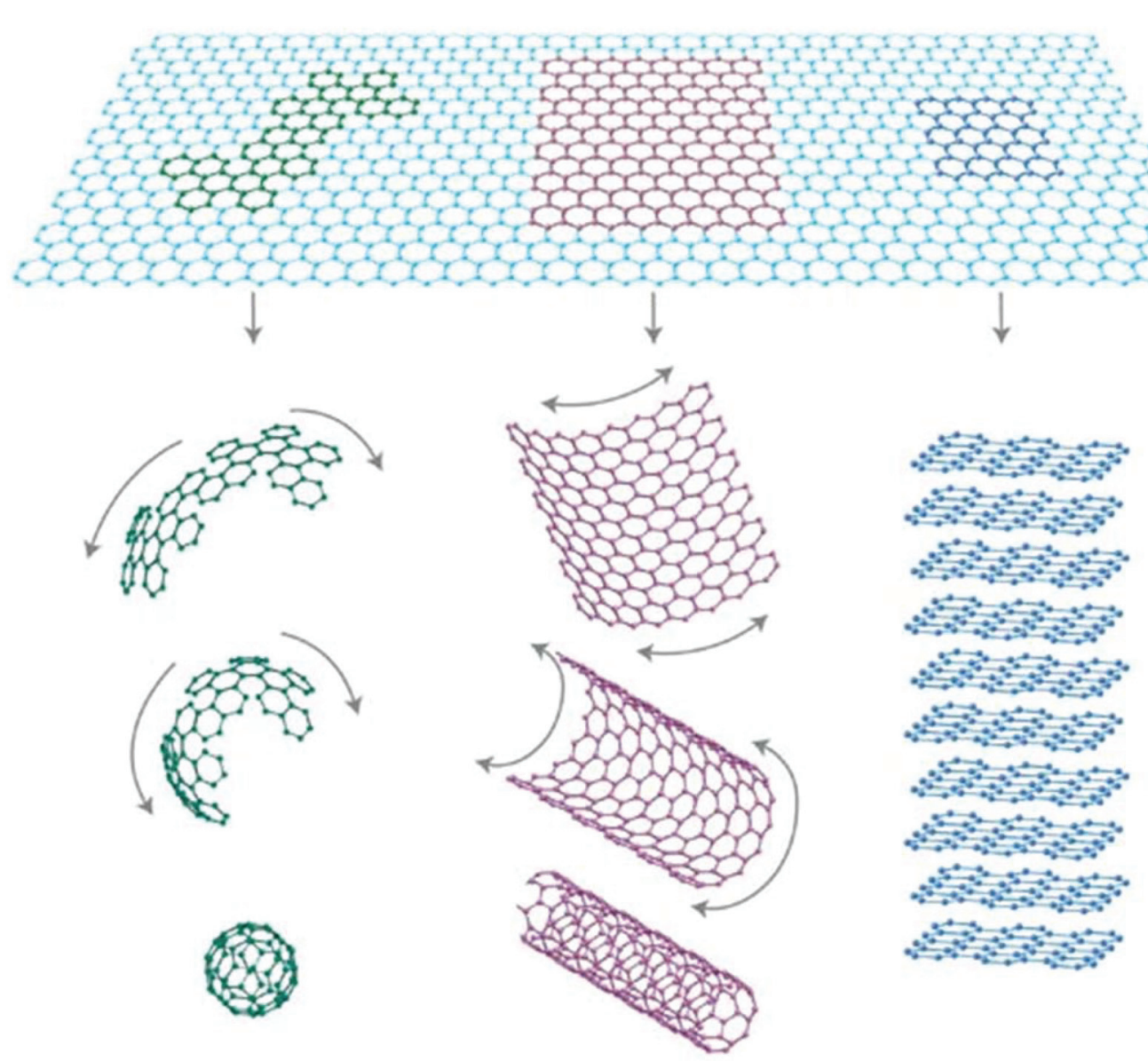

Fig. 8 Graphene in various forms; it can be wrapped up into OD buckyballs, rolled into 1D nanotubes or stacked into 3D graphite. ${ }^{134}$ Reprinted with permission from ref. 134 (Copyright @ 2007 Nature). 
intercalation compounds. Particular attention has been paid to the use of graphene nanoplatelets (GNP) and various other graphene-based materials as nanofillers in many engineering applications. $^{133}$

GNP possesses a high aspect ratio, predominantly ideal for reinforcement. ${ }^{135-137}$ Studies show that GNP has extensive benefits and has a potential to replace CNTs. This occurrence can be explained by the existence of the planar structure as stated before, easing the stress transfer during the dispersion process. ${ }^{138-140}$ Graphene oxide $(\mathrm{GO})^{124,141}$ derived essentially from graphene-based materials has also emerged as a possible route for reinforcing the mechanical properties and fracture toughness of epoxies. A clear appreciation of the chemical and physical structures of graphene oxide is the first step in achieving the correct functionalization of chemically modified graphene. ${ }^{142}$ Currently, there exist three main routes for graphene dispersion: (1) mechanical exfoliation, (2) chemical exfoliation and (3) chemical vapour deposition. Mechanical exfoliation is characterized as a preferable tactic. Efficaciously executed by Novoselov et al. $^{143}$ in 2004 , it allows the preparation of monocrystalline films of graphene.

It has been documented that the presence of graphene oxide in nanocomposite has benefited the performance of the latter. Qiu et $a l^{144}$ concluded that the presence of graphene oxide prohibited crack propagation by generating a large amount of plastic deformation. Chatterjee et $a l^{145}$ concluded that the bigger the size of the graphene nanoplatelets, the better the fracture toughness performance would be.

Raman spectroscopy has been extensively used to investigate the structure and deformation of graphene. ${ }^{146}$ Using this method, the amount of layers present in graphene films can be found. In addition, it has been used to monitor the stress transfer occurring between the matrix resin and the nanofiller during the dispersion process. Strong interfacial adhesion occurring between the platelets and the matrix resin system is vital for optimal enhancement. ${ }^{147-149}$ The levels of reinforcement of graphene acting as nanofillers could be evaluated in a rational manner using this technique. ${ }^{150}$

\subsection{Comparative analysis of the mechanical properties of nanocomposites using graphene}

Extensive research studies were carried out using graphene to improve the toughness of epoxies. Selected experimental results are presented in Table 2 that shows that chemically functionalized graphene oxide (ATGO) exhibits the highest improvement on the mode I fracture toughness $\left(1404 \mathrm{~J} \mathrm{~m}^{-2}\right)$ for the 11 graphene modified epoxy based nanomaterials. Rafiee et $a l .{ }^{140}$ studied the mechanical properties and fracture resistance of epoxy based nanocomposites with $0.1 \mathrm{wt} \%$ of graphene platelets (GPL), SWCNT and MWCNT. The epoxy resin (bisphenol-A) was kept the same for all nanofillers for comparative analysis and was used as a benchmark. GPL provided a much higher stiffness and tensile strength, 31\% and 40\%, respectively, higher compared with neat epoxy.

Tang et $a l .{ }^{151}$ investigated thoroughly the effect of graphene dispersion on the mechanical properties of epoxy resin. Gra- phene sheets were exfoliated from GO by means of thermal reduction. The studies were focused on different dispersions techniques: with and without a ball mill mixing resulting in higher dispersed reduced graphene oxide (RGO) and a poorly dispersed one to find out how dispersion affects the properties of the nanocomposite. For the good dispersion level, at $0.05 \mathrm{wt} \%$ content of RGO incorporated with epoxy, an increase in Young's modulus by $2.3 \%$ was noticed. The UTS increased slightly by $5.6 \%$ at the same loading. The elastic modulus and tensile properties did not demonstrate drastic differences between the two dispersion levels. Reasonably, the highly dispersed graphene fillers were more effective than the poorly dispersed one, due to transmitting the applied load by the agglomerate.

The mechanical properties of graphene oxide/epoxy nanocomposites were also reported by Bortz et al. ${ }^{152}$ The Young's modulus was enhanced by $6 \%$ at $0.5 \mathrm{wt} \%$ loading. Increasing the loading content also showed an improvement on stiffness. The maximum value of UTS occurred at $0.5 \mathrm{wt} \%$ loading, an increase of $13 \%$ in comparison with the neat epoxy. Both Young's modulus and UTS decreased beyond $0.5 \mathrm{wt} \%$ loading. The highest increase occurred at low graphene content $(<0.5 \mathrm{wt} \%)$ for both the stiffness and the strength.

The mechanical properties of epoxy resins modified using GPL and surface-modified graphene platelets (m-GPL) were studied by Zaman et al. ${ }^{153}$ Dumb-bell specimens were manufactured for tensile testing. The neat epoxy recorded a value of 2.7 GPa and $64 \mathrm{MPa}$ for the Young's modulus and UTS, respectively. Epoxy/GPL demonstrated a promising increase in modulus from 1 to $2.5 \mathrm{wt} \%$ loading but the stiffness faced a sudden drop up to $4.0 \mathrm{wt} \%$ loading. The maximum Young's modulus occurred at $4.0 \mathrm{wt} \%$ for epoxy/m-GPL with a value of $3.25 \mathrm{GPa}$. At $1.0 \mathrm{wt} \%$, epoxy/GP experienced an increase in the stiffness by $12.5 \%$ whereas epoxy/m-GP had an increase of only $3.7 \%$. As seen from Fig. 9, increasing the graphene content to $4.0 \mathrm{wt} \%$ provided a spectacular enhancement in fracture toughness of epoxy/m-GPL, 20\% higher compared to the neat epoxy. Another observation was that the tensile strength for both cases decreases drastically.

In further studies, Zaman et al. ${ }^{154}$ attempted to improve the mechanical properties using covalently modified graphene. Chemically modified graphene platelets (m-GnPs) were produced in an effort to achieve highly enhanced mechanical properties alongside good dispersibility. The neat epoxy had a value of $2.7 \mathrm{GPa}, 64 \mathrm{MPa}$ and 5.31\% for the Young's modulus, UTS and elongation at break, respectively. With the addition of $0.12 \mathrm{wt} \%$ of $\mathrm{m}-\mathrm{GnPs}$, the stiffness increased by $11 \%$ whilst a decrease in UTS and elongation at break were noticed at 3.8\% and $24 \%$, respectively.

Chatterjee $e t$ al. ${ }^{155}$ investigated the reinforcement effects of expanded graphene nanoplatelets (EGNP) in epoxy composites. The microscopic TEM images showed that a well-dispersed composite with the nanofillers could be established with up to $0.5 \mathrm{wt} \%$ loading. Increasing the EGNP nanofiller content led to unavoidable agglomeration and resulted in a decrease in mechanical properties. At $0.5 \mathrm{wt} \%$ of EGNP content, the 
Table 2 Graphene

\begin{tabular}{|c|c|c|c|c|c|c|c|c|c|c|c|c|c|c|c|}
\hline & \multicolumn{2}{|l|}{ Materials } & \multirow{3}{*}{$\begin{array}{l}\text { Particles } \\
\text { loading } \\
\text { (wt\%) }\end{array}$} & \multirow{3}{*}{$\begin{array}{l}\text { Particle } \\
\text { Size (nm) }\end{array}$} & & \multicolumn{7}{|c|}{ Effect on the mechanical properties } & \multirow{3}{*}{$\begin{array}{l}\text { Type of } \\
\text { mechanical } \\
\text { testing }\end{array}$} & \multirow[b]{3}{*}{ Production method } & \multirow[b]{3}{*}{ Ref. } \\
\hline & \multirow[b]{2}{*}{ Nanomaterials } & \multirow[b]{2}{*}{ Resin } & & & & \multirow{2}{*}{$\begin{array}{l}E \\
(\mathrm{GPa})\end{array}$} & \multirow{2}{*}{$\begin{array}{l}\text { UTS } \\
(\mathrm{MPa})\end{array}$} & \multirow{2}{*}{$\begin{array}{l}\% \\
\mathrm{EL}\end{array}$} & \multicolumn{4}{|c|}{$\begin{array}{l}\text { Fracture toughness } \\
G:\left(\mathrm{J} \mathrm{m}^{-2}\right) K:(\mathrm{MPa} \sqrt{ } \mathrm{m})\end{array}$} & & & \\
\hline & & & & & & & & & $G_{\mathrm{IC}}$ & $K_{\mathrm{IC}}$ & $G_{\text {IIC }}$ & $K_{\text {IIC }}$ & & & \\
\hline 15 & Graphene $\left(\mathrm{RGO}^{a}\right)$ & Epoxy (DGEBA) & 0.05 & & NR & 3.0 & 53 & & 77 & 0.48 & & & Tensile -flexural & Sonication/mechanical & 151 \\
\hline & & & & & MR & 3.0 & 56 & & 126 & 0.62 & & & $\begin{array}{l}\text { test/compact } \\
\text { tension }\end{array}$ & mixing/ball milling & \\
\hline 16 & Graphene Oxide & Epoxy (Bisphenol & 0.5 & & NR & 3.0 & 66 & & 250 & 0.75 & & & Tensile test/ & & 152 \\
\hline & & A/F diglycidyl) & & & MR & 3.2 & 75 & & 530 & 1.2 & & & $\begin{array}{l}\text { (SENB) /SEM/ } \\
\text { TEM }\end{array}$ & & \\
\hline 17 & TRGO $^{b}$ & Epoxy (bisphenol & 0.5 & & NR & & & & & 0.82 & & & $\left(3 \mathrm{P}-\mathrm{ENB}^{\mathrm{C}}\right) / \mathrm{SEM}$ & Three-roll-mill/mixing/ & 128 \\
\hline & GNP & A (Araldite LY556) & & $20-50$ & MR & & & & & 0.71 & & & & degassed under vacuum & \\
\hline & MWCNT (NC7000) & & & 9.5 & MR & & & & & 0.62 & & & & & \\
\hline 18 & GP & Epoxy (DGEBA, & 0.0 & & NR & 2.7 & 64 & & 204 & 0.7 & & & Tensile testing/ & Sonication/mechanical & 153 \\
\hline & & Araldite-F) & $1.0 \mathrm{GP}$ & & MR & 3.0 & 62 & & 298 & 0.95 & & & compact tension & mixer & \\
\hline & $\mathbf{m}-\mathbf{G P}^{d}$ & & $1.0 \mathrm{~m}-\mathrm{GP}$ & & MR & 2.8 & 59 & & 245 & 0.75 & & & $(\mathrm{CT})^{\mathrm{T}}$ & & \\
\hline & & & $4.0 \mathrm{GP}$ & & MR & 2.9 & 50 & & 417 & 1.02 & & & & & \\
\hline & & & $4.0 \mathrm{~m}-\mathrm{GP}$ & & MR & 3.3 & 53 & & 613 & 1.3 & & & & & \\
\hline 19 & m-GnPs & Epoxy & 0.12 & & NR & 2.7 & 64 & & 140 & 0.66 & & & & Thermal shocking & 216,154 \\
\hline & & & & & MR & 2.9 & 62 & & 300 & 1.00 & & & & sonication & \\
\hline 20 & EGNP $^{e}$ & Ероху (ЕРIKOTE & 0.5 & & NR & 3.8 & & & 68 & 0.51 & & & $(3-\mathrm{PB}) /\left(\mathrm{SENT}^{f}\right)$ & Ultrasonic/3-roll mill & 155 \\
\hline & & 828LVEL) & & & MR & 4.0 & & & 168 & 0.82 & & & & & \\
\hline 21 & GNP + CNT (XG & Epoxy (Araldite & 0.0 & $\mathrm{GNP}=7$ & NR & & & & & 0.77 & & 1.71 & (SENB) & Three roll mill/ & 162 \\
\hline & Sciences + USRN $^{g}$ ) & LY564 + Aradure & GNP $(0.5)$ & $\mathrm{CNT}=5-15$ & MR & & & & & 0.96 & & 1.68 & & dispersion process. & \\
\hline & & 2954) & $\begin{array}{l}\operatorname{GNP}(0.7)+ \\
\operatorname{CNT}(0.3)\end{array}$ & & MR & & & & & 1.25 & & 1.52 & & Cured and post-cured & \\
\hline 22 & Pristine & Epoxy (bisphenol- & 0.1 & & NR & 2.7 & 55 & & 250 & 0.95 & & & Compact tension & Sonication & 138 \\
\hline & SWNT & A) & & 2 & MR & 2.6 & 62 & & 380 & 1.15 & & & $(\mathrm{CT})$ & & \\
\hline & MWNT & & & 20 & MR & 2.9 & 64 & & 420 & 1.86 & & & & & \\
\hline & GPL & & & & MR & 3.7 & 78 & & 580 & 1.43 & & & & & \\
\hline 23 & $\mathbf{A T G O}^{h}$ & Epoxy (DGEBA) + & 0.0 & & NR & 2.2 & 68 & & 865 & 1.38 & & & Tensile test/ & (Modified hummers & 156,152 \\
\hline & & YD-128 & 0.1 & & MR & 2.4 & 71 & & 876 & 1.45 & & & (SENB) & method)/high-speed & \\
\hline & & & 0.5 & & MR & 3.2 & 75 & & 1404 & 2.12 & & & & stirring/vacuum mixing & \\
\hline 24 & APTS- GO ${ }^{i}$ & Epoxy Araldite & 0.2 & $0.5-10 \mu \mathrm{m}$ & NR & 2.5 & 70 & 4.6 & 360 & 1.02 & & & Tensile test & Sonication/vacuum & 158 \\
\hline & & LY5052 & & & MR & 3.3 & 81 & 8.4 & 390 & 1.22 & & & fatigue test/ & drying & \\
\hline & GPTS- GO $^{j}$ & & & & MR & 3.0 & 79 & 8.7 & 620 & 1.46 & & & (SENB) & & \\
\hline 25 & - & Epoxy ML-526 & 0.5 & & NR & 2.5 & 61 & 12.2 & 350 & 0.97 & & & (SENB) & Stirring grinding/ & 157 \\
\hline & GPL & (Bisphenol-A) & & $40-120$ & MR & 2.8 & 70 & 7.8 & 575 & 1.35 & & & & synthesis method & \\
\hline & GNS & & & $5-10 \mu \mathrm{m}$ & MR & 3.1 & 66 & 7.2 & 420 & 1.14 & & & & & \\
\hline
\end{tabular}

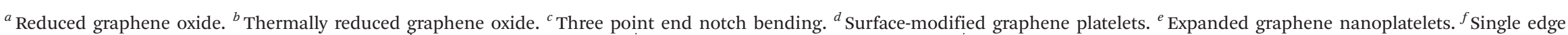
notch tension. ${ }^{g}$ US Research Nanomaterials Inc. ${ }^{h}$ Attached graphene oxide. ${ }^{i}$ Amino functionalized graphene oxide. ${ }^{j}$ Epoxy functionalized graphene oxide. 
stiffness increased from 3.82 GPa for the neat epoxy to 4.0 GPa $(4.7 \%$ increment). The Young's modulus increased up to $1.5 \mathrm{wt} \%$ loading, and beyond this point, there was a decrease up to $2.0 \mathrm{wt} \%$. The increase in Young's modulus was due to the load transfer from the matrix to the EGNP nanofillers.

In another article published by Tong et $a l^{156}$ silanized silica nanoparticles attached to graphene oxide (ATGO) were used to enhance the mechanical properties of epoxy. The Young's modulus and UTS of pristine epoxy was found to be $2.2 \mathrm{GPa}$ and $68 \mathrm{MPa}$, respectively. The results showed that $0.1 \mathrm{wt} \%$ ATGO improved the elastic modulus and the UTS by $9 \%$ and $4 \%$, respectively.

Shokrieh et al. $^{157}$ investigated the effects of both graphene nanoplatelets (GPL) and graphene nanosheets (GNS) on the mechanical properties of epoxy based composites. Tensile tests were carried out to evaluate the tensile and elastic modulus of the resulting nanocomposite. The pristine epoxy recorded a value of $2.5 \mathrm{GPa}, 61 \mathrm{MPa}$ and $12.2 \%$ for the Young's modulus, UTS and elongation at break, respectively. With the addition of $0.1 \mathrm{wt} \%$ of GPL, an increment of $4.5 \%$ in stiffness was noticed. Increasing the content to $0.5 \mathrm{wt} \%$ resulted in a further increase in stiffness by $10.4 \%$. The UTS increased by $14.7 \%$ in comparison with the pristine epoxy. A reduction of $36 \%$ in the elongation at break was also detected. Interestingly, GNS contributed to a higher stiffness, considerably higher than that of GPL, a value of $23 \%$. However, GNS experienced a decrease in the UTS from $70 \mathrm{MPa}$ to $66 \mathrm{MPa}$. A key reason for this decrease in UTS could be associated with the increase of stress concentrations caused by the re-agglomeration of GPL.

Li et $a l^{158}$ studied the effects of functionality of graphene oxide on the mechanical properties of epoxy based composites by mixing two different modified graphene oxides (GO) into amino-functionalized GO (APTS-GO) and epoxy-functionalized GO (GPTS-GO). The addition of $0.2 \mathrm{wt} \%$ of APTS-GO resulted in an increase in both the Young's modulus and tensile strength, by $32 \%$ and $16 \%$ respectively. Similarly, GPTS-GO showed a promising increase in stiffness by $20 \%$, lower than that produced by APTS-GO whilst still providing an enhancement in the toughness of the nanocomposite. The UTS of the GPTS-GO modified epoxy based composite increased by $13.6 \%$ relative to the neat epoxy but $2.4 \%$ lower than that modified by APTS-GO. In contrast to the findings on the elastic modulus and tensile strength, the enhancement in the elongation at break is more apparent for GPTS-GO (Fig. 10).

Shen et al. ${ }^{159}$ investigated the reinforcing effect of graphene nanosheets on the cryogenic mechanical properties of epoxy resins. The preparation of the graphene based epoxy nanocomposite was carried out by sonication, followed by vacuum degassing. Images acquired using SEM and TEM revealed that at low graphene content, the dispersion was highly satisfactory but became more severe as the graphene content increases. A tensile test was carried out under cryogenic temperature conditions to evaluate the mechanical properties. At $77 \mathrm{~K}$, it was noted that the cryogenic tensile strength increased with the addition of graphene content, reaching its peak at $0.1 \mathrm{wt} \%$ content with a decrease in tensile strength up to $0.5 \mathrm{wt} \%$

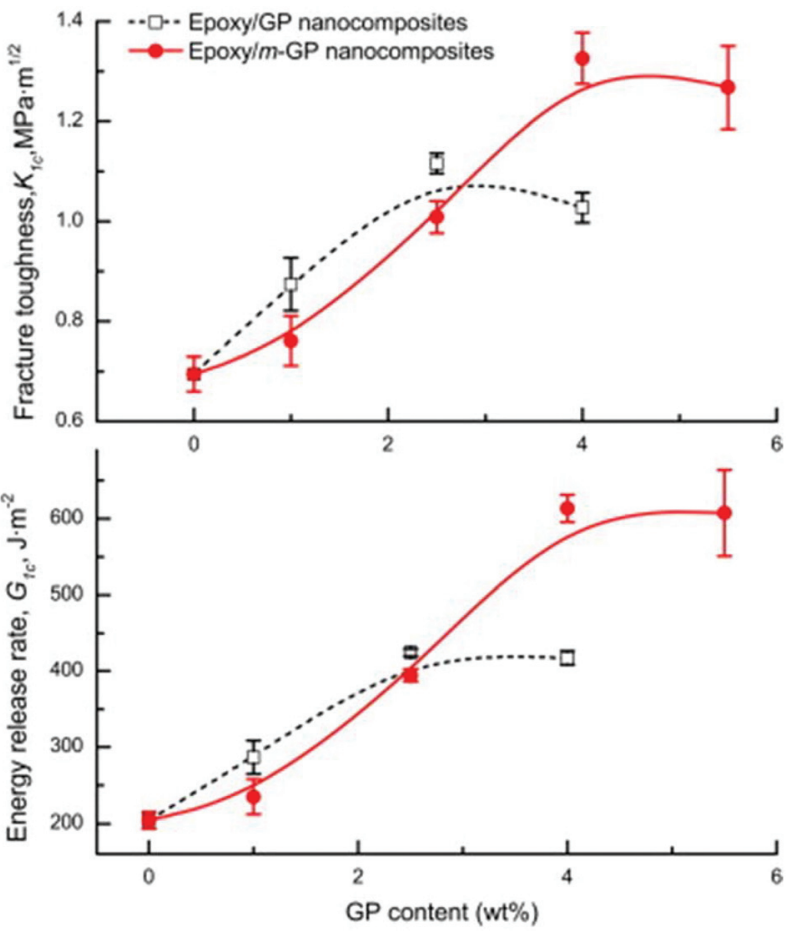

Fig. 9 Fracture toughness of neat epoxy, epoxy/GP and epoxy/m-GP nanocomposites. ${ }^{153}$ Reprinted with permission from ref. 153 (Copyright (C) 2011 Elsevier).

loading. The cryogenic Young's modulus was found to increase linearly up to a value of $6.9 \mathrm{GPa}$ at $0.5 \mathrm{wt} \%$ loading.

\subsection{Comparative analysis of the fracture toughness of nanocomposites using graphene}

Rafiee et $a .^{138}$ reported that GPL out-perform CNTs, resulting in a $126 \%$ increase in the fracture toughness of the neat epoxy. Compact tension specimens were used to determine mode I fracture toughness. Mode I fracture toughnesses for SWCNT, MWCNT and GPL compared with the neat epoxy were all enhanced by $45 \%, 66 \%$ and $126 \%$, respectively. GPL superiority is very obvious in comparison with the other nanocomposites.

The fracture properties of epoxy filled with reduced graphene oxide (RGO) at highly and poorly dispersed levels were studied by Tang et al. ${ }^{151}$ The highly dispersed RGO experienced an increase in mode I fracture toughness. Interestingly, for the poorly dispersed RGO, up to $0.1 \mathrm{wt} \%$ loading, there was an increase in the fracture performance. However, beyond this point, up to $0.2 \mathrm{wt} \%$, saturation occurs with no change in the value of $G_{\mathrm{IC}}$. At $0.05 \mathrm{wt} \%$, the highly dispersed RGO resulted an increase of $63 \%$ for mode I fracture toughness whilst the poorly dispersed RGO had an increase of only $27 \%$. Therefore, highly dispersed RGO sheets were more efficient in the toughness improvement for epoxy.

As specified before, Bortz et al. ${ }^{160}$ conducted studies on the fracture toughness improvement of epoxy using graphene oxide (GO). Improvements of $28 \%$ to $111 \%$ in mode I fracture 

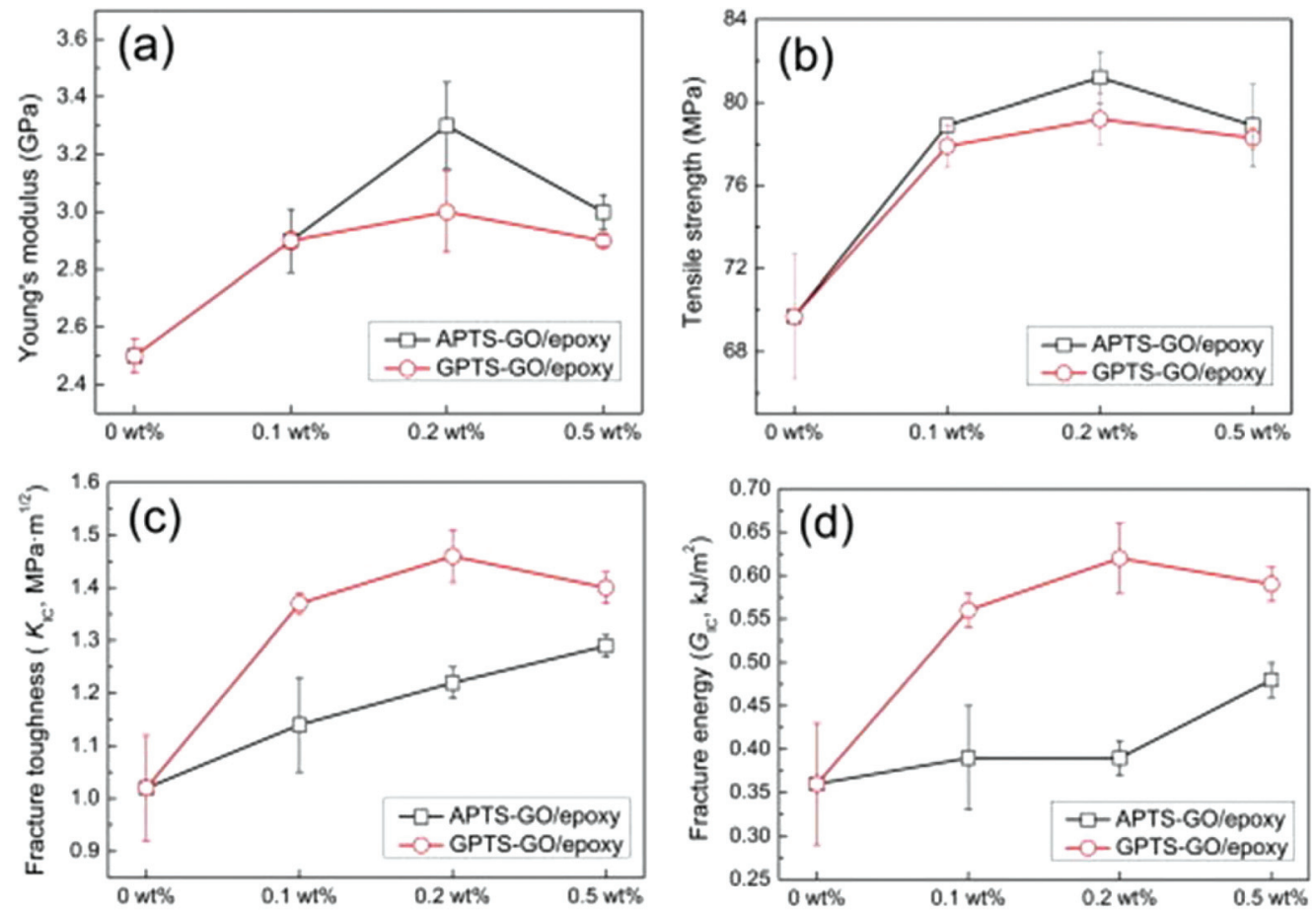

Fig. 10 Mechanical properties of neat epoxy and nanocomposite at different loadings of re-functionalized GO. ${ }^{158}$ Reprinted with permission from ref. 158 (Copyright @ 2013 Elsevier).

toughness through the incorporation of $<1.0 \mathrm{wt} \%$ of GO into a matrix resin were achieved. Again, at low graphene content (up to $0.5 \mathrm{wt} \%)$, the enhancements were very impressive. At 0.5 wt $\%$ loading, an increase of $109 \%$ in fracture toughness compared to the pristine epoxy was observed.

The importance of surface modification was highlighted by the increment in fracture toughness. Zaman et al. ${ }^{153}$ investigated the fracture toughness of epoxy matrix resins filled with graphene platelets (GP) and surface modified graphene platelets (m-GP) using a compact tension test. The study showed that at $4.0 \mathrm{wt} \%$, both the functionalized (m-GP) and non-functionalized (GP) epoxy made a major increase in mode I fracture toughness $G_{\text {IC }}$. Epoxy/GP showed an enhancement in mode I fracture toughness at low graphene content whilst the surface modified graphene platelets registered a continual upsurge up to $5.5 \mathrm{wt} \%$. At $4.0 \mathrm{wt} \%$, GP resulted in an increase in values from $200 \mathrm{~J} \mathrm{~m}^{-2}$ to $417 \mathrm{~J} \mathrm{~m}^{-2}$, an increment of $104 \%$ whilst $\mathrm{m}$-GP increased the toughness to $613 \mathrm{~J} \mathrm{~m}^{-2}$, more than $200 \%$. Even though clusters existed in the m-GP composites, the good dispersibility and exfoliation of graphene sheets still enabled the enhancements.

Furthermore, Zaman et al. ${ }^{161}$ studied how chemically modified graphene in the polymer nanocomposite can enhance the fracture toughness. The neat epoxy had a value of mode I fracture toughness $G_{\text {IC }}$ of about $140 \mathrm{~J} \mathrm{~m}^{-2}$. An increase of $110 \%$ in $G_{\text {IC }}$ with the addition of $0.12 \mathrm{wt} \%$ of $\mathrm{m}$-GnPs was observed. This trend was satisfied when the particles loading was increased giving the highest fracture toughness of $557 \mathrm{~J} \mathrm{~m}^{-2}$ at
$0.48 \mathrm{wt} \%$. The high molecular weight surfactant provided a good dispersion of m-GnPs in the epoxy, eventually leading to satisfactory results.

Expanded graphene nanoplatelets (EGNP) filled with epoxy were used to improve the fracture toughness of a nanocomposite by Chatterjee et al. ${ }^{155}$ The neat epoxy had a $G_{\text {IC }}$ value of about $68 \mathrm{~J} \mathrm{~m}^{-2}$. Increasing the content of EGNP resulted in higher fracture toughness, until saturation occurs. At $0.5 \mathrm{wt} \%$ loading, a value of $168 \mathrm{~J} \mathrm{~m}^{-2}$ for mode I fracture toughness was noted: a $147 \%$ increment.

Moghadam and Taheri ${ }^{162}$ studied the toughening mechanisms of GNP in epoxy based composites. Neat epoxy had a value of $0.77 \mathrm{MPa} \sqrt{\mathrm{m}}$ for mode I fracture toughness. GNP filled epoxy resins at $0.5 \mathrm{wt} \%$ loading provided a value of 0.98 MPa $\sqrt{ } \mathrm{m}, 27 \%$ higher in comparison with the neat epoxy. The incorporation of $0.7 \mathrm{wt} \%$ of GNP alongside $0.3 \mathrm{wt} \%$ of CNT increased mode I fracture toughness by $62 \%$. A significant improvement was noticed when multiphase nanofillers were used in the matrix resin system.

As stated in the previous section, Tongwu et al. ${ }^{156}$ studied different methods to enhance the fracture properties of epoxies using multiphase nanoparticles such as silanized silica attached graphene oxide. The neat epoxy recorded a value of $865 \mathrm{~J} \mathrm{~m}^{-2}$ for mode I fracture toughness which is higher than the values acquired by all the other studies reviewed in this paper. At $0.1 \mathrm{wt} \%$ of ATGO loading, the $G_{\text {IC }}$ increased moderately by $1.27 \%$. However, further loading up to $0.5 \mathrm{wt} \%$ produced a remarkable enhancement of $62 \%$. 


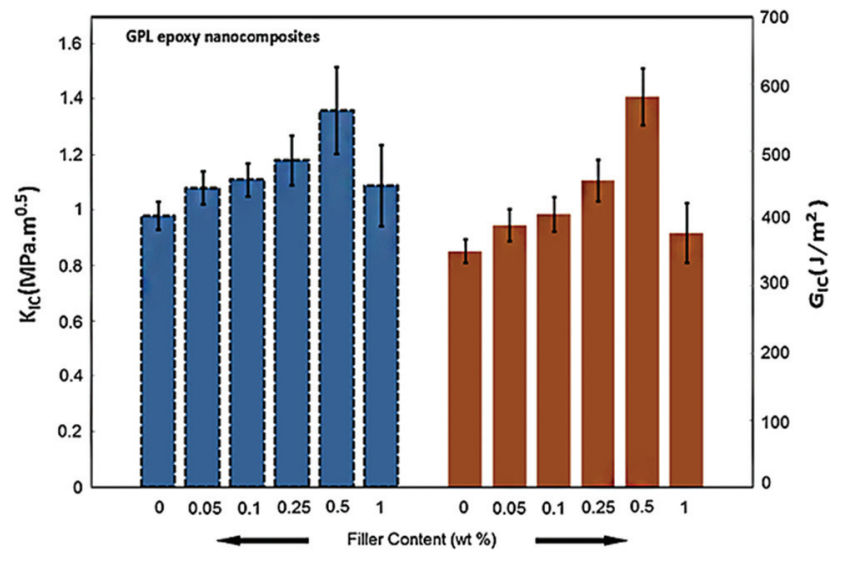

Fig. 11 Effect of graphene nanoplatelets (GPL) loading on fracture toughness of graphene/epoxy nanocomposites. ${ }^{157}$ Reprinted with permission from ref. 157 (Copyright $\odot 2014$ Wiley).

Shokrieh et al. $^{157}$ looked into the effects of graphene nanoplatelets (GPL) and graphene nanosheets (GNS) on the fracture toughness of epoxy. Single-edge-notch bending (SENB) was used to determine mode I fracture toughness of the nanocomposites. A value of $350 \mathrm{~J} \mathrm{~m}^{-2}$ was recorded for the neat epoxy. The addition of $0.5 \mathrm{wt} \%$ of GPL produced a $64 \%$ increase in value from $350 \mathrm{~J} \mathrm{~m}^{-2}$ to $575 \mathrm{~J} \mathrm{~m}^{-2}$. GNS also increased the mode I fracture toughness by $20 \%$, which was lower than that produced by GPL. Analysis of the SEM images revealed that inelastic matrix deformation and voids development by debonding of the particles from the matrix are accountable for the toughening mechanisms.

The fracture toughness of epoxy based composites with amino-functionalized GO (APTS-GO) and epoxy-functionalized GO (GPTS-GO) fillers was studied by Li et al. ${ }^{158}$ The neat epoxy recorded a value of $360 \mathrm{~J} \mathrm{~m}^{-2}$. The addition of $0.5 \mathrm{wt} \%$ of APTS-GO contributed to a rise in mode I fracture toughness by 8.3\% (Fig. 11). Significant improvement was observed: in the case of APTS-GO, an increase of $G_{\text {IC }}$ by $72 \%$. GPTS-GO was more adequate in enhancing the ductility and fracture toughness performance whilst APTS-GO was more advantageous for the elastic modulus and tensile strength.

\subsection{Highlights summary of nanocomposites using graphene}

Graphene can be used to produce advanced materials due to their excellent physicochemical properties and the natural abundance of their precursor, graphite. By exploring the growth, chemical modification, and doping of graphene and using in new configurations, more novel applications will emerge. Incorporation of graphene as a nanofiller considerably contributed to higher stiffness and mode I fracture toughness as observed by all the 11 reported studies. Functionalization such as amino and epoxy functionalized graphene as investigated by Li et al. ${ }^{158}$ significantly contributed to the improvement of performance at different levels. Functionalization is a convenient route to magnify the enhancements of the material properties if applied correctly. This statement is in good agree- ment with the work carried out on modified graphene platelets by Zaman et al., ${ }^{153}$ where enhancements of the fracture toughness were reported. More interestingly, the study carried out by Tongwu et al. ${ }^{156}$ showed a value of $865 \mathrm{~J} \mathrm{~m}^{-2}$ for the neat epoxy DGEBA YD-128 and D-230 acting as a curing agent, noticeably higher than the values obtained by all the other studies reviewed in this paper.

\section{Clay}

Nanoclays, also referred to as nano-montmorillonite, are highly potential nanofillers due to their exfoliated arrangements in the soft polymer. ${ }^{163-167}$ They provide a good range of mechanical and fracture properties such as high stiffness. ${ }^{168-171}$ On the other hand, there exist drawbacks ${ }^{172}$ when manufacturing those exfoliated structures. An innovative nanocomposite discovered by Lau et al. ${ }^{173}$ could be an answer to this problem. The growth of nanotubes from nanoclay platelets provided a more robust reinforcement. It has been documented that the addition of nanoclay to epoxy resin has a remarkable effect on the interfacial shear strength. ${ }^{174}$

Several studies on nanoclay have been carried out to integrate nanoplatelets for improving the mechanical properties of epoxy. The results of these studies are summarized in Table 3. Most of the research studies show that the increase in Young's modulus using nanoclay is due to the orientation of the clay platelets occurring along the loading directions. ${ }^{175,176}$ When the weight percentage loading of nanoclay as nanofillers is beyond an optimal level, the mechanical properties of the nanocomposite performances decrease. ${ }^{177}$ This very interesting fact about nanoclay needs to be taken into consideration. A maximum of $5 \mathrm{wt} \%$ loading has been proven to be ideal to obtain good mechanical properties. ${ }^{178}$

\subsection{Comparative analysis of the mechanical properties of nanocomposites using nanoclay}

Qi et $a l{ }^{171}$ investigated the mechanical properties of epoxy when nanoclay additives with MMT-cetylpyridinium chloride (CPC) were incorporated into the matrix. An increase of 3.0\% in stiffness and a decrease of $30 \%$ in tensile strength (TS) and the strain at $5.0 \mathrm{wt} \%$ nanoclay loading were reported. The significant declines in TS and strain to rupture were attributed to poor dispersion of the nanoclay.

Wang et al. ${ }^{179}$ studied an innovative approach for dispersing nanoclay particles into the epoxy resin using solvent. The resulting nanofillers, known as silane-modified clay (SMC) in the epoxy matrix, were prepared and tested to evaluate the mechanical properties of the nanocomposite. The tensile properties of the neat epoxy were 1.8 GPa for the stiffness and 46 MPa for the tensile strength. A linear increase in Young's modulus and UTS was observed for the nanocomposite with SMC as shown in Fig. 12. At $3.0 \mathrm{wt} \%$, an increment of $31 \%$ and $14 \%$ for the Young's modulus and UTS, respectively, was recorded. This trend is due to the high stiffness of the clay particles. An interesting observation about the tensile strength 


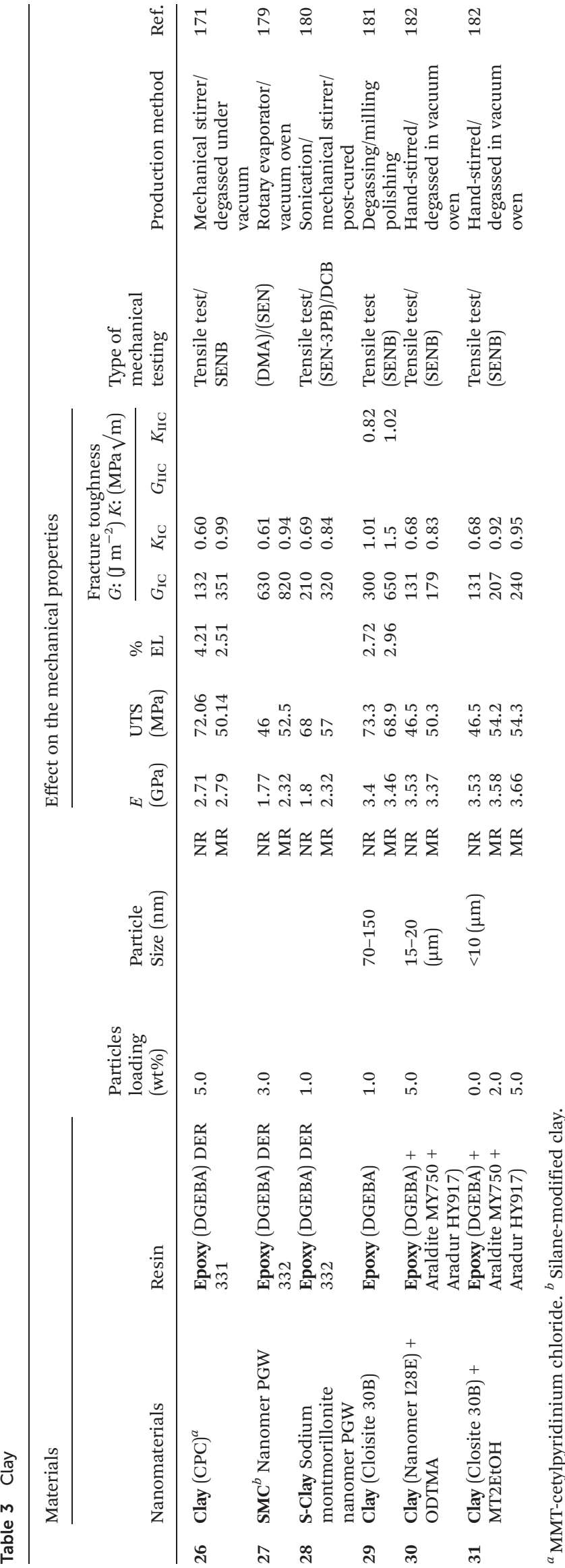

was made at $2.0 \mathrm{wt} \%$ loading. At this loading, SMC faced the highest UTS, an increase of $25 \%$ compared to the neat epoxy, much higher than that recorded for the one with $3.0 \mathrm{wt} \%$ of SMC. The decline in tensile strength at higher loading was caused by weaker boundaries between the nanoparticles and the matrix and the imperfections with the nanocomposite.

A similar research study based on highly exfoliated clay with epoxy nanocomposite, centred on the change in mechanical properties, was reported by Wang et al. ${ }^{180}$ Using the "slurry-compounding" process, nanoclay incorporation into epoxy with a highly exfoliated morphology was efficaciously executed. The introduction of nanoclay in the matrix increased the Young's modulus of the nanocomposite with increasing nanofiller loadings. At $1.0 \mathrm{wt} \%$ loading, an increase in stiffness by $28 \%$ was observed whereas the tensile strength experienced a decrease of $16 \%$ in comparison with the pristine epoxy. This trend was observed at higher nanoclay loading.

Zappalorto et al. ${ }^{181}$ examined the mechanical properties of the epoxy/nanoclay composite (Cloisite 30B). Tensile tests using the dog-bone specimen were conducted to evaluate the elastic modulus, TS and \%EL at break of the pristine and modified nanocomposite. The Young's modulus is marginally affected by the addition of the nanofiller, an enhancement of $1.5 \%$, whereas the tensile strength experienced a decrease in value from $73.3 \mathrm{MPa}$ to $68.9 \mathrm{MPa}$, a drop by $6 \%$. Contrary to improvements in stiffness, the modified resin had an unfavourable consequence on the tensile strength.

Guevara et $a l .{ }^{182}$ investigated the mechanical properties of the epoxy-clay nanocomposite by opting for two completely opposite surface-treated montmorillonite. Two different types of clay, Cloisite 30B and Nanomer I.28E, were chosen in their study using the same benchmark resin. The neat epoxy had a value of $3.53 \mathrm{GPa}$ for the elastic modulus and a value of 46.5 MPa for the tensile strength. At $5.0 \mathrm{wt} \%$ loading, the stiffness of the epoxy-clay nanocomposite with Nanomer I.28E decreased by $5.4 \%$ whereas an increase of $3.7 \%$ was observed for the epoxy-clay nanocomposite with Cloisite 30B. The decrease in modulus was associated with voids formation in the material. However, at the same particle loading, the tensile strength of the epoxy-clay nanocomposite with Nanomer I.28B increased by $8.2 \%$, and a similar effect for the one with Cloisite $30 \mathrm{~B}$ was observed, with an increase of $16.8 \%$.

Yang et al. ${ }^{183}$ studied the cryogenic mechanical behaviours of the montmorillonite (MMT)/epoxy nanocomposite. Ultrasonic mixing followed by degassing was used for the preparation of the nanocomposite. At liquid nitrogen temperature ( $77 \mathrm{~K})$, the mechanical properties were investigated in terms of modulus and tensile strength. Using transmission electron microscopy (TEM), the dispersion process of the organo-MMT in epoxy was analysed, demonstrating intercalation and exfoliation in the resulting nanocomposite. Tensile testing was carried out under cryogenic conditions at $77 \mathrm{~K}$. At $1.0 \mathrm{wt} \%$ content of organo-MMT, the tensile strength increased to 120 MPa in comparison with the neat epoxy at $104 \mathrm{MPa}$. A sudden drop in the tensile strength was observed with increasing content, a value of $78 \mathrm{MPa}$ at $2.0 \mathrm{wt} \%$. On the other hand, the 

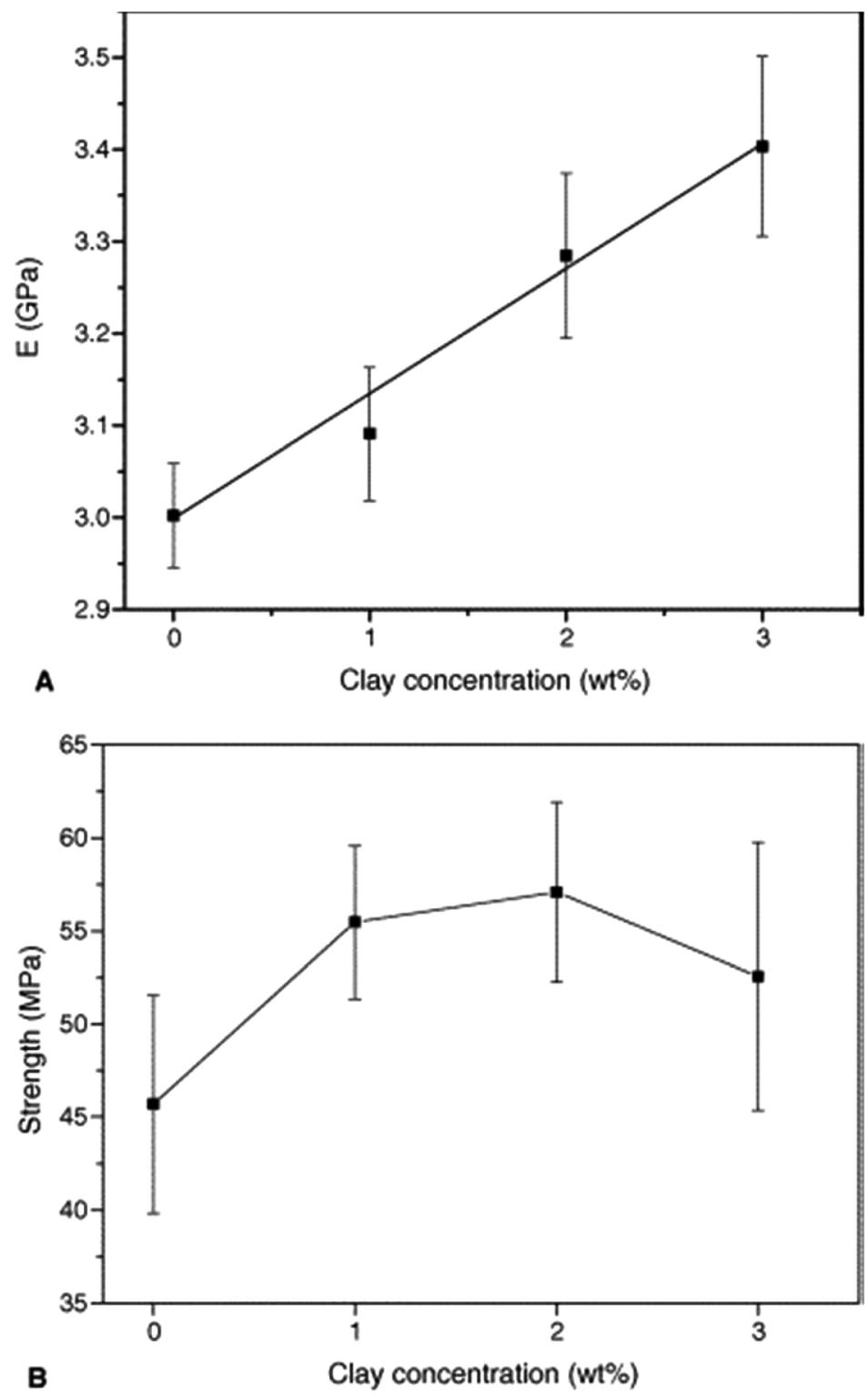

Fig. 12 Variation of (a) tensile modulus and (b) tensile strength with clay concentration in nanoclay/epoxy nanocomposite. ${ }^{179}$ Reprinted with permission from ref. 179 (Copyright @ 2006 Elsevier).

cryogenic tensile modulus increased linearly with increasing content. At $3.0 \mathrm{wt} \%$, the composition of the nanocomposite recorded the highest value at $5.8 \mathrm{GPa}$ in comparison with the neat epoxy (3.0 GPa).

\subsection{Comparative analysis of the fracture toughness of nanocomposites using nanoclay}

Qi et $a l .{ }^{171}$ also investigated the effects of nanoclay additives on the fracture toughness of epoxy. Different types of nanoclay such as Cloisite 30B, Nanomer I.30E and MMT-cetylpyridinium chloride (CPC) were mixed with DGEBA-based epoxy resin and the fracture properties of the resulting nanocompo- sites were measured. For the nanocomposite with $5.0 \mathrm{wt} \%$ of CPC, a substantial increase of $165 \%$ in mode I fracture toughness was observed. All the different types of nanoclay followed the same trend with increasing fracture toughness values. SEM analysis shows that the increase in fracture toughness was attributed to the clay particles delaying the crack propagation.

Wang et al. ${ }^{179}$ investigated the fracture properties of epoxy with silane-modified clay (SMC). Three-point bend tests were carried out in order to evaluate the mode I fracture toughness. Initial observation revealed that the neat epoxy had a $G_{\text {IC }}$ value of $630 \mathrm{~J} \mathrm{~m}^{-2}$. By adding $1 \mathrm{wt} \%$ and $2 \mathrm{wt} \%$ of SMC, the mode I fracture toughness of epoxy was increased by $140 \%$ and $190 \%$, respectively. The fracture toughness dropped with further 

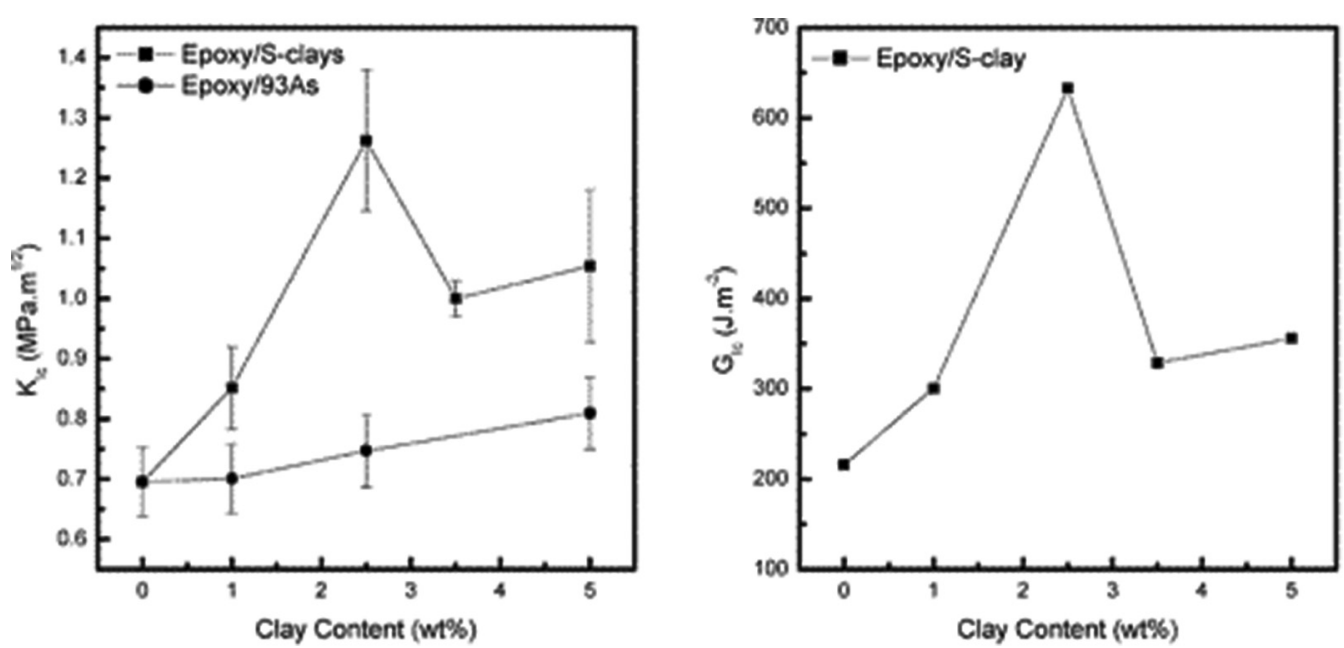

Fig. 13 Fracture toughness of S-clays/epoxy nanocomposites using the SEN-3PB test at various wt\% of clay loading. ${ }^{180}$ Reprinted with permission from ref. 180 (Copyright @) 2005 ACS Publication).

increase of nanoclay content to $3 \mathrm{wt} \%$. TEM images showed that clay is highly exfoliated and well-dispersed into the epoxy resin.

Wang et al. ${ }^{180}$ also studied the fracture properties of highly exfoliated clay based epoxy. A three point bending test was carried out to determine the mode I fracture toughness. An initial observation revealed that the values of $G_{\text {IC }}$ were much higher than that of the pristine epoxy which demonstrates a toughening mechanisms taking place. At $1.0 \mathrm{wt} \%$, an increase in the fracture toughness by $52 \%$ was noted. At $2.5 \mathrm{wt} \%$, the highest value for the mode I fracture toughness was recorded as $632 \mathrm{~J} \mathrm{~m}^{-2}$, an increase by $66 \%$ in comparison with the pure epoxy. Beyond this point of loading, a decrease in $G_{\text {IC }}$ was observed as shown in Fig. 13.

The mode I fracture toughness of epoxy-nanoclay composites was also studied by Zappalorto et al. ${ }^{181}$ using a single edge notch bending test. Primarily, a value of $300 \mathrm{~J} \mathrm{~m}^{-2}$ for the neat epoxy was reported. The addition of $1.0 \mathrm{wt} \%$ of nanoclay made a substantial improvement from $300 \mathrm{~J} \mathrm{~m}^{-2}$ to $650 \mathrm{~J} \mathrm{~m}^{-2}$, a $116 \%$ increment. The increases in the mode I fracture toughness is independent of the loading ratio of the nanofiller at $<1.0 \mathrm{wt} \%$. For mode II fracture toughness, a higher increment, by $24.1 \%$, was observed at $1.0 \mathrm{wt} \%$.

SENB tests were used to determine the fracture toughness of two different types of epoxy-clay composites: (1) Cloisite 30B and (2) Nanomer I.28B, a study conducted by Guevara et al. ${ }^{182}$ The neat epoxy had a fracture toughness of $131 \mathrm{~J} \mathrm{~m}^{-2}$, which is common for brittle resins. At $5.0 \mathrm{wt} \%$ loading, both nanofillers increased the fracture toughness, 36\% increase for the one with Nanomer I.28E whilst Closite 30B provided an increase of $83 \%$. Voids formed by debonding of the clay platelets from the matrix were detected by SEM studies.

\subsection{Highlights summary of nanocomposites using nanoclay}

In the majority of published studies, enhancements in the mechanical and fracture toughness of epoxy-nanoclay compo- sites are reported to occur at a nanoclay loading of around $5.0 \mathrm{wt} \%$, which is higher in comparison with the CNTs and grapheme nanomaterials. Closite 30B provided the highest stiffness improvement amongst all the nanoclays that have been reviewed. However, nanocomposites with silane-modified clay (SMC) had the highest mode I fracture toughness value. In all of the 6 epoxy-nanoclay composite reports, the same epoxy system DGEBA was used but the mode I fracture toughness of the pristine epoxies were not in the same range. This could be associated with the molecular weight of the epoxies, the types of hardeners and curing agents and the processing conditions used, resulting in different fracture properties. The preparation of epoxy is vitally important in enhancing the toughness of the nanocomposite.

\section{Silica}

The use of silicate-based fillers in nanocomposites has been of major interest for many researchers as there is a prospect to yield higher mechanical properties and fracture toughness, ${ }^{184-193}$ also resulting in substantial enhancement in the elastic modulus and yield strength. Selected results from the studies on the use of silicate-based fillers in epoxy based nanocomposites are summarized in Table 4 . The nanosilica particles are amply small, which benefits the resin transfer moulding manufacturing process as they are not filtered-out during the process.

Considered as a promising potential material, nanosilica is currently at the forefront of nanocomposite applications, industrial formulations and adhesives, amongst others. In many instances, the effect of nanosilica has stiffened, strengthened and toughened the epoxy matrix system. Studies have pointed out that the use of nanosilica particles causes a more significant improvement in the stiffness, better than microfillers. ${ }^{194,195}$ Dispersion processes for nanosilica have been 


\begin{tabular}{|c|c|c|c|c|c|c|c|c|c|c|c|c|c|c|c|}
\hline & \multicolumn{2}{|l|}{ Materials } & \multirow{3}{*}{$\begin{array}{l}\text { Particles } \\
\text { loading } \\
\text { (wt\%) }\end{array}$} & \multirow{3}{*}{$\begin{array}{l}\text { Particle } \\
\text { Size (nm) }\end{array}$} & & \multicolumn{7}{|c|}{ Effect on the mechanical properties } & \multirow{3}{*}{$\begin{array}{l}\text { Type of } \\
\text { mechanical } \\
\text { testing }\end{array}$} & \multirow[b]{3}{*}{ Production method } & \multirow[b]{3}{*}{ Ref. } \\
\hline & \multirow[b]{2}{*}{ Nanomaterials } & \multirow[b]{2}{*}{ Resin } & & & & \multirow{2}{*}{$\begin{array}{l}E \\
(\mathrm{GPa})\end{array}$} & \multirow{2}{*}{$\begin{array}{l}\text { UTS } \\
\text { (MPa) }\end{array}$} & \multirow{2}{*}{$\begin{array}{l}\% \\
\mathrm{EL}\end{array}$} & \multicolumn{4}{|c|}{$\begin{array}{l}\text { Fracture toughness } \\
G:\left(\mathrm{J} \mathrm{m}^{-2}\right) K:(\mathrm{MPa} \sqrt{ } \mathrm{m})\end{array}$} & & & \\
\hline & & & & & & & & & $G_{\mathrm{IC}}$ & $K_{\mathrm{IC}}$ & $G_{\text {IIC }}$ & $K_{\text {IIC }}$ & & & \\
\hline \multirow[t]{3}{*}{32} & Silica + GO & Epoxy (EPON 828) & 0.0 & D:400nm & NR & 1.36 & 51 & 6.14 & 2408 & 1.81 & & & (DMA)/tensile & High-shear mixer/ & 196 \\
\hline & (Submicro sized & & 0.1 & & MR & 1.45 & 59.1 & 6.51 & 3217 & 2.16 & & & test/single & ultrasonic/degassed in & \\
\hline & silica) & & 5.0 & & MR & 1.62 & 67.3 & 6.77 & 4770 & 2.78 & & & cantilever mode & vacuum/sonication & \\
\hline \multirow[t]{2}{*}{33} & Silica (Nanopox & Epoxy (DGEBA/F) & 0.1 & 20 & NR & 2.21 & & & 357 & 1.08 & & & Tensile test/ & Mechanical stirrer/ & 197 \\
\hline & E430) & & & & MR & 2.32 & 92.3 & & 400 & 1.21 & & & TEM/(3-PB) & vacuum oven & \\
\hline \multirow[t]{2}{*}{34} & Binary Silica & Epoxy bisphenol & 2.0 & 20 & NR & 2.86 & 42.1 & & 280 & 0.95 & & & Tensile test/ & Mechanical stirrer/ & 19 \\
\hline & Nanopox_F400 & A (DGEBA) & & & MR & 2.88 & 45.1 & & 310 & 1.01 & & & (SENB) (CT) & vacuum oven & \\
\hline \multirow[t]{2}{*}{35} & Binary Rubber & Epoxy bisphenol & 2.0 & & NR & 2.86 & 42.1 & & 280 & 0.95 & & & Tensile test/ & In situ through sol-gel & 19 \\
\hline & Spherical rubber & A (DGEBA) & & & MR & 2.63 & 45.6 & & 340 & 1.01 & & & (SENB) $(\mathrm{CT})$ & $\begin{array}{l}\text { process/mechanical } \\
\text { stirrer/vacuum oven }\end{array}$ & \\
\hline \multirow[t]{2}{*}{36} & $\mathbf{R} / \mathbf{S}^{a}$ Spherical & Epoxy bisphenol & $6.0 / 2.0$ & 20 & NR & 2.86 & 42.1 & & 280 & 0.95 & & & Tensile test/ & In situ through sol-gel & 19 \\
\hline & $\begin{array}{l}\text { rubber /Nanopox_ } \\
\text { F400 }\end{array}$ & A (DGEBA) & & & MR & 2.52 & 39.8 & & 1720 & 1.03 & & & (SENB) (CT) & $\begin{array}{l}\text { process/mechanical } \\
\text { stirrer/vacuum oven/ } \\
\text { cured }\end{array}$ & \\
\hline \multirow[t]{2}{*}{37} & Silica Surface- & Epoxy $\left(\right.$ DGEBA $\left.^{b}\right)$ & 4.0 & 20 & NR & 2.96 & & & 87 & 0.51 & & & Compact tension/ & Sol-gel/release-coated & 198 \\
\hline & $\begin{array}{l}\text { Modified (Nanopox } \\
\text { F400) }\end{array}$ & & & & MR & 3.20 & & & 132 & 0.65 & & & & moulds/cured & \\
\hline \multirow[t]{2}{*}{38} & CNF (Helical-ribbon) & Epoxy (Resoltech & 0.5 & 60 & NR & & & & 250 & 0.78 & & & Three point & High shear mixer- & 217 \\
\hline & & 1800/1805) & & & MR & & & & 550 & 1.25 & & & flexural & polishing machine & \\
\hline 39 & Silica (Organosilicate & Epoxy (Araldite & 7.2 & & NR & 3.1 & 80.3 & 7.4 & 130 & 0.74 & & & $\left(\mathrm{SENB}^{c}\right) / \mathrm{V}-\mathrm{Notch}$ & Casting in an & 184 \\
\hline & Clay) & CY 225) & & & MR & 4.7 & 51.5 & 1.2 & 160 & 1.13 & & 4.7 & & aluminium mould & \\
\hline 40 & Silica (Nanopox & Epoxy (DGEBA) & 0.0 & 20 & NR & 2.96 & & & 103 & 0.59 & & & Tensile test/ & Sol-gel process/cured & 199 \\
\hline & F400) & Albidur HE600 & 4.0 & & MR & 3.20 & & & 291 & 1.03 & & & compact & & \\
\hline & & & 7.8 & & MR & 3.42 & & & 352 & 1.17 & & & tensions/(SENB) & & \\
\hline 41 & Silica (Nanopox & Epoxy (DGEBA) & 0.0 & 20 & NR & 2.96 & & & 103 & 0.59 & & & Tensile test/ & Sol-gel process/cured & 200 \\
\hline & $\mathbf{F} 400)+\mathbf{C T B N}^{d}$ & Albidur HE600 & $4.0 / 0.0$ & & MR & 3.20 & & & 291 & 1.03 & & & compact & & \\
\hline & & & $4.5 / 9.0$ & & MR & 2.77 & & & 918 & 1.70 & & & tensions/(SENB) & & \\
\hline 42 & Silica Sol (Nanopox & Epoxy (Bisphenol & 3.0 & 20 & NR & 3.01 & 67.49 & 2.69 & 60 & 0.46 & & & Tensile/compact & Four step curing & 18 \\
\hline & E470) & -A)/(Anhydride & & & MR & 3.39 & 82.09 & 2.62 & 120 & 0.68 & & & test & schedule/cured in oven & \\
\hline & Silica $/ \mathrm{LR}^{e}$ & Hardener) & $9.0 / 9.0$ & & MR & 3.20 & 73.51 & 3.39 & 390 & 1.20 & & & & & \\
\hline 43 & Nonporous Silica & Epoxy (DGEBA + & 0.0 & - & NR & 3.53 & 88.15 & & 280 & 1.07 & & & Tensile test/(3 & Mixing/sonication. & 201 \\
\hline & (Aerosil 200, 90, and & MTHPA $\left.^{f}\right)$ & 1.0 & 12 & MR & 3.61 & & & 380 & 1.25 & & & $\left.\mathrm{~PB}^{g}\right)$ & Vacuum oven & \\
\hline & OX50) & & 1.0 & 20 & MR & 3.57 & & & 350 & 1.18 & & & & & \\
\hline & & & 1.5 & 40 & MR & 3.61 & & & 330 & 1.17 & & & & & \\
\hline 44 & Silica $\mathrm{SM}^{h}$ by & Epoxy (DER331 + & 0.0 & - & NR & 3.50 & 85 & & 300 & 1.11 & & & Tensile test/ & Dilution/vacuum oven/ & 202,218 \\
\hline & Organo-silicane & Piperidine) & 2.5 & 23 & MR & 3.50 & 83 & & 700 & 1.70 & & & (SENB)/SEM & thermally cured. & \\
\hline & & (DGEBA) & & 74 & MR & 3.67 & 81 & & 710 & 1.75 & & & & & \\
\hline & & & & 170 & MR & 3.50 & 83 & & 680 & 1.68 & & & & & \\
\hline 45 & Silica (Nanopox & Epoxy (DGEBA + & 0.0 & & NR & 2.75 & 57.1 & & 180 & 0.73 & & & (SENB)/compact & Mechanically mixed/ & 203 \\
\hline & F400) & $\left.\mathrm{J} 230^{i}\right)$ & 10.0 & & MR & 3.64 & 58.3 & & 370 & 1.23 & & & test/TEM & release agent-coated & \\
\hline & & & 20.0 & & MR & 3.85 & 59.5 & & 660 & 1.68 & & & & rubber moulds & \\
\hline 46 & Silica (Nanopox & Epoxy (DGEBA + & 0.0 & & NR & 3.2 & 88.2 & & 70 & 0.51 & & & (SENB)/compact & Mechanically mixed/ & 203 \\
\hline & F400) & $\left.\operatorname{DDS}^{j}\right)$ & 10.0 & & MR & 3.79 & 104.3 & & 110 & 0.69 & & & test/TEM & release agent-coated & \\
\hline & & & 20.0 & & MR & 4.48 & 107.4 & & 130 & 0.82 & & & & rubber moulds & \\
\hline
\end{tabular}

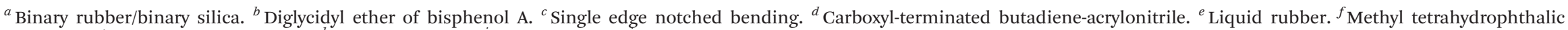
anhydride. ${ }^{g}$ Three-point bending test. ${ }^{h}$ Surface modified. ${ }^{i}$ Jeffamine D230. ${ }^{j}$ 4,40-Diaminodiphenyl sulfone. 
studied by numerous researchers and have achieved homogeneity in most cases.

\subsection{Comparative analysis of the mechanical properties of nanocomposites using nanosilica}

Chen et al. ${ }^{196}$ studied the incorporation of silica nanoparticles in epoxy resin with the introduction of graphene oxide (GO) into the interface of the nanocomposite. The interface interaction is a fundamental phase in achieving high performance nanocomposite materials. The Young's modulus, tensile strength and percentage elongation at break for the neat epoxy was $1.36 \mathrm{GPa}, 51 \mathrm{MPa}$ and $6.14 \%$, respectively. The addition of $0.1 \mathrm{wt} \%$ of silica with GO functionalization at the interface achieved an increase of $6.6 \%$ in stiffness, $15.8 \%$ in the tensile strength and $6 \%$ in the strain to rupture in comparison with the neat epoxy. A further increase in the loading to $5.0 \mathrm{wt} \%$ enhanced the improvements in mechanical and fracture properties (Fig. 14). In comparison with the pristine epoxy, the stiffness increased by $19 \%$, higher than that at $1.0 \mathrm{wt} \%$. A similar trend was observed for the tensile strength and the strain at break. The graphene oxide coated on the surface of the silica nanoparticle was the primary source of such an enhancement in the modulus and strength.

Liang and Pearson ${ }^{197}$ examined two types of nanosilica particles with varying particle sizes in an effort to improve the properties of the resin. The Young's moduli moderately increase with the addition of the nanoparticle. At $0.1 \mathrm{wt} \%$ loading, an increase in stiffness of $4.5 \%$ was observed.

The effect of having multiphase silica and other materials in the nanocomposite to improve its mechanical properties was studied by Liu et al. ${ }^{19}$ Binary silica added to epoxy was first assessed, and at a later stage, binary rubber was added to the previous mixture to appreciate any differences in the mechanical properties. The addition of $2.0 \mathrm{wt} \%$ of silica to the epoxy matrix resulted in a moderate increase in stiffness by $2 \%$ whilst the tensile strength had a similar effect, a $7.1 \%$ increment. Binary rubber added to epoxy at comparable weight content resulted in a decrease in stiffness, an 8\% drop. However, there was a slight increase in the tensile strength by $8.3 \%$. The combination of both binary silica and binary rubber together with the epoxy resin was finally scrutinized. At $6.0 \mathrm{wt} \%$ of rubber and $2.0 \mathrm{wt} \%$ of silica, the stiffness, as expected, experienced a decrease by $11.8 \%$. Interestingly, the tensile strength followed the same trend by $5 \%$.

The mechanical properties of nanosilica filled epoxy were studied by Blackman et al. ${ }^{198}$ The Young's modulus of nanosilica based epoxy was found to be increased by $8 \%$ in comparison with the neat epoxy.

Brunner et al. ${ }^{184}$ investigated the influence of silicate-based nanofillers on the mechanical properties of epoxy. At $7.2 \mathrm{wt} \%$ loading, the stiffness increased by $51 \%$ whilst the tensile strength and the strain at rupture decreased drastically by $35.8 \%$ and $83 \%$, respectively, when compared to the neat epoxy.

Modified nanosilica particles to enhance the mechanical properties of epoxy were investigated by Johnsen et al. ${ }^{199}$ Using the sol-gel technique, the nanosilica particles were introduced into the epoxy resin, resulting in a highly homogeneous structure. In the case of the unmodified epoxy resin, a value of 2.96 GPa for the Young's modulus was noted. By adding $4.0 \mathrm{wt} \%$ modified nanosilica, the stiffness increased by $8.1 \%$. Further increase in the concentration of nanosilica revealed a higher stiffness increment by $15.5 \%$ at $7.8 \mathrm{wt} \%$ content. A maximum value of $3.85 \mathrm{GPa}$ was recorded for the one with $13.4 \mathrm{wt} \%$ of nanosilica. They also validated the findings theoretically using the Halpin-Tsai method. Good agreement between the theory and the experimental results was observed.

In continuation of this work, Kinloch et al. ${ }^{200}$ analysed the effect of combining nanosilica with rubber on the mechanical properties of the thermosetting epoxy polymers. For the neat epoxy, the Young's modulus had a value of $2.96 \mathrm{GPa}$. Adding $4.0 \mathrm{wt} \%$ of the carboxyl-terminated butadiene-acrylonitrile

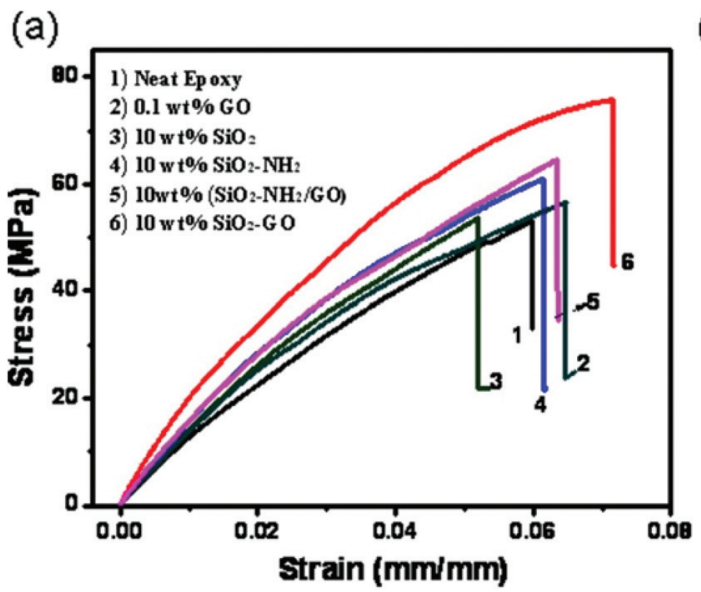

(b)

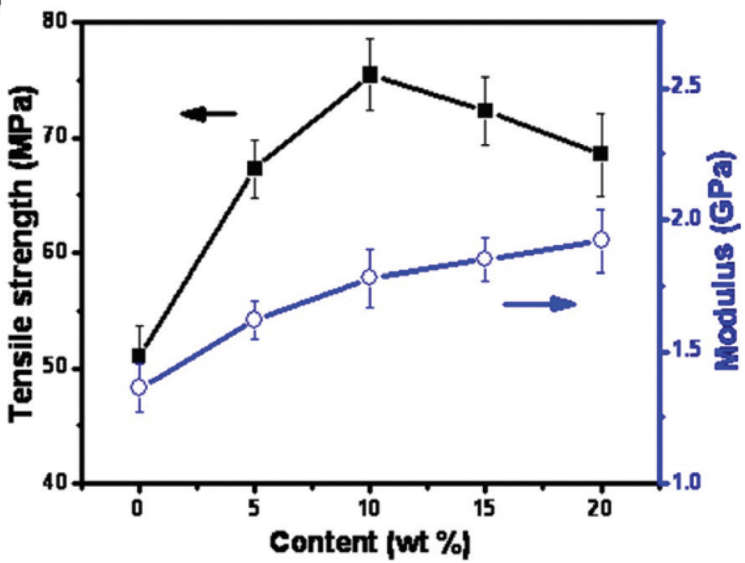

Fig. 14 (a) Stress-strain curves for neat epoxy and epoxy composites; (b) effect of $\mathrm{SiO}_{2}-\mathrm{GO}$ content on the tensile strength and modulus of epoxy resins. ${ }^{196}$ Reprinted with permission from ref. 196 (Copyright @ 2012 ACS Publication). 

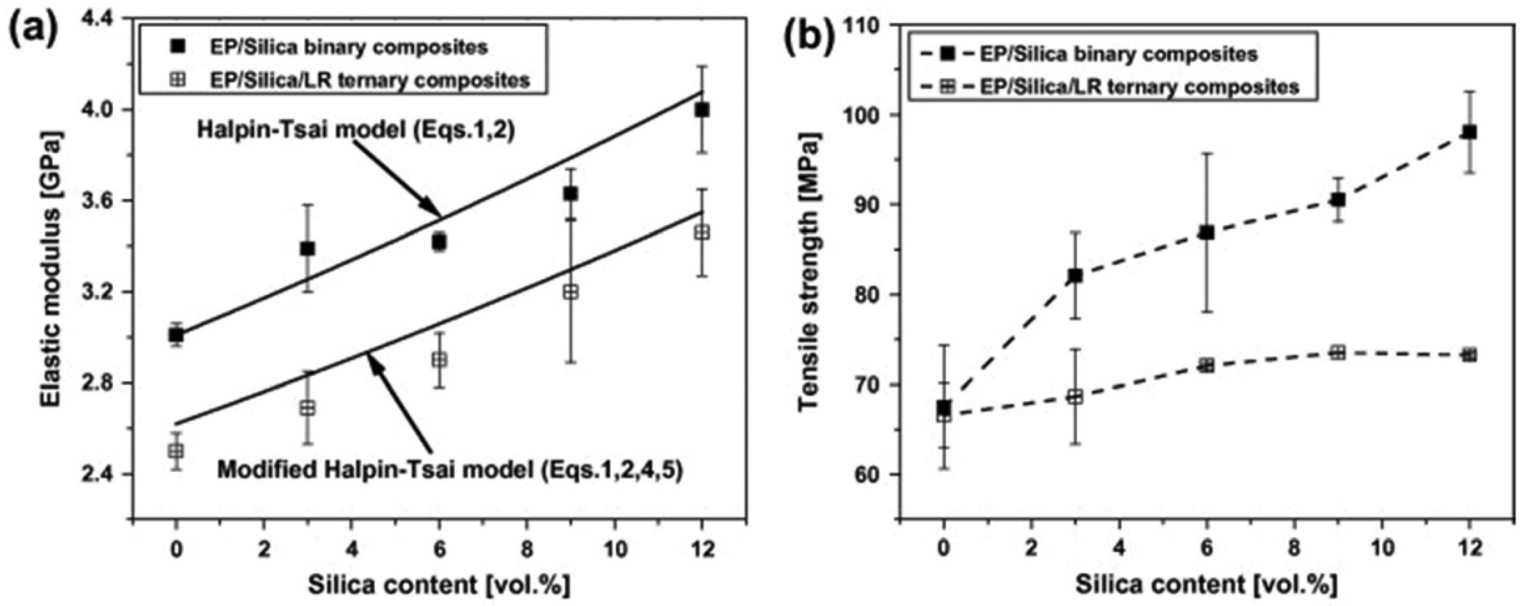

Fig. 15 Tensile properties of the nanocomposite: (a) Young's modulus, (b) tensile strength. ${ }^{18}$ Reprinted with permission from ref. 18 (Copyright $\odot$ 2012 Elsevier).

(CTBN) rubber to the epoxy increased the stiffness by $8.1 \%$. When $4.5 \mathrm{wt} \%$ of silica was mixed with $9.0 \mathrm{wt} \%$ of CTBN modified epoxy, the modulus surprisingly decreased by $6.4 \%$.

Tang et al. ${ }^{18}$ also carried out a similar study on the effect of incorporating submicron rubber into nanosilica modified epoxy and its influence on the mechanical properties of the resulting nanocomposite. At $3.0 \mathrm{wt} \%$ loading of silica, the Young's modulus increased from $3.01 \mathrm{GPa}$ to $3.39 \mathrm{GPa}$, an increment of $12.6 \%$, whilst the tensile strength produced an increase of $21.6 \%$. The involvement of multi-phase particles indeed had an exceptional consequence on the stiffness and percentage elongation at break, demonstrating competence of engineering the mechanical properties of the nanocomposite. With $12.0 \mathrm{wt} \%$ of silica and $9.0 \mathrm{wt} \%$ of liquid rubber, an increase of $14.9 \%$ in stiffness and $5.9 \%$ in elongation at break in comparison with the neat epoxy was recorded (Fig. 15). They attributed the decrease in tensile strength due to the addition of rubber as the secondary filler.

Zamanian et $a .^{201}$ evaluated the mechanical properties of nonporous nanosilica based epoxy by varying the particle size of the latter. The effect of different sized nanoparticles of $12 \mathrm{~nm}, 20 \mathrm{~nm}$ and $40 \mathrm{~nm}$ diameters were investigated. The neat epoxy had a value of $3.53 \mathrm{GPa}$ for the Young's modulus. A moderate increase of $2.2 \%$ in the stiffness was observed for the one with $12 \mathrm{~nm}$ diameter silica. The diameter of the nano phase decreased with increasing particle size. Such an effect was due to the agglomeration occurring within the nanosilica particles, which reduces the surface to volume ratio.

The influence of the size of nanosilica was also investigated by Dittanet et al. ${ }^{202}$ Nanosilica of $23 \mathrm{~nm}, 74 \mathrm{~nm}$, and $170 \mathrm{~nm}$ in diameter were used at $2.5 \mathrm{wt} \%$ loading to study the effect of the size on the mechanical properties of the nanocomposites. The tensile properties of the nanocomposite were determined using a dog-bone shaped tensile specimen. The neat epoxy provided a value of $3.5 \mathrm{GPa}$ for the Young's modulus and $85 \mathrm{MPa}$ for the tensile strength. The one with $74 \mathrm{~nm}$ silica increased the stiffness by $4 \%$ but the Young's modulus dropped back to its original value for the one using $170 \mathrm{~nm}$ silica. A decrease in the tensile strength with increasing the size of the nanofiller was also observed.

Ma et $a .^{203}$ studied the effect of inorganic clay nanoparticles on the mechanical properties for two different epoxy systems. Nanosilica particles have been added to two epoxies, namely J230 and DDS individually, and their properties were evaluated. In the case of J230, increasing the content of the silica resulted in an increase in the stiffness as well as the tensile strength. At $20 \mathrm{wt} \%$, the stiffness increased by $40 \%$ and the tensile strength increased by $4.2 \%$. Similar trends were observed for the DDS but with higher levels of increase in both properties. At the same concentration of silica (20 wt\%), the stiffness increased by $40 \%$, exactly the same amount as that for the other epoxy system but the UTS was higher, an increment of $21.7 \%$, significantly higher than the J230.

In a similar study, Huang et al. ${ }^{204}$ focused on the cryogenic properties of the epoxy matrix system incorporated with silica nanoparticles. Cryogenic tensile properties at $77 \mathrm{~K}$ and the thermal expansion coefficient of the nanocomposite were studied. Mechanical stirring and degassing were the approach used for the preparation of the epoxy resin/silica nanocomposite. Scanning electron microscopy (SEM) was used to analyse the fracture surfaces. The results obtained from the tensile tests under cryogenic conditions showed an increase in the tensile strength with increasing silica contents. At $2 \mathrm{wt} \%$ content, the tensile strength increases by $16.4 \%$ in comparison with the pristine epoxy. A further increase was noticed at $4 \mathrm{wt} \%$ content, a maximum value of $102 \mathrm{MPa}$. In the case of the cryogenic modulus, a linear increase was observed for both $2 \mathrm{wt} \%$ and $4 \mathrm{wt} \%$ contents, a value of $5.3 \mathrm{GPa}$ and $5.9 \mathrm{GPa}$, respectively. 
5.2 Comparative analysis of the fracture toughness of nanocomposites using nanosilica

Interestingly the integration of nanosilica to epoxy and introducing graphene oxide into the interface of the particles/resin provides a major enhancement in the fracture properties. Chen et al. ${ }^{196}$ studied this phenomenon for optimizing the mode I fracture toughness. With the addition of $0.1 \mathrm{wt} \%$ of silica and graphene oxide, an increase of $34 \%$ in the value of $G_{\text {IC }}$ was noted in comparison with the neat epoxy. More increase in $G_{\text {IC }}$ mode I fracture toughness was noted at $5.0 \mathrm{wt} \%$ loading, $98 \%$ increment as compared to the pristine epoxy. As stated in the previous section, such a level of improvement is attributed to the GO coated on the surface of the nanosilica.

The toughening mechanisms of nanosilica epoxy were investigated by Liang and Pearson ${ }^{197}$ to improve the fracture properties of the nanocomposite. A study based on different particle sizes of nanosilica was initially adapted in an effort to increase the fracture toughness performance. An increase of $12 \%$ in $G_{\text {IC }}$ in comparison with the neat epoxy was noted.

Liu et al. ${ }^{19}$ also investigated the effects of combining nanosilica with rubber nanoparticles in the epoxy system. Using compact tension tests, mode I fracture toughness $\left(G_{\mathrm{IC}}\right)$ for $2.0 \mathrm{wt} \%$ loading of nanosilica with the epoxy has shown an increase of $11 \%$. A further $21 \%$ increase in $G_{\text {IC }}$ was noticed when binary rubber was mixed with the epoxy. In comparison with the pristine epoxy, $G_{\mathrm{IC}}$ had a value of $1720 \mathrm{~J} \mathrm{~m}^{-2}, 5.1$ times higher (Fig. 16). From the SEM micrographs, debonding and pull-out of nanosilica particles and matrix plastic deformation were apparently noticeable. The energy dissipation from these factors contributed to the toughening mechanism of the nanocomposite. Further microscopic studies on the fracture surface of the binary rubber revealed nanocavitation and shear deformation as the key reason for the significant improvement in the fracture toughness.

Blackman et al. ${ }^{198}$ investigated the fracture and fatigue performance of nanosilica modified epoxy polymers. Interesting observations were made by the authors when the loading of nanosilica was increased progressively. An increment of 51.7\% in mode I fracture toughness was observed in comparison with the neat epoxy. Microscopic studies were performed to analyse the nature of such enhancement. Debonding of nanosilica and plastic void growth were the factors that essentially contributed to the toughening mechanisms of the nanocomposite.

The fracture toughness of the epoxy with a silicate-based nanofiller was studied by Brunner et al. ${ }^{184}$ The neat epoxy recorded a value of $130 \mathrm{~J} \mathrm{~m}^{-2}$ for mode I fracture toughness. The addition of $7.2 \mathrm{wt} \%$ of nanosilica contributed to an increase in the fracture toughness from $130 \mathrm{~J} \mathrm{~m}^{-2}$ to $160 \mathrm{~J}$ $\mathrm{m}^{-2}$, an increase of $23 \%$. The distinct structural features which appeared on the fracture surface, examined by the SEM images, were associated with the improvement in fracture toughness.

Johnsen et al. ${ }^{199}$ examined the toughening mechanisms of epoxy/nanosilica composites. As specified before, a high dispersion process resulted in high fracture toughness for the
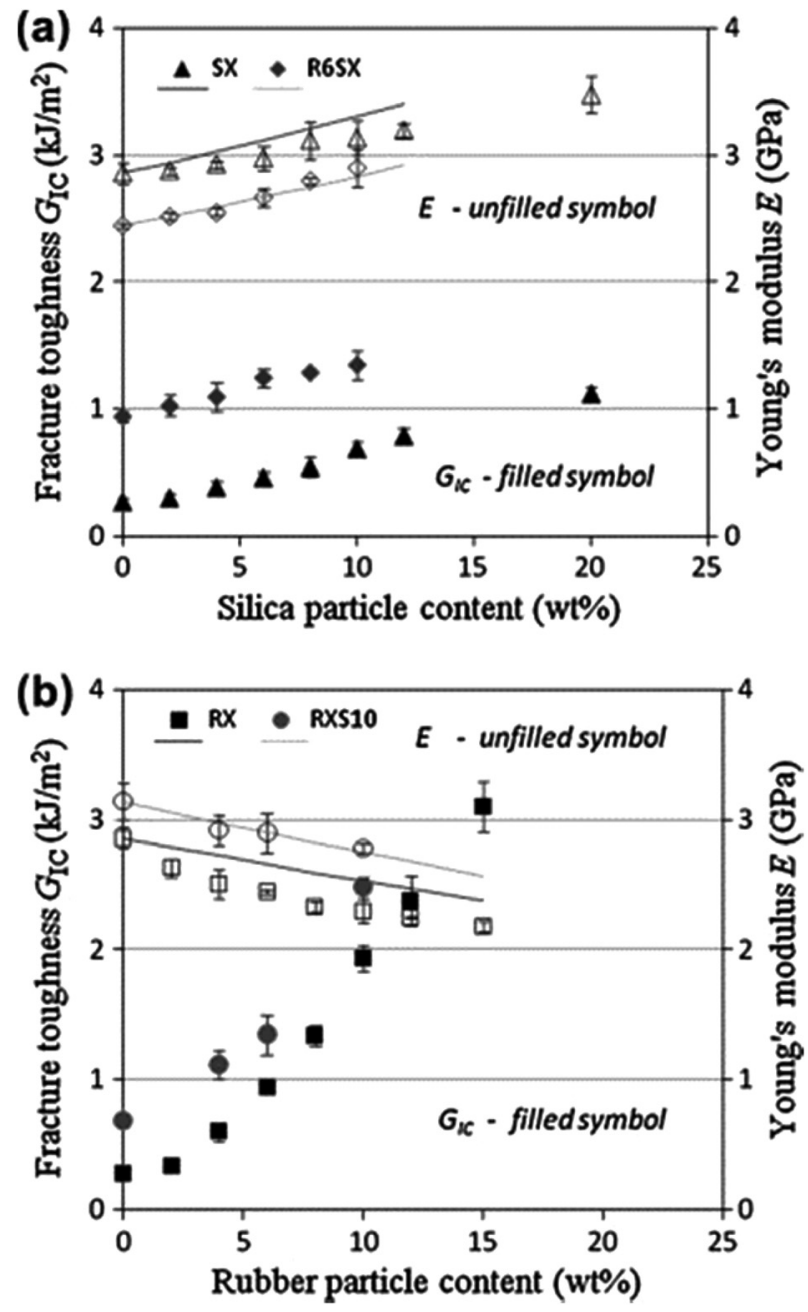

Fig. 16 Fracture toughness of the nanocomposite when (a) nanosilica was added and (b) rubber particle was added. ${ }^{19}$ Reprinted with permission from ref. 19 (Copyright @ 2011 Elsevier).

nanocomposite. Single-edge notch bend (SENB) specimens were used to evaluate the fracture toughness of the nanocomposite. Initially, the neat epoxy gave a value of $103 \mathrm{~J} \mathrm{~m}^{-2}$ for mode I fracture toughness. Fracture energy increased from $103 \mathrm{~J} \mathrm{~m}^{-2}$ to $291 \mathrm{~J} \mathrm{~m}^{-2}$ at $4.0 \mathrm{wt} \%$ loading, a $182 \%$ increment. Further increase in nanofiller loading by $7.8 \mathrm{wt} \%$ increased the fracture toughness performance. SEM studies revealed the presence of debonding and plastic void growth as contributing factors for the enhancement of fracture toughness.

Kinloch et al. ${ }^{200}$ demonstrated that the fracture toughness can be increased considerably in a multiphase epoxy resin containing nanosilica and the carboxyl-terminated butadiene-acrylonitrile (CTBN) rubber. The findings showed that the addition of nanosilica to the epoxy resin resulted in an increase in the mode I fracture toughness. At $4.0 \mathrm{wt} \%$ of CTBN, mode I fracture toughness increased by $182 \%$. However, a more substantial increase was observed with varying the wt $\%$ loading of nanosilica, alongside the presence of micro-rubber particles. Adding $4.0 \mathrm{wt} \%$ of CTBN and $9.0 \mathrm{wt} \%$ of nanosilica together 
resulted in an increase of $791 \%$ in mode I fracture toughness. Having a multiphase hybrid epoxy polymer could potentially further increase the toughness if a good appreciation of the mechanisms such as crack deflection and crack twisting could be achieved.

Fracture mechanisms of rigid-soft particles filled with epoxy were investigated by Tang et al. ${ }^{18}$ The fracture behaviour of epoxy resin by the inclusion of liquid rubber and nanosilica acting as multi-phase particles was evaluated. The addition of nanosilica alone caused an increase in mode I fracture toughness by $50 \%$. Addition of $12 \mathrm{wt} \%$ of nanosilica and $9.0 \mathrm{wt} \%$ of liquid rubber produced an increase in the value of $G_{\text {IC }}$ by $670 \%$ in comparison with the pristine epoxy. The rubber particles developed into smaller sizes due to the presence of nanosilica. The enlarged plastic deformation which occurred around the crack tip was the key reason associated with the toughening mechanisms of the nanocomposite.

As mentioned in the previous section, Zamanian et al. $^{201}$ studied the fracture toughness of nanosilica based epoxy by changing the particle size. The three point bending test was carried out to determine the fracture properties of the nanocomposite. In the case of the pristine epoxy, mode I fracture toughness was determined to be $280 \mathrm{~J} \mathrm{~m}^{-2}$ and a maximum value of $G_{\text {IC }}$ was measured with the particles size of $12 \mathrm{~nm}$ diameter at $1.0 \mathrm{wt} \%$ loading. Further increase in the size of the particles to $20 \mathrm{~nm}$ diameter revealed a drop in the fracture toughness. For higher volume concentration of nanosilica, the trend reversed due to agglomeration of the nanofiller. This is because the surface area of particles will increase when the diameter is reduced, resulting in higher fracture performance.

Dittanet et $a .^{202}$ carried out a similar experiment based on varying the particle size of the nanosilica. Mode I fracture toughness $\left(G_{\mathrm{IC}}\right)$ increased from $700 \mathrm{~J} \mathrm{~m}^{-2}$ to $710 \mathrm{~J} \mathrm{~m}^{-2}$ with increasing the size from $23 \mathrm{~nm}$ to $74 \mathrm{~nm}$, respectively. Further studies carried out by Manwar et al. ${ }^{205}$ support this claim. Increasing the particles size increases mode I fracture toughness at low particle size but reversed when the particle size is increased, the same observations as those reported by Zamanian et al. ${ }^{201}$

\subsection{Highlights summary of nanocomposites using nanosilica}

The involvement of rubber in silica based epoxy has seen major improvements in mode I fracture toughness but resulted in poor stiffness performance due to the low Young's modulus of rubber particles as highlighted by Liu et al. ${ }^{19}$ This technique could be highly effective if a compromise for the stiffness could be acceptable. Varying the particle sizes of the silica could be another prospective way of achieving high performances as reported by Johnsen et al. ${ }^{199}$ Moreover, values obtained in the case when silica was mixed with graphene oxide $^{196}$ demonstrated a large offset from the other reported values as tabulated in Table 4. Controversially, the neat epoxy epon 828 reported to have a value of $2408 \mathrm{~J} \mathrm{~m}^{-2}$ in ref. 196 contradict the study conducted by Sun et al., ${ }^{80}$ who used the same epoxy system epon 828 and reported a value of $113 \mathrm{~J} \mathrm{~m}^{-2}$. More studies of the same nature should be carried out in this area in order to eliminate any discrepancies which might have occurred.

\section{Conclusion}

In engineering structures, the strength and toughness of materials are two critical properties that determine the suitability and lifetime of the materials. A wide range of particle reinforcements have been employed to enhance these two properties in polymers, but usually the strength and toughness changes occur in the opposite direction. Nanoparticles have a substantial interface in the polymer matrix, strongly influencing the mechanical response of the polymer. Hence nanomaterials have potential to increase both the strength and the toughness.

The enhancement in strength, stiffness and the fracture toughness by introducing CNTs, graphene, nanoclay and nanosilica incorporated into the epoxy matrix together with other materials such as the inclusion of different rubber particles, tailored according to the engineering needs, is a massive bonus for several nanocomposite applications. Past studies have shown that excellent mechanical properties and toughening mechanisms can be achieved by incorporation of the proper type, size and amount of nanoparticles into the epoxy resin. A lot of critical aspects such as the specific surface area, aspect ratio, filler loading, particle sizes ${ }^{206}$ type of epoxy resin, alignment, functionalization and different techniques of the dispersion process have an effect on the performance of the resulting nanocomposite. Dispersion of the nanomaterials has been one of the major contributing factors as well as interfacial adhesion between the nanofillers and the epoxy matrix. Attaining a homogeneous dispersion was one of the main factors in achieving outstanding results. In the case where either chemical or physical functionalization was carried out, the values for the stiffness, tensile strength as well as the fracture toughness substantially increased and those effects were explained accordingly in the studies carried out, normally attributed to the presence of molecular interactions during processing of the nanocomposites. Different variants of the epoxy were used as the resin system.

Numerous toughening mechanisms in epoxy based nanocomposites have been reviewed and summarized in this paper. Debonding, ${ }^{207}$ which is currently present in hard particles such as clay and silica, as well as cavitation ${ }^{208}$ in soft particles such as rubber are the main driving forces that trigger other important energy dissipation mechanisms; matrix shear deformation, crack deflection, crack twisting and crack bridging are amongst those which contributed to this phenomenon as discussed in the previous sections.

A comparative illustration of the effect of loading content of selected nanoparticles, i.e. carbon nanotubes, graphene, nanoclay and nanosilica, on fracture toughness, stiffness and tensile strength is shown in Fig. 17-19. CNTs showed a good effect on fracture toughness at low loading (0.1-2.0 wt\%). Most of the studies on graphene demonstrated a very good effect on 


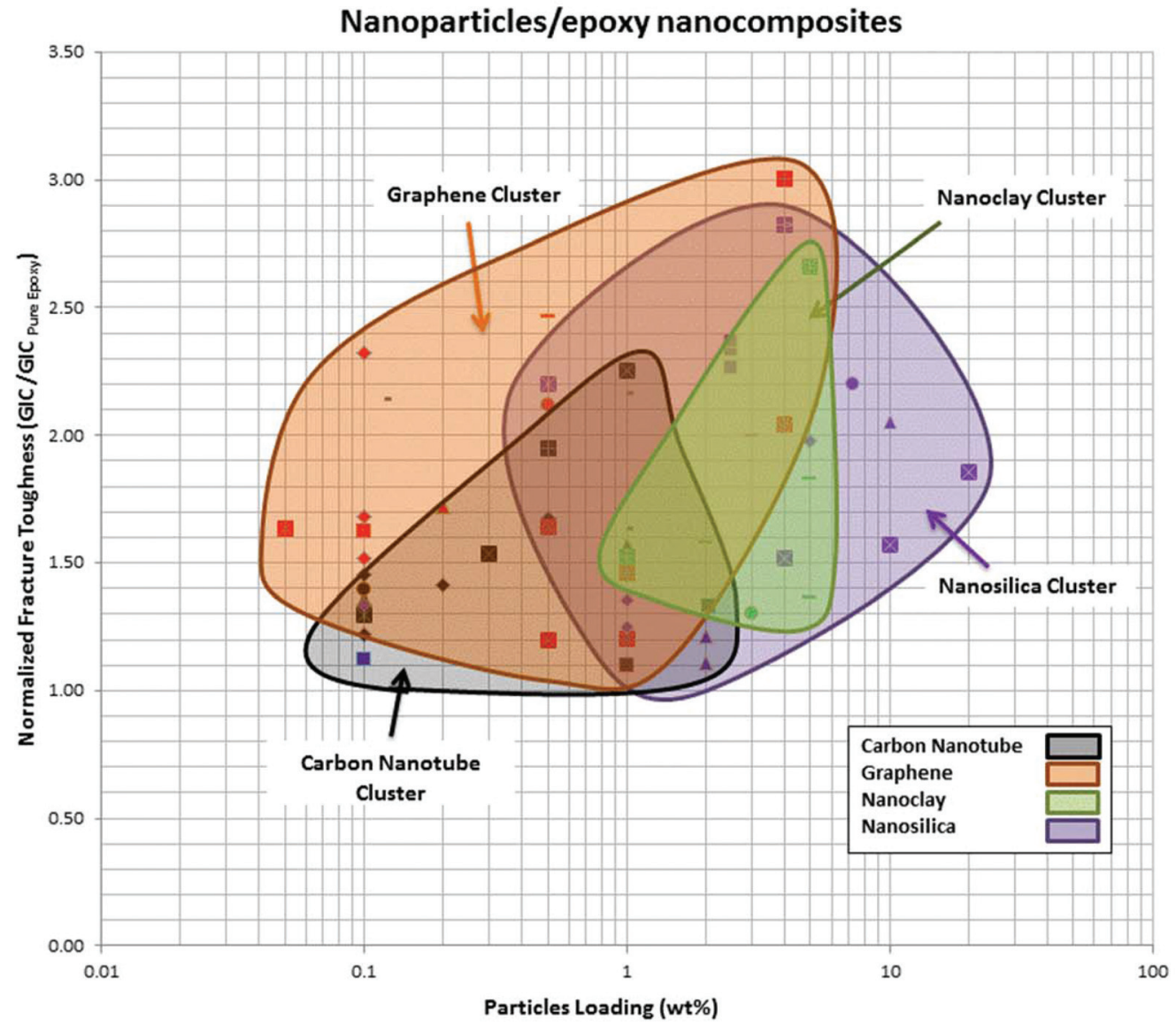

- Gojny et al. (2005)

- Sun et al. (2008)

$\Delta$ Gojny et al. (2004)

Gojny et al. (2005)

Ayatollahi et al.(2011)

- Gojny et al. (2005)

\#Gkikas et al.(2012)

- Karapappas et al. (2009)

- Tang et al. (2011)

- Hsieh et al. (2011)

- Hsieh et al. (2011)

A Tang et al. (2013)

Derez et al. (2008)

- Tang et al. (2013)

- Bortz et al. (2013)

- Zaman et al. (2011)

- Galpaya et al. (2012)

- Chatterjee et al.(2012)

- Rafiee et al. (2008)

- Tongwu et al. (2013)

$\Delta$ Liet al. (2013)

Shokrieh et al. (2014)

ai et al. (2006)

- Wang et al. (2006)

in Wang et al. (2005)

- Zappalorto et al. (2013)

- Guevara-Morales et al. (2014)

- Chen et al. (2012)

E Liang et al. (2009)

A Liu et al . (2011)

Blackman et al. (2007)

Bortz et al. (2011)

- Brunner et al. (2006)

\# Johnsen et al. (2007)

Kinloch et al. (2005)

- Tang et al. (2012)

- Zamanian et al. (2013)

- Dittanet et al. (2012)

A. Ma et al. (2008)

a Ma et al. (2008)

Fig. 17 Map of fracture toughness of nanoparticles/epoxy nanocomposites with respect to particle loading.

fracture toughness properties at very low graphene loading, generally under $1 \mathrm{wt} \%$ loading. In the case of the nanoclay and nanosilica, improvements in $G_{\text {IC }}$ were observed at much higher loadings $(0.5-20 \mathrm{wt} \%)$. Interestingly, there were three outliers $^{19,20,200}$ whilst plotting the graph with a normalized fracture toughness value ranging from 5.11 to 8.9 due to involvement in a second phase reinforcement using rubber nanoparticles with CNTs and nanosilica. The fracture toughness performances in those cases were extremely higher at the expense of their Young's modulus.

As observed previously, improvements for the nanocomposites were achieved at very low CNTs content loading. In order to achieve optimal mechanical properties, the theory of stress transfer between CNTs and the matrix resin is fundamentally important. The importance of the duration and amplitude of sonication was also regarded as a central factor to the enhancement of the CNT nanocomposite. Reducing the sonication power for instance resulted in an exceptional increase in fracture toughness by $550 \%$ as reported by Gkikas et al. ${ }^{17}$ The importance of functionalization by amino groups has also shown a major improvement in the mechanical properties as confirmed by Gojny et al. ${ }^{76}$ This improvement was also sup- ported by Tang et al. ${ }^{112}$ and Zaman et al. ${ }^{153}$ with similar findings from their studies based on ozone functionalization of MWCNT. The highest Young's modulus was noted in the case of DWCNT when surface functionalization was carried out. The outcome of multiphase is another great potential route that could be explored as reported by Tang et al. ${ }^{20}$ with the presence of liquid rubber. A significant increase of $409 \%$ in mode I fracture toughness in comparison with pristine epoxy was noted, which is the highest increase amongst the 14 CNTs research studies reviewed.

The addition of graphene as a nanofiller significantly increased the Young's modulus and mode I fracture toughness as highlighted in all the papers that have been reviewed. The importance of opting for different types of functionalization has also been scrutinized by Li et al. ${ }^{158}$ Amino and epoxy functionalized graphene both considerably contributed to different levels of performances. This statement is in good agreement with the work carried out on modified graphene platelets by Zaman et al. ${ }^{153}$ where enhancements in the fracture toughness were noticed. Rafiee et al. ${ }^{138}$ concluded that the fracture toughness of graphene is more effective in comparison with different nanomaterials. Introduction of surface modification 

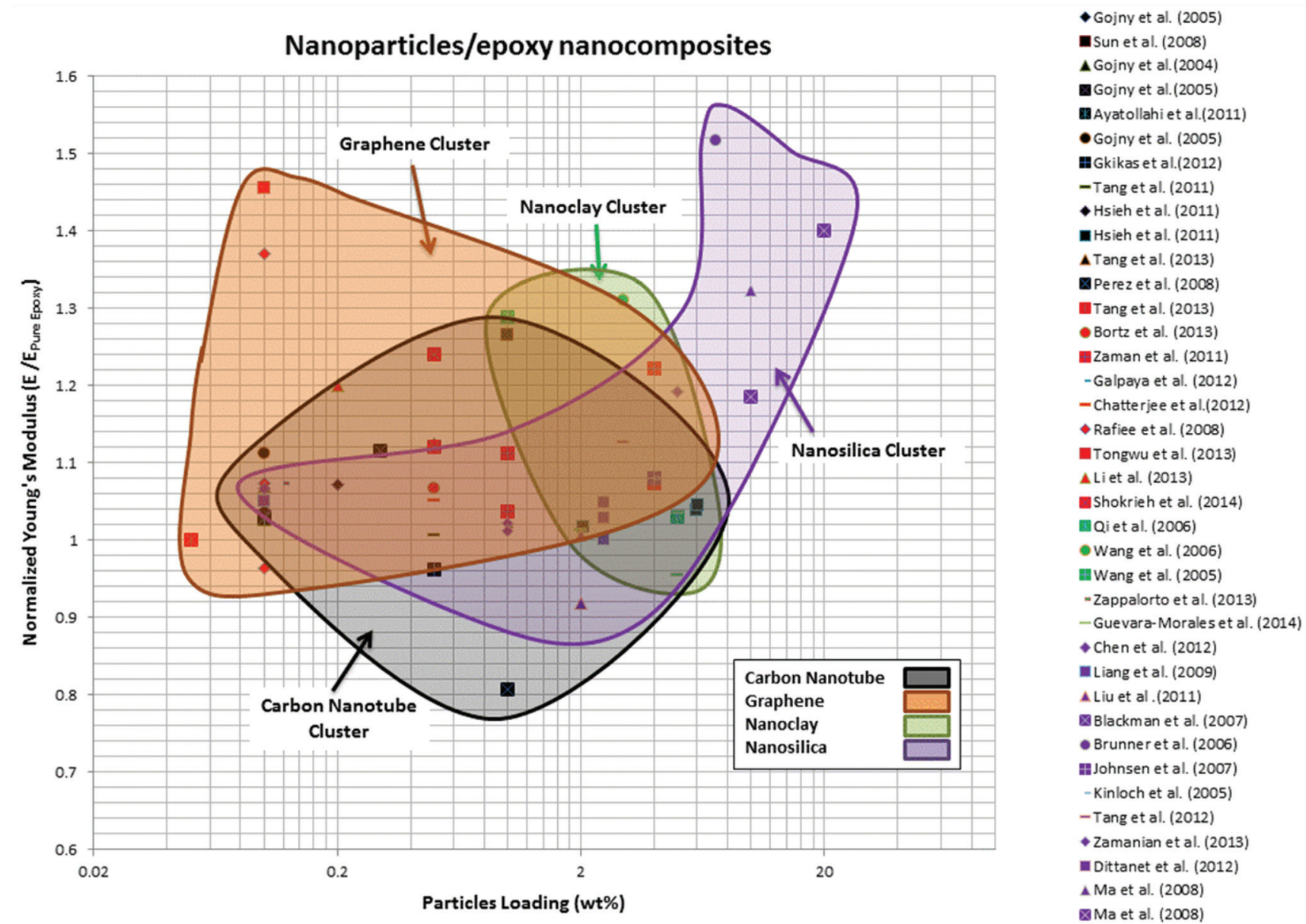

Fig. 18 Map of stiffness of nanoparticles/epoxy nanocomposites with respect to particle loading.

in a multi-phase environment has benefited the fracture toughness when graphene oxide was mixed with nanosilica as the interface. ${ }^{196}$ Such a level of improvement could be further investigated. Some research studies have reported exceptional mechanical properties with graphene at low content as compared to CNTs.

Enhancement in the mechanical and fracture properties of nanoclay occurred at a higher weight percentage content of around $5.0 \mathrm{wt} \%$ in comparison with the CNTs and graphene. Closite 30B provided the highest stiffness increment amongst all the nanoclays. Values obtained for mode I fracture toughness were lower than those recorded for CNTs and graphene. In most cases, the tensile strength was decreased whilst the stiffness was marginally increased. The same epoxy system DGEBA was used for all the nanoclay reviewed studies but the findings for mode I fracture toughness of the pristine epoxies were not in the same range. This could be associated with the difference in molecular weight, type and amount of hardeners and curing agents and the curing process conditions used. The preparation of epoxy is thus vitally important in enhancing the nanocomposite.

The effect of having multiphase in nanocomposites is highly beneficial in order to attain good mechanical and frac- ture properties of nanocomposite. The involvement of rubber in silica based epoxy has shown a major improvement in mode I fracture toughness, a value of $1720 \mathrm{~J} \mathrm{~m}^{-2}, 5.1$ times higher in comparison with the pristine epoxy, but resulted in poor stiffness performance due to the low modulus of rubber particles as highlighted by Liu et al. ${ }^{19}$ This technique could be highly effective if a compromise for the stiffness could be accepted. Varying the particle sizes of silica could be another prospective way of achieving high performances. A study conducted by Johnsen et al. ${ }^{199}$ reported an increase in both the mechanical and fracture toughness by increasing the size of particles, but after reaching its peak there was a sudden drop in the performance.

Opting for an ideal nanofiller to enhance the nanocomposite is crucial to achieve good mechanical and fracture properties. Amongst all the CNTs, MWCNT is still the most interesting candidate with very promising results despite a few drawbacks, if appropriate dispersion techniques and functionalization are carefully chosen. Multiphase nanocomposite could also be potentially explored due to satisfactory results in some cases. Inclusion of rubber particles could also be another ideal route for improving mode I fracture toughness if a compromise could be found for its ductility. On the other hand, graphene 

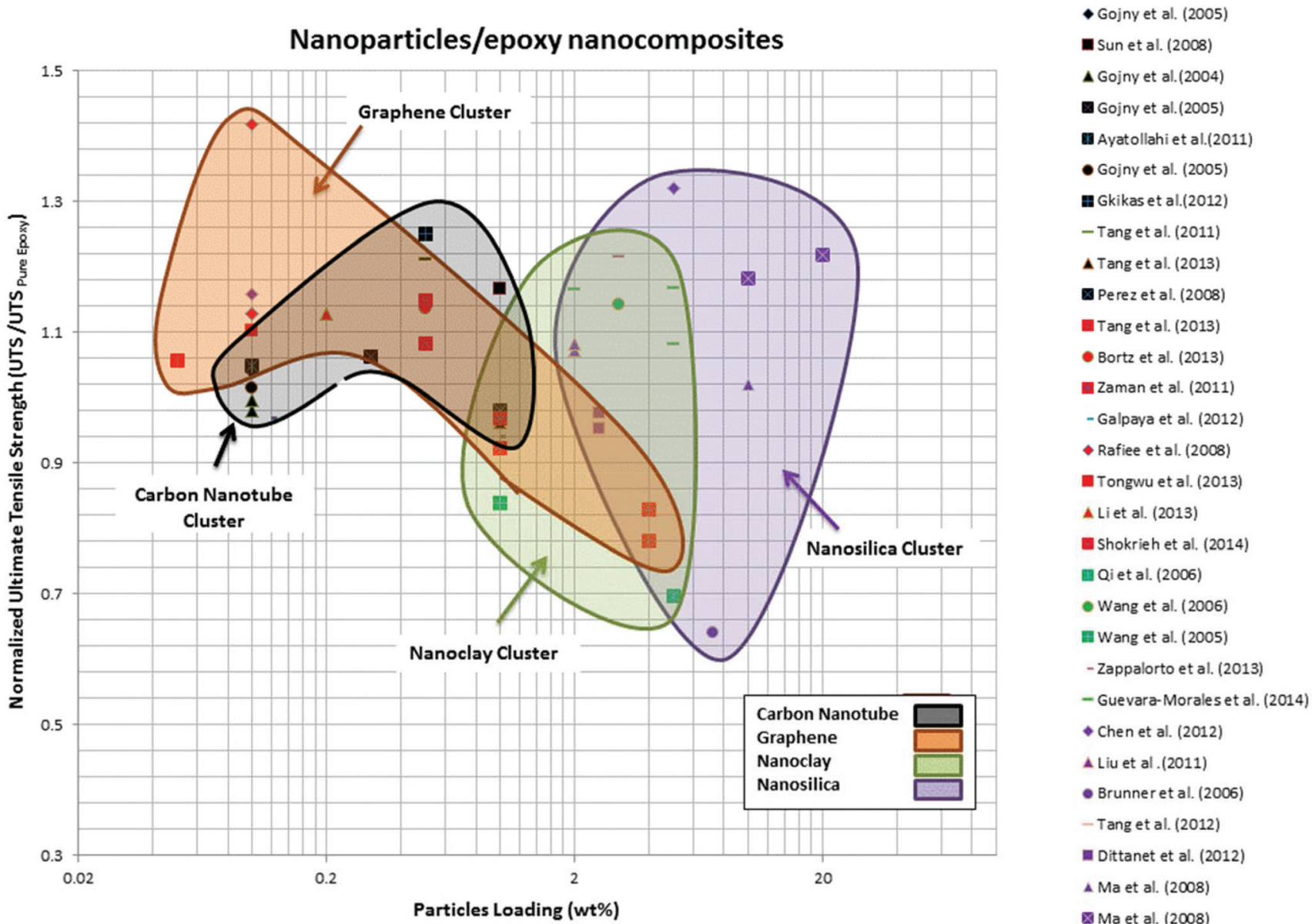

Fig. 19 Map of ultimate tensile strength of nanoparticles/epoxy nanocomposites with respect to particle loading.

has attracted more interest nowadays, being at the forefront of nanotechnology. Graphene can be synthesized by simple chemical methods at low cost on a large-scale production, whereas CNTs contain a large amount of impurities and are often more expensive. Homogeneous dispersion is well achieved with graphene in comparison with CNTs due to the planar structure, which eases the stress transfer during dispersion. Moreover, both CNTs and graphene require a low content ratio to enhance the nanocomposite whereas much higher loadings are required for clay and silica.

\section{Future research challenges for the enhancement of mechanical properties of epoxy}

Epoxy resin is inherently brittle, and this problem can be mitigated by the incorporation of nanoadditives. Despite many achievements in the development of novel nanoadditives for epoxy, challenges still exist in materials selection and process design to fulfill the potential of nanocomposites and improve the performance of FRP composites for advanced industrial applications.

The research reported in this paper demonstrated that dispersing CNTs, graphene, nanoclay and nanosilica into the epoxy has the potential to significantly improve the mechanical characteristics of epoxy resin. However, there still exist underlying concerns that need to be fully explored in order to face the future challenges in this evolving field. The reported experimental studies were carried out using different dispersion techniques and functionalization methods which restricted the thorough understanding of the reinforcement mechanism of CNTs, graphene, nanoclay and nanosilica in epoxy nanocomposites. Understanding the stress transfer between the matrix system and the respective nanomaterial is imperative to maximise and enhance the mechanical and fracture properties of the nanoparticles/epoxy nanocomposite. Despite the fact that a large number of publications have emphasized analysing the mechanical and fracture characteristics of the nanocomposite, less effort has been placed on the crucial understanding of stress transfer mechanisms and interfacial bond strength between nanoparticles and the epoxy system. 
Moreover it is essentially important to develop tools and techniques for the quantitative analysis of the extent of dispersion or agglomeration during the preparation stage for particles of different sizes and aspect ratios. There is concern on how the structural distinctive shape of CNTs for example can be unaffected to retain their anticipated properties after dispersion and functionalization.

For CNT nanoparticles, new approaches are required to tackle higher viscosities on increasing CNT loading. Furthermore, functionalization of CNTs either by chemical ${ }^{69}$ or physi$\mathrm{cal}^{209,210}$ treatments may help to improve the CNT dispersion and aid stress transfer between CNTs and the epoxy matrix. ${ }^{211}$ Alternatively, nitrogen-doped CNTs are reported to be sufficiently chemically reactive, intrinsically, to improve interactions with the epoxy matrix. The very high surface area of SWCNTs might lead to greater impact of the CNTs on the composite performance; the flexibility of SWCNTs also tends to encourage bundling and this makes it hard to maintain the desired orientation. The tendency of SWCNTs to form bundles reduces the ability of the innermost tubes to contribute efficiently to the reinforcement; similar effects can also occur in MWCNTs but may be mitigated by local defects. ${ }^{212}$ In addition, the aspect ratio and alignment of CNTs are also important factors that determine the composite performance and need optimisation. ${ }^{213}$

This review has shown that the incorporation of graphene into epoxy in polymer nanocomposites is crucial to broaden the function and enhance the performance of the mechanical reinforcement of graphene in epoxy resin. No doubt, graphene and its related nanomaterials have an exciting future for utilization as reinforcement nanoparticles in epoxy with regard to specific applications. The outstanding properties of graphene nanoparticles comprising of large specific surface area, high mechanical strength, and low manufacturing cost make them ideal nanoparticles for enhancing the epoxy performance. More recently research has focused on functionalized graphene.

Multi-functionalities of a single material for certain applications can be realized by functionalized graphenes as the major strategy. This new family of $2 \mathrm{D}$ carbon materials offers encouraging and prospective platforms to investigate the structure, chemistry, properties, engineering, and technological applications of functionalized graphene/epoxy. More theoretical and experimental efforts are required to investigate the stability, physical and chemical properties of these nanocomposites. Future work is likely to focus on the synthesis of graphene at the macroscopic scale and new or improved methods to realize the large-scale synthesis of graphene, thereby opening new avenues for the potential applications of graphene-based epoxy. Limited work has been carried out to investigate how the matrix is bonded to the graphene surface and effective characterization techniques are still in demand. The relationship between the interfacial bonding mode and the final nanocomposite performance needs to be elucidated. However, graphene is very easily aggregated. Effective interfacial engineering techniques (chemical modification, plasmon treatment etc.) and processing techniques are required for manufacturing high performance epoxy nanocomposites.

Also, experimental investigation of different CNTs/graphene nanoparticles, combined with modelling, will establish the required data for the optimum type, aspect ratio, and orientation of CNTs/graphene in different composites, which are likely to vary for different properties of interest. Effective interfacial engineering techniques such as chemical modification, plasmon treatment and processing techniques are still desired for manufacturing high performance epoxy nanocomposites.

\section{Acknowledgements}

The authors acknowledge the Faculty of Science, Engineering and Computing (SEC) of Kingston University London for the financial support provided to the first author, having been awarded a PhD studentship.

\section{References}

1 A. J. Kinloch, Toughening Epoxy Adhesives to Meet Today's Challenge, Mater. Res. Soc., 2003, 28(06), 445-448.

2 S. Sprenger, Epoxy Resin Composites with SurfaceModified Silicon Dioxide, Appl. Polym. Sci., 2013, 130(3), 1421-1428.

3 U. Vietri, L. Guadagno, M. Raimondo, L. Vertuccio and K. Lafdi, Nanofilled epoxy adhesive for structural aeronautic materials, Composites, Part B, 2014, 61, 73-83.

4 R. Kurahatti, A. O. Surendranathan, S. A. Kori, N. Singh, A. V. Kumar and S. Srivastava, Defence applications of polymer nanocomposites, Def. Sci., 2010, 60(5), 551-563.

5 M. B. Jakubinek, B. Ashrafi, Y. Zhang, Y. Martinez-Runi, C. T. Kingston, A. Johnston and B. Simard, Single-walled carbon nanotube-epoxy composites for structural and conductive aerospace adhesives, Composites, Part B, 2015, 69, 87-93.

6 J. L. Tsai, B. H. Huang and Y. L. Cheng, Enhancing Fracture Toughness of glass/epoxy composites for wind blades using silica nanoparticles and rubber particles, Procedia Eng., 2011, 14, 1982-1987.

7 N. R. Paluvai, S. Mohanty and S. K. Nayak, Synthesis and Modifications of Epoxy Resins and Their Composites: A Review, Polym.-Plast. Technol. Eng., 2014, 53(16), 17231758.

8 A. J. Kinloch, S. H. Lee and A. C. Taylor, Improving the fracture toughness and the cyclic-fatigue resistance of epoxy-polymer blends, Polymer, 2014, 55, 6325-6334.

$9 \mathrm{~J}$. M. Wernik and S. A. Meguid, On the mechanical characterization of carbon nanotube reinforced epoxy adhesives, Mater. Des., 2014, 59, 19-32.

10 T. D. Chang and J. O. Brittain, Studies of epoxy resin systems: Part D: Fracture toughness of an epoxy resin: 
A study of the effect of crosslinking and sub-Tg aging, Polym. Eng. Sci., 1982, 22(18), 1228-1236.

11 R. A. Pearson and A. F. Yee, Toughening mechanisms in elastomer-modified: Part 3 The effect of cross-link density, Mater. Sci., 1989, 24, 2571-2580.

12 A. C. Garg, Failure Mechanisms in toughened epoxy resins - A review, Compos. Sci. Technol., 1988, 31(3), 179223.

13 A. Martone, C. Formicola, M. Giordano and M. Zarrelli, Reinforcement efficiency of multi-walled carbon nanotube/epoxy nano composites, Compos. Sci. Technol., 2010, 70(7), 1154-1160.

14 Y. Zhao, Z.-K. Chen, Y. Liu, H.- M. Xiao, Q.-P. Feng and S.-Y. Fu, Simultaneously enhanced cryogenic tensile strength and fracture toughness of epoxy resins by carboxylic nitrile-butadiene nano-rubber, Composites, Part A, 2013, 66, 178-187.

15 Y. Zhou, F. Pervin, V. K. Rangari and S. Jeelani, Fabrication and evaluation of carbon nano fiber filled carbon/ epoxy composite, Mater. Sci. Eng., A, 2006, 426(1-2), 221228.

16 X. Wang, J. Jin and M. Song, An investigation of the mechanism of graphene toughening epoxy, Carbon, 2013, 65, 324-333.

17 G. Gkikas, N. Barkoula and A. Paipetis, Effect of dispersion conditions on the thermo-mechanical and toughness properties of multi walled carbon nanotubesreinforced epoxy, Composites, 2012, 43, 2697-2705.

18 L.-C. Tang, H. Zhang, S. Sprenger, L. Ye and Z. Zhang, Fracture mechanisms of epoxy-based ternary composites filled with rigid-soft particles, Compos. Sci. Technol., 2012, 72(5), 558-565.

19 H.-Y. Liu, G.-T. Wang, Y.-W. Mai and Y. Zeng, On fracture toughness of nano-particle modified epoxy, Composites, Part B, 2011, 42(8), 2170-2175.

20 L.-C. Tang, Y.-J. Wan, K. Peng, Y.-B. Pei, L.-B. Wu, L.-M. Chen, L.-J. Shu, J.-X. Jiang and G.-Q. Lai, Fracture toughness and electrical conductivity of epoxy composites filled with carbon nanotubes and spherical particles, Composites, Part A, 2013, 95-101.

21 P. Richard, T. Prasse, J. Y. Cavaille, L. Chazeau, C. Gauthier and J. Duchet, Reinforcement of rubbery epoxy by carbon nanofibres, Mater. Sci. Eng., A, 2003, 352(1-2), 344-348.

22 T. Adachi, M. Osaki, W. Araki and S.-C. Kwon, Fracture toughness of nano and micro spherical silica-particlefilled epoxy composites, Acta Mater., 2008, 56(9), 21012109.

23 A. J. Kinloch, S. J. Shaw and D. A. Tod, Deformation and fracture behaviour of a rubber-toughened epoxy: 1 Microstructure and fracture studies, Polymer, 1983, 24(10), 1341-1364.

24 T. H. Hsieh, A. J. Kinloch, K. Masania and A. C. Taylor, The mechanisms and mechanics of the toughening of epoxy polymers modified with silica nanoparticles, Polymer, 2010, 51, 6284-6294.
25 C. Chen, R. S. Justice, D. W. Schaefer and J. W. Baur, Highly dispersed nanosilica-epoxy resins with enhanced mechanical properties, Polymer, 2008, 49(17), 3805-3815.

$26 \mathrm{~J}$. Lee and A. F. Yee, Inorganic particle toughening I: micro-mechanical deformations in the fracture of glass bead filled epoxies, Polymer, 2001, 42(2), 577-588.

27 M. R. Dadfar and F. Ghadami, Effect of rubber modification on fracture toughness properties of glass reinforced hot cured epoxy composites, Mater. Des., 2013, 47, 16-20.

28 R. Thomas, D. Yumei, H. Yuelong, Y. Le, P. Moldenaers, Y. Weimin, T. Czigany and S. Thomas, Miscibility, morphology, thermal and mechanical properties of a DEBA based epoxy resin toughened with a liquid rubber, Polymer, 2008, 49(1), 278-294.

29 B. Philippe and I. Hatsuo, Partially miscible blends of epoxy resin and epoxidzed rubber: Structural characterization of epoxidized rubber and mechanical properties of the blends, Appl. Polym. Sci., 1994, 53(4), 441-454.

30 B. Philippe and I. Hatsuo, Composition of the continous phase in partially miscible blends of epoxy resin and epoxidized rubber by dynamic mechanical analysis, Polymer, 1994, 35(5), 956-966.

31 L.- C. Tang, X. Wang, Y.-J. Wan, L.-B. Wu, J.-X. Jiang and G.- Q. Lai, Mechanical Properties and fracture behaviors of epoxy composites with multi-scale rubber particles, Mater. Chem. Phys., 2013, 141(1), 333-342.

32 J. Chen, A. J. Kinloch, S. Sprenger and A. C. Taylor, The mechanical properties and toughnening mechanisms of an epoxy polymer modified with polysiloxane-based coreshell particles, Polymer, 2013, 64(16), 4276-4289.

33 R. Day, P. Lovell and A. Wazzan, Toughened carbon/epoxy composites made by using core/shell particles, Compos. Sci. Technol., 2001, 61(1), 41-56.

34 O. S. Zaroog, M. A. M. Zein and A. N. A. Manap, Fracture toughness of composite materials, Sci. Res., 2012, 3(8), 1759-1766.

35 M. H. G. Wichmann, K. Schulte and D. Wagner, On nanocomposite toughness, Compos. Sci. Technol., 2008, 68(1), 329-331.

36 H. Rokni, A. S. Milani, R. J. Seethaler and M. Omidi, Quantification of Matrix and Reinforcement Effects on the Young's Modulus of Carbon Nanotube/Epoxy Composites using a Design of Experiments Approach, Int. J. Compos. Mater., 2013, 3(6A), 45-47.

37 S. C. Tjong, Structural and mechanical properties of polymer nanocomposites, Mater. Sci. Eng., R, 2006, 53(3-4), 73-197.

38 Z. Spitalsky, D. Tasis, K. Papagelis and C. Galiotis, Carbon nanotube-polymer composites: Chemistry, processing, mechanical and electrical properties, Prog. Polym. Sci., 2010, 35, 357-401.

39 B. Ashrafi, J. Guan, V. Mirjalili, Y. Zhang, L. Chun, P. Hubert, B. Simard, C. T. Kingston, O. Bourne and A. Johnston, Enhancement of mechanical performance of epoxy/carbon fiber laminate composites using single- 
walled carbon nanotubes, Compos. Sci. Technol., 2011, 71, 1569-1578.

40 A. J. Kinloch and A. C. Taylor, The mechanical properties and fracture behaviour of epoxy-inorganic micro and nano composites, Mater. Sci., 2006, 41(11), 3271-3297.

41 J. H. Hodgkin, G. P. Simon and R. J. Varley, Thermoplastic toughnening of epoxy resins: a critical review, Polym. Adv. Technol., 1998, 9(1), 3-10.

42 D. Hull and T. W. Clyne, Polymer Matrices, in An Introduction to Composite Materials, Cambridge University Press, Cambridge, 1996, 30-34.

43 R. E. Shalin, Epoxy Matrices, in Polymer Matrix Composites, Chapman \& Hall, London, 1995, 11-34.

44 T. Ueki, S. Nishijima and Y. Izumi, Designing of epoxy resins systems for cryogenic use, Cryogenics, 2005, 45(2), 141-148.

45 C. Zhen-Kun, Y. Jiao-Ping, Q.-Q. Ni, S.-Y. Fu and Y.-G. Huang, Reinforcement of epoxy resins with multiwalled carbon nanotubes for enhancing cryogenic mechanical properties, Polymer, 2009, 60(19), 4763-4759.

46 H. Zhang, L.-C. Tang, Z. Zhang, K. Friedrich and S. Sprenger, Fracture behaviours of in situ silica nanoparticle-filled epoxy at different temperatures, Polymer, 2008, 49(17), 3816-3826.

47 S. C. Lin and E. M. Pearce, Epoxy resins. II. The preparation, characterization and curing of epoxy resins and their copolymers, J. Polym. Sci., Polym. Chem. Ed., 1979, 17(10), 3095-3119.

48 N. J. Sultan and J. F. McGarry, Effect of rubber particle size on deformation mechanisms in glass epoxy, Polym. Eng. Sci., 1963, 13(1), 29-34.

49 H. R. Azimi, R. A. Pearson and R. W. Hertzberg, Fatigue of rubber-modified epoxies: effect of particle size and volume fraction, Mater. Sci., 1996, 31(14), 3777-3789.

50 A. F. Yee and A. R. Pearson, Toughening mechanisms in elastomer-modified epoxies, Mater. Sci., 1986, 21(7), 24622474.

51 Y. Liu and W. Z. H. Zhang, Mechanical properties of epoxy resins/hydroxyl-terminated polyester blends: effect of twophase structure, Polym. Int., 2005, 54, 1408-1415.

52 B. A. Cherian, A. L. Varghese and T. E. Thachil, Epoxymodified unsaturated polyester hybrid networks, Eur. Polym., 2007, 43, 1460-1469.

53 C. K. Chozhan, M. Alagar, J. R. Sharmila and G. Periyannan, Thermo mechanical behaviour of unsaturated polyester toughned epoxy-clay hybrid nanocomposites, Polym. Res., 2007, 14, 319-328.

54 C. K. Chozhan, R. Rajeskaran, M. Alagar and G. Periyannan, Thermomechanical Behavior of Vinyl Ester Oligomer-Toughened Epoxy-Clay Hybrid Nanocomposites, Polym. Mater., 2008, 57(4), 319-337.

55 J. Moosburge-Will, J. Jager, S. Horn and C. Welhausen, Investigation of phase morphology of polyethermidetoughened epoxy resin by scanning probe microscopy, Polym. Test., 2012, 31(8), 1008-1018.

56 B. Francis, S. Thomas, J. Jose, R. Ramaswamy and L. V. Rao, Hydroxyl terminated poly(ether ether ketone) with pendent methyl group toughened epoxy resin: miscibility, morphology and mechanical properties, Polymer, 2006, 46(26), 12372-12386.

57 Y.-X. He, Q. Li, T. Kuila, H. N. Kim, T. Jiang, K.-T. Lau and J. L. Lee, Micro-crack behavior of carbon fiber reinforced thermoplastic modified epoxy composites for cryogenic applications, Composites, Part B, 2013, 44(1), 533-539.

$58 \mathrm{~J}$. J. Chrusciel and E. Lesniak, Modification of epoxy resins with functional silanes, polysilixanes, silsesquioxanes, silica and silicates, Polym. Sci., 2015, 41.

59 X.-L. Xie, Y.-W. Mai and X.-P. Zhou, Dispersion and alignment of carbon nanotubes in polymer matrix: A review, Mater. Sci. Eng., R, 2005, 49(4), 89-112.

60 C. E. Pizzutto, J. Suave, J. Bertholdi, S. H. Pezzin and A. F. Coelho, Mechanical and Dilatometric Properties of Carboxylated SWCNT/Epoxy Composites: Effects of the Dispersion in the Resin and in the Hardener, Reinf. Plast. Compos., 2010, 29(4), 524-529.

61 M. Yourdkhani and P. Hubert, A systematic study on dispersion stability of carbon-nanotube modified epoxy resins, Carbon, 2015, 81, 251-259.

62 J. Coleman, U. Khan and Y. Gun'ko, Mechanical Reinforcement of Polymers Using Carbon Nanotubes, $A d v$. Mater., 2006, 18(6), 689-706.

63 V. Vahedi, P. Pasbakhsh and S.-P. Chai, Toward high performance epoxy/halloysite nanocomposites: New insights based on rheological, curing and impact properties, Mater. Des., 2015, 48, 42-53.

64 L. Vaisman, H. D. Wagner and G. Marom, The role of surfactants in dispersion of carbon nanotubes, Adv. Colloid Interface Sci., 2006, 128-130, 37-46.

65 M. Moniruzzaman and K. I. Winey, Polymer Nanocomposites Containing Carbon Nanotubes, Macromolecules, 2006, 39(16), 5194-5205.

66 O. Breuer and U. Sundararaj, Big returns from small fibers: A review of polymer/carbon nanotube composites, Polym. Compos., 2004, 25(6), 630-645.

67 S. Bal and S. S. Samal, Carbon nanotube reinforced polymer composites - A state of the art, Bull. Mater. Sci., 2007, 30(4), 379-386.

68 F. Du, J. E. Fischer and K. I. Winey, Coagulation method for preparing single-walled carbon nanotube/poly(methyl methacrylate) composites and their modulus electrical conductivity, and thermal stability, Polym. Phys., 2003, 41(24), 3333-3338.

69 M. S. P. Shaffer and A. H. Windle, Fabrication and characterization of carbon canotube/poly (vinyl alcohol) composites, Adv. Mater., 1999, 11(11), 937-941.

70 K. Mukhopadhyay, C. D. Dwivedi and G. N. Mathur, Conversion of carbon nanotubes to carbon nanofibers by sonication, Carbon, 2002, 40(8), 1373-1376.

71 S.- Y. Fu, Z.-K. Chen, S. Hong and C. C. Han, The reduction of carbon nanotube (CNT) length during the manufacture of $\mathrm{CNT} /$ polymer composites and a method to simulataneously determine the resulting CNT and interfacial strengths, Carbon, 2009, 47(14), 3192-3200. 
72 P.-C. Ma, N. A. Siddiqui, G. Marom and J.-K. Kim, Dispersion and functionalization of carbon nanotubes for polymer based nanocomposites : A review, Composites, Part A, 2010, 41(10), 1346-1367.

73 J. A. Suarez, M. Campo, M. Sanchez, C. Romon and A. Urena, Influence of the functionalization of carbon nanotubes on calendering dispersion effectiveness in a low viscosity resin for VARIM processes, Composites, Part $B, 2012$, 43(8), 3482-3490.

74 P.-C. Ma, N. A. Siddiqui, G. Marom and J.-K. Kim, Dispersion and functionalization of carbon nanotubes for polymer-based nanocomposites: A review, Composites, Part A, 2010, 41(10), 1345-1367.

75 A. Allaoui, S. Bai, H. M. Cheng and J. B. Bai, Mechanical and electrical properties of a MWNT/epoxy composite, Compos. Sci. Technol., 2002, 62(15), 1993-1998.

76 F. H. Gojny, M. H. Wichmann, B. Fiedler and K. Schulte, Influence of different carbon nanotubes on the mechanical properties of epoxy matrix composites - A comparative study, Compos. Sci. Technol., 2005, 65, 2300-2313.

77 K. L. Lu, R. M. Lago, Y. K. Chen, M. L. Green, P. J. Harris and S. C. Tsang, Mechanical Damage of Carbon Nanotubes by Ultrasound, Carbon, 1996, 34, 814-816.

78 K. B. Shelimov, R. O. Esenaliev, A. G. Rinzler, C. B. Huffman and R. E. Smalley, Purification of singlewall carbon nanotubes by ultrasonically assisted filtration, Chem. Phys. Lett., 1998, 282(5-6), 429-434.

79 F. H. Gojny, M. H. Wichmann, U. Kopke, B. Fiedler and K. Schulte, Carbon nanotube-reinforced epoxy-composites: enhanced stiffness and fracture toughness at low nanotube content, Compos. Sci. Technol., 2004, 64, 23612371.

80 M. H. G. Wichmann, J. Sumfleth, F. H. Gojny, M. Quaresimin, B. Fiedler and K. Schulte, Glass-fibrereinforced composites with enhanced mechanical and electrical properties - Benefits and limitations of a nanoparticle modified matrix, Eng. Fract. Mech., 2006, 73(16), 2346-2359.

81 P. Karapappas, A. Vavouliotis, P. Tsotra, V. Kostopoulos and A. Palpetis, Enhanced Fracture Properties of Carbon Reinforced Composites by the Addition of Multi-Wall Carbon Nanotubes, Compos. Mater., 2009, 43, 977-985.

82 L. Radushkevich and V. Lukyanovich, Russ. J. Phys. Chem. A, 1952, 26, 88-95.

83 A. Oberlin, M. M. Endo and T. Koyama, Filamentous growth of carbon through benzene decomposition, J. Cryst. Growth, 1976, 32(3), 335-349.

84 A. Oberlin, M. Endo and T. Koyama, High resolution electron microscope observations of graphitized carbon fibers, Carbon, 1976, 14(2), 133-135.

85 M. Endo and H. Kroto, Formation of carbon nanofibers, J. Phys. Chem., 1992, 96(17), 6941-6944.

86 S. Iijima, Helical microtubules of graphitic carbon, Nature, 1991, 354, 56-58.

87 H. Cebeci, R. Guzman de Villoria, J. Hart and B. L. Wardle, Multifunctional properties of high volume fraction aligned carbon nanotube polymer composites with controlled morphology, Compos. Sci. Technol., 2009, 69, 2649-2656.

88 A. N. S. Alamry, B. G. Prusty, M. R. Mada and S. Bandyopadhyay, Improved Crack Resistance and Fracture Toughness Using MWCNT Modified Epoxy for Delaminated Composite Structures, Procedia Mater. Sci., 2014, 3, 805-810.

89 D. Qian, E. C. Dickey, R. Andrews and T. Rantell, Load transfer and deformation mechanisms in carbon nanotube-polystyrene composites, Appl. Phys. Lett., 2000, 76, 2868.

90 I. Kinloch, M. Shaffer, Y. Lam and A. Windle, Highthroughput screening for carbon nanotube production, Carbon, 2004, 42(1), 101-110.

91 S. Lu, Z. Guo, W. Ding, D. A. Dikin, J. Lee and R. S. Ruoff, In situ mechanical testing of templated carbon nanotubes, Sci. Instrum., 2006, 77, 125101-125101.

92 F. H. Gojny, J. Nastalczyk, Z. Roslaniec and K. Schulte, Surface modified multi-walled carbon nanotubes in CNT/ epoxy-composites, Chem. Phys. Lett., 2003, 370(5-6), 820824.

93 O. Monticelli, Z. Musina, S. Russo and S. Bals, On the use of TEM in the characterization of nanocomposites, Mater. Lett., 2007, 61(16), 3446-3450.

94 O. Lourie and H. D. Wagner, Evaluation of Young's Modulus of Carbon Nanotubes by Micro-Raman Spectroscopy, Mater. Res., 1998, 13(09), 2418-2422.

95 S. Xie, W. i. Li, Z. i. Pan, B. Chang and L. Sun, Mechanical and physical properties on carbon nanotube, Phys. Chem. Solids, 2000, 61, 1153-1158.

96 M. Yu, O. Lourie, M. Dyer, K. Moloni, T. F. Kelly and R. S. Ruoff, Strength and breaking mechanism of multiwalled carbon nanotubes under tensile load, Science, 2000, 287(5453), 637-640.

97 B. I. Yakobson and P. Avouris, Mechanical Properties of Carbon Nanotubes, in Carbon Nanotubes, 80, Springer, Berlin, Heidelberg, Houston, TX, 2001, 287-327.

98 J. I. Weon and H. J. Sue, Effects of clay orientation and aspect ratio on mechanical behavior of nylon-6 nanocomposite, Polymer, 2005, 46(17), 6325-6334.

99 B. Wetzel, P. Rosso, F. Haupert and K. Friedrich, Epoxy nanocomposites - fracture and toughnening mechanisms, Eng. Fract. Mech., 2006, 73(16), 2375-2398.

100 A. Peigney, C. Laurent, E. Flahaut, R. R. Bacsa and A. Rousset, Specific surface area of carbon nanotubes and bundles of carbon nanotubes, Carbon, 2001, 36(4), 507514.

101 A. Hirsch, Functionalization of Single-Walled Carbon Nanotubes, Angew. Chem., Int. Ed., 2002, 41(11), 18531859.

102 K. Balasubramanian and M. Burghard, Chemically Functionalized Carbon Nanotubes, Small, 2005, 1(2), 180192.

103 R. Sattar, A. Kausar and M. Siddiq, Advances in thermoplastic polyurethane composites reinforced with carbon 
nanotubes and carbon nanofiberes: A review, Plast. Film Sheeting, 2014, 1, 1-40.

104 P. Steurer, R. Wissert, R. Thomann and R. Mulhaupt, Functionalized Graphenes and Thermoplastic Nanocomposites Based upon Expanded Graphite Oxide, Macromolecular, 2009, 30(4-5), 316-327.

105 J. A. Kim, D. G. Seong, T. J. Kang and J. R. Youn, Effects of surface modification on rheological and mechanical properties of CNT/epoxy composites, Carbon, 2006, 44, 18981905.

106 J. Zhu, J. Kim, H. Peng, J. L. Margrave, V. N. Khabashesku and E. V. Barrera, Improving the Dispersion and Integration of Single-Walled Carbon Nanotubes in Epoxy Composites through Functionalization, Nano Lett., 2003, 3(8), 1107-1113.

107 K. Schulte, F. H. Gojny, B. Fiedler, J. K. W. Sandler and W. Bauhofer, Carbon Nanotube-Reinforced Polymers: a state of the Art Review, in Polymer Composites from Nanoto Macro-scale, Springer, 2005, 3-23.

108 T. Yokozeki, Y. Iwahori, M. Ishibashi, k. Yanagisawa, K. Imai, M. Arai, T. Takahashi and K. Enomoto, Fracture toughness improvement of CFRP laminates by dispersion of cup-stacked carbon nanotubes, Compos. Sci. Technol., 2009, 69(14), 2268-2273.

109 X.-H. Zhang, Z.-H. Zhang, W.-J. Xu, F.-C. Chen, J.-R. Deng and X. Deng, Toughening of cycloaliphatic epoxy resin by multiwalled carbon nanotubes, Appl. Polym., 2008, 110(3), 1351-1357.

110 F. H. Gojny and K. Schulte, Functionalisation effect on the thermo-mechanical behaviour of multi-wall carbon nanotube/epoxy-composites, Compos. Sci. Technol., 2004, 64(15), 2303-2308.

111 B. Fiedler, F. H. Gojny, M. H. G. Wichmann, M. C. M. Nolte and K. Schulte, Fundamental aspects of nano-reinforced composites, Compos. Sci. Technol., 2006, 66(16), 3115-3125.

112 L.-C. Tang, H. Zhang, J.-H. Han, X.-P. Wu and Z. Zhang, Fracture mechanisms of epoxy filled with ozone functionalized multi-wall carbon nanotubes, Compos. Sci. Technol., 2011, 72, 7-13.

113 J. Zhu, H. Peng, F. Rodriguez-Macias, J. L. Margrave, V. N. Khabashesku, A. M. Imam, K. Lozano and E. V. Barrera, Reinforcing Epoxy Polymer Composites Through Covalent Integration of Functionalized Nanotubes, Adv. Funct. Mater., 2004, 14(7), 643-648.

114 Q.-P. Feng, X.-J. Shen, J.-P. Yang, S.-Y. Fu, Y.-W. Mai and K. Friedrich, Synthesis of epoxy composites with high carbon nanotube loading and effects of tubular and wavy morphology on composite strength and modulus, Polymer, 2011, 52(26), 6037-6045.

115 T. H. Hsieh, A. J. Kinloch, A. C. Taylor and I. Kinloch, The effect of carbon nanotubes on the fracture toughness and fatigue performance of a thermosetting epoxy polymer, Mater. Sci., 2011, 46, 7525-7535.

116 T. H. Hsieh, A. J. Kinloch, A. C. Taylor and S. Sprenger, The Effect of Silica Nanoparticles and Carbon Nanotubes on the Toughness of a Thermosetting Epoxy Polymer, Appl. Polym. Sci., 2011, 119(4), 2135-2142.

117 J.-P. Yang, Z.-K. Chen, Q.-P. Feng, Y.-H. Deng, Q.-Q. Ni and S.- F. Fu, Cryogenic mechanical behaviours of carbon nantube reinforced composites based on modified epoxy by poly(ethersulfone), Composites, Part B, 2012, 43(1), $22-26$.

118 M.-G. Kim, J.-B. Moon and C.-G. Kim, Effect of CNT functionalization on crack resistance of a carbon/epoxy composite at a cryogenic temperature, Composites Part A, 2012, 43(9), 1620-1627.

119 K.-T. Lau, T.-T. Wong, J. Leng, D. Hui and K. Y. Rhee, Property enhancement of polymer-based composites at cryogenic environment by using tailored carbon nanotubes, Composites, Part B, 2013, 54, 41-43.

120 L. Sun, G. L. Warren, J. Y. O'Reilly, W. N. Everett, S. M. Lee, D. Davis, D. Lagoudas and H. J. Sue, Mechanical properties of surface-functionalized SWCNT/epoxy composites, Carbon, 2008, 46, 320-328.

121 M. Ayatollahi, S. Shadlou and M. Shokrieh, Fracture toughness of epoxy/multi-walled carbon nanotube nanocomposites under bending and shear loading conditions, Mater. Des., 2011, 32, 2115-2124.

122 M. Ayatollahi, S. Shadlou and M. Shokrieh, Mixed mode brittle fracture in epoxy/multi-walled carbon nanotube nanocomposites, Eng. Fract. Mech., 2011, 78, 2620-2632.

123 X. F. Yi, A. K. Mishra, N. H. Kim, B.- C. Ku and J. H. Lee, Synergistic effects of oxidized CNTs and reactive oligomer on the fracture toughness and mechanical properties of epoxy, Composites, Part A, 2013, 49, 58-67.

124 R. J. Young, I. A. Kinloch, L. Gong and K. S. Novoselov, The mechanics of graphene nanocomposites: A review, Compos. Sci. Technol., 2012, 72(12), 1459-1476.

125 V. Dhand, K. Y. Rhee, H. J. Kim and D. H. Jung, A Comprehensive Review of Graphene Nanocomposites: Research Status and Trends, Nanomaterials, 2013, 2013, 14.

126 V. Singh, D. Joung, L. Zhai, S. Das, S. I. Khondaker and S. Seal, Graphene based Materials: Past, present and future, Mater. Sci., 2011, 56, 1178-1271.

127 S. Stankovich, D. A. Dikin, G. H. B. Dommett, K. M. Kohlhaas, E. J. Zimney, E. Stach, R. D. Piner, S. T. Nguyen and R. S. Ruoff, Graphene-based composite materials, Nature, 2006, 442, 282-286.

128 S. Chandrasekaran, N. Sato, F. Tölle, R. Mülhaupt, B. Fiedler and K. Schulte, Fracture toughness and failure mechanism of graphene based epoxy composites, Compos. Sci. Technol., 2014, 97, 90-99.

129 J. R. Potts, D. R. Dreyer, C. W. Bielawski and R. S. Ruoff, Graphene-based polymer nanocomposites, Polymer, 2011, 52(1), 5-25.

130 Y. Zhu, S. Murali, W. Cai, X. Li, J. W. Suk, J. R. Potts and R. S. Ruoff, Graphene and graphene oxide: synthesis, properties, and applications., Adv. Mater., 2010, 22(35), 3906-3924.

131 O. C. Compton and S. T. Nguyen, Graphene Oxide, Highly Reduced Graphene Oxide, and Graphene: Versatile Build- 
ing Blocks for Carbon-Based Materials, Small, 2010, 6(6), 711-723.

132 A. Yasmin and I. M. Daniel, Mechanical and thermal properties of graphite platelet/epoxy composites, Polymer, 2004, 45(24), 8211-8219.

133 W.-W. Liu, S.-P. Chai, A. R. Mohamed and U. Hashim, Synthesis and characterization of graphene and carbon nanotubes: A review on the past and recent developments, Ind. Eng. Chem., 2014, 20(4), 1171-1185.

134 A. K. Geim and K. S. Novoselov, The rise of graphene, Nat. Mater., 2007, 6, 183-191.

135 Y. Si and E. T. Samulski, Synthesis of Water Soluble Graphene, Nano Lett., 2008, 8(6), 1679-1682.

136 L. M. Viculis, J. J. Mack, O. M. Mayer, H. T. Hahn and R. B. Kaner, Intercalation and exfoliation routes to graphite nanoplatelets, Mater. Chem., 2005, 15, 974-978.

137 H. Varela-Rizo, I. Rodriguez-Pastor, C. Merino and I. Martin-Gullon, Highly crystalline graphene oxide nanoplatelets produced from helical-ribbon carbon nanofibers, Carbon, 2010, 48, 3635-3658.

138 M. A. Rafiee, J. Rafiee, Z. Wang, H. Song, Y. Zhong-Zhen and N. Koratkar, Enhanced Mechanical Properties of Nanocomposites at Low Graphene Content, J. Am. Chem. Soc., 2008, 3884-3890.

139 X. Zhao, Q. Zhang and D. Chen, Enhanced Mechanical Properties of Graphene-Based Poly(vinyl alcohol) Composites, Macromolecules, 2010, 43(5), 2357-2363.

140 M. A. Rafiee, W. Lu, A. V. Thomas, A. Zandiatashbar, J. Rafiee, J. M. Tour and N. A. Koratkar, Graphene Nanoribbon Composites, ACS Nano, 2010, 4(12), 7415-7420.

141 S. Goenka, V. Sant and S. Sant, Graphene-based nanomaterials for drug delivery and tissue engineering, J. Controlled Release, 2014, 173(10), 75-88.

142 J. P. Rourke, P. A. Pandey, J. J. Moore, M. Bates and I. A. Kinloch, The real graphene oxide revealed. Stripping the oxidation debris from the graphene-like sheets, Angew. Chem., Int. Ed., 2011, 50(14), 3173-3177.

143 K. S. Novoselov, A. K. Geim, S. V. Morozov, Y. Jiang, S. V. Dubonos, I. V. Grigorieva and A. A. Firsov, Electric Field Effect in Atomically Thin Carbon Films, Science, 2004, 306(5696), 666-669.

144 J. Qiu and S. Wang, Enhancing polymer performancethrough graphene sheets, Appl. Polym., 2011, 119(6), 3670-3674.

145 S. Chatterjee, F. Nafezarefi, N. H. Tai, L. Schlagenhauf, F. A. Nuesch and B. T. T. Chu, Size and synergy effects of nanofiller hybrids including graphene nanoplatelets and carbon nanotubes in mechanical properties of epoxy composites, Carbon, 2012, 50(15), 5380-5386.

146 L. Gong, I. A. Kinloch, R. J. Young, I. Riaz, R. Jalil and K. S. Novoselov, Interfacial stress transfer in a graphene monolayer nanocomposite, Adv. Mater., 2010, 22(24), 2694-2697.

147 M. Kluppel, The role of disorder in filler reinforcement of elastomers on various length scales, Adv. Polym. Sci., 2003, 164, 1-86.
148 B. Pukanszky and E. Fekete, Adhesion and surface modification, Adv. Polym. Sci., 1999, 139, 109-153.

149 D. H. Wagner and R. A. Vaia, Nanocomposites: Issues at the interface, Mater. Today, 2004, 7, 38-42.

150 L. Gong, R. J. Young, I. A. Kinloch, I. Riaz, R. Jalil and K. S. Novoselov, Optimizing the reinforcement of polymer based nanocomposites by graphene, J. Am. Chem. Soc., 2012, 6(3), 2086-2095.

151 L. C. Tang, Y. J. Wan, D. Yan, Y. B. Pei, Y. B. Li, L. B. Wu, J. X. Jiang and G. Q. Lai, The effect of graphene dispersion on the mechanical properties of graphene/epoxy composites, Carbon, 2013, 60, 16-27.

152 D. R. Bortz, E. G. Heras and M. G. Ignacio, Impressive Fatigue Life and Fracture Toughness Improvements in Graphene Oxide/Epoxy Composites, Macromolecules, 2012, 45(1), 238-245.

153 I. Zaman, T. T. Phan, H.-C. Kuan, Q. L. L. Meng, T. Bao, L. Luong, O. Youssf and J. Ma, Epoxy/graphene platelets nanocomposites with two levels of interface strength, Polymer, 2011, 52, 1603-1611.

154 I. Zaman, H.-C. Kuan, Q. Meng, A. Michelmore, N. Kawashima, T. Pitt, L. Zhang, S. Gouda, L. Luong and J. Ma, A Facile Approach to Chemically Modified Graphene and its Polymer Nanocomposites, Adv. Funct. Mater., 2012, 22(13), 2735-2743.

155 S. Chatterjee, J. Wang, W. S. Kuo, N. H. Tai, C. Salzmann, W. Li, R. Hollertz, F. Nuesch and B. Chu, Mechanical reinforcement and thermal conductivity in expanded graphene nanoplatelets reinforced epoxy composites, Chem. Phys. Lett., 2012, 531, 6-10.

156 J. Tongwu, K. Tapas, K. Nam Hoon, B.-C. Ku and J. Hee Lee, Enhanced mechanical properties of silanized silica nanoparticle attached graphene oxide/epoxy composites, Compos. Sci. Technol., 2013, 79, 115-125.

157 M. Shokrieh, S. Ghoreishi, M. Esmkhani and Z. Zhao, Effects of graphene nanoplatelets and graphene nanosheets on fracture toughness of epoxy nanocomposites, Fatigue Fract. Eng. Mater. Struct., 2014, 37(10), 11161123.

158 Z. Li, R. Wang, R. J. Young, L. Deng, F. Yang, L. Hao, W. Jiao and W. Liu, Control of the functionality of graphene oxide for its application in epoxy nanocomposites, Polymer, 2013, 54(23), 6437-6446.

159 X.- J. Shen, Y. Liu, H.- M. Xiao, Q.- P. Feng, Z.- Z. Yu and S.- Y. Fu, The reinforcing effect of graphene nanosheets on the cryogenic mechanical properties of epoxy resins, Compos. Sci. Technol., 2012, 72(13), 1581-1587.

160 D. R. Bortz, E. G. Heras and I. Martin-Gullon, Impressive Fatigue Life and Fracture Toughness Improvements in Graphene Oxide/Epoxy Composites, Macromolecules, 2012, 45(1), 238-245.

161 I. Zaman, H.-C. Kuan, Q. Meng, A. Michelmore, N. Kawashima, T. Pitt, L. Zhang, S. Gouda, L. Luong and J. Ma, A Facile Approach to Chemically Modifi ed Graphene and its Polymer Nanocomposites, Adv. Funct. Mater., 2012, 22(13), 2735-2743. 
162 B. A. Moghadam and F. Taheri, Fracture and toughening mechanisms of GNP-based nanocomposites in modes I and II fracture, Eng. Fract. Mech., 2014, 131, 329-339.

163 K.-T. Lau, C. Gu and D. Hui, A critical review on nanotube and nanotube/nanoclay related polymer composite materials, Composites, Part B, 2006, 37(6), 425-436.

164 I. Isik, U. Yilmazer and G. Bayram, Impact modified epoxy/montmorillonite nanocomposites: synthesis and characterization, Polymer, 2003, 44(20), 6371-6377.

165 B. C. Kim, S. W. Park and D. G. Lee, Fracture toughness of nano-particle reinforced epoxy composite, Compos. Struct., 2008, 86(1-3), 69-77.

166 W. Liiu, S. V. Hoa and M. Pugh, Organoclay-modified high performance epoxy nanocomposites, Compos. Sci. Technol., 2005, 65(2), 307-316.

167 M. M. Shokrieh, A. R. Kefayati and M. Chitsazzadeh, Fabrication and mechanical properties of clay/epoxy nanocomposite and its polymer, Mater. Des., 2012, 40, 443452.

168 S. R. Ha, S. H. Ryu, S. J. Park and K. Y. Rhee, Effect of clay surface modification and concentration on the tensile performance of clay/epoxy nanocomposites, Mater. Sci. Eng., 2007, 448(1-2), 264-268.

169 S. R. Ha, K. Y. Rhee, H. C. Kim and J. T. Kim, Fracture performance of clay/epoxy nanocomposites with clay surfacemodified using 3-aminopropyltriethoxysilane, Colloids Surf., A, 2008, 313-314(1), 112-115.

170 N. Salahuddin, A. Moet, A. Hiltner and E. Baer, Nanoscale highly filled epoxy nanocomposite, Eur. Polym. J., 2002, 38(7), 1477-1482.

171 B. Qi, Q. X. Zhang, M. Bannister and Y. M. Mai, Investigation of the mechanical properties of DGEBA-based epoxy resin with nanoclay additives, Compos. Struct., 2006, 75(1-4), 514-519.

172 C.-K. Lam, K.-T. Lau, H.-Y. Cheung and H.-Y. Ling, Effect of ultrasound sonication in nanoclay clusters of nanoclay/ epoxy composites, Mater. Lett., 2005, 59(11), 13691372.

173 K. T. Lau, M. Lu, J. Q. Qi, D. D. Zhao, H. Y. Cheung and C. K. Lam, Cobalt hydroxide colloidal particles precipitation on nanoclay layers for the formation of novel nanocomposites of carbon nanotubes/nanoclay, Compos. Sci. Technol., 2006, 66(3-4), 450-458.

174 K. Devendra and T. Rangaswamy, Evaluation of Thermal Properties of E-Glass/Epoxy Composites Filled by Different Filler Materials, Comput. Eng. Res., 2012, 2(5), 17081713.

175 A. Yasmin, J. L. Abot and I. M. Daniel, Processing of clay/ epoxy nanocomposites by shear mixing, Scr. Mater., 2003, 49, 81-86.

176 R. Velmurugan and T. P. Mohan, Room temperature processing of epoxy-clay nanocomposites, Mater. Sci., 2004, 39, 7333-7339.

177 M.-l. Chan, K.-t. Lau, T.-t. Wong, M.-p. Ho and D. Hui, Mechanism of reinforcement in a nanoclay/polymer composite, Composites, Part B, 2011, 42, 1708-1712.
178 A. H. Hemmasi, I. Ghasemi, B. Bazyar and A. Samariha, Influence of Nanoclay on the Physical Properties of Recycled High- Density Polyethylene/Bagasse Nanocomposite, Middle East Sci. Res., 2011, 8(3), 648-651.

179 L. Wang, K. Wang, L. Chen, Y. Zhang and C. He, Preparation, morphology and thermal/mechanical properties of epoxy/nanoclay composite, Composites, Part A, 2006, 37, 1890-1896.

180 K. Wang, L. Chen, J. Wu, M. L. Toh, C. He and A. F. Yee, Epoxy Nanocomposites with Highly Exfoliated Clay: Mechanical Properties and Fracture Mechanisms, Macromolecules, 2005, 38(3), 788-800.

181 M. Zappalorto, M. Salviato and M. Quaresimin, Mixed mode $(\mathrm{I}+\mathrm{II})$ fracture toughness of polymer nanoclay nanocomposites, Eng. Fract. Mech., 2013, 111, 50-64.

182 A. Guevara-Morales and A. C. Taylor, Mechanical and dielectric properties of epoxy-clay nanocomposites, Mater. Sci., 2014, 49, 1574-1584.

183 J.- P. Yang, G. Yang, G. Xu and S.-Y. Fu, Cryogenic mechanical behaviors of MMT/epoxy nanocomposites, Compos. Sci. Technol., 2007, 67(14), 2934-2940.

184 A. Brunner, A. Necola, M. Rees, P. Gasser, X. Kornmann, R. Thomann and M. Barbezat, The influence of silicatebased nano-filler on the fracture toughness of epoxy resin, Eng. Fract. Mech., 2006, 73, 2336-2345.

185 J. Jordan, K. l. Jacob, R. Tannenbaum, M. A. Sharaf and I. Jasiuk, Experimental trends in polymer nanocomposites - a review, Mater. Sci. Eng., A, 2005, 393(1), 1-11.

186 J. T. Han and K. Cho, Layered silicate-induced enhancement of fracture toughness of epoxy molding compounds over a wide temperature range, Macromol. Mater. Eng., 2005, 290, 1184-1191.

187 P. Rosso, L. Ye, K. Friedrich and S. Sprenger, A toughened epoxy resin by silica nanoparticle reinforcement, Polym. Sci., 2005, 100, 1849-1855.

188 H. Zhang, Z. Zhang, K. Friedrich and C. Eger, Property improvements of in situ epoxy nanocomposites with reduced interparticle distance at high nanosilica content, Acta Mater., 2006, 54, 1833-1842.

189 M. Battistella, M. Cascione, B. Fiedler, M. H. G. Winchmann, M. Quaresimin and K. Schulte, Fracture behaviour of fumed silica/epoxy nanocomposites, Composites, Part A, 2008, 39(12), 1851-1858.

190 G. Ragosta, M. Abbate, P. Musto, G. Scarinzi and L. Mascia, Epoxy-silica particulate nanocomposite: Chemical interactions, reinforcement and fracture toughness, Polymer, 2005, 46(23), 10506-10516.

191 O. Cheng-Fang and S. Ming-Chin, Epoxy composites reinforced by different size silica nanoparticles, Appl. Polym. Sci., 2010, 115(5), 2648-2653.

192 S. Deng and L. F. K. Ye, Fracture behaviours of epoxy nanocomposites with nanosilica at low and elevated temperatures, Mater. Sci., 2007, 42(8), 2766-2774.

193 H. Zou, S. Wu and J. Shen, Polymer/Silica Nanocomposites: Preparation, Characterization, Properties and Applications, Chem. Rev., 2008, 108, 3893-3957. 
194 L. Ruiz- Perez, G. J. Royston, J. P. A. Fairclough and A. J. Ryan, Toughening by nanostructure, Polymer, 2008, 49, 4475-4488.

195 Y. L. Liang and R. A. Pearson, Toughening mechanisms in epoxy-silica nanocomposites (ESNs), Polymer, 2009, 50(20), 4895-4905.

196 L. Chen, S. Chai, K. Liu, N. Ning, J. Gao, Q. Liu, F. Chen and Q. Fu, Enhanced Epoxy/Silica Composites Mechanical Properties by Introducing Graphene Oxide to the Interface, ACS Appl. Mater. Interfaces, 2012, 4(8), 4398-4404.

197 Y. Liang and R. Pearson, Toughening mechanisms in epoxy-silica nanocomposites (ESNs), Polymer, 2009, 50, 4895-4905.

198 B. R. K. Blackman, A. J. Kinloch, J. Lee, A. C. Taylor, R. Agarwal and G. Schueneman, The fracture and fatigue behaviour of nano-modified epoxy polymers, Mater. Sci., 2007, 42(16), 7046-7051.

199 B. B. Johnsen, A. J. Kinloch, R. D. Mohammed, A. C. Taylor and S. Sprenger, Toughening mechanisms of nanoparticle-modified epoxy polymers, Polymer, 2007, 48(2), 530-541.

200 A. J. Kinloch, R. D. Mohammed and A. C. Taylor, The effect of silica nano particles and rubber particles on the toughness of multiphase thermosetting epoxy polymers, Mater. Sci., 2005, 40(18), 5083-5086.

201 M. Zamanian, M. Mortezaei, B. Salehnia and J. Jam, Fracture toughness of epoxy polymer modified with nanosilica particles: Particle size effect, Eng. Fract. Mech., 2013, 97, 193-206.

202 P. Dittanet and R. A. Pearson, Effect of silica nanoparticle size on toughening mechanisms of filled epoxy, Polymer, 2012, 53, 1890-1905.

203 J. Ma, M.-S. Mo, X.-S. Du, P. Rosso, K. Friedrich and H.-C. Kuan, Effect of inorganic nanoparticles on mechanical property, fracture toughness and toughening mechanism of two epoxy systems, Polymer, 2008, 49, 3510-3523.

204 C. J. Huang, S. Y. Fu, Y. H. Zhang, B. Lauke, F. Li and L. Ye, Cryogenic properties of SiO2/epoxy nanocomposites, Cryogenics, 2005, 45(6), 450-454.

205 H. Manwar, N. Atsushi, N. Shigehiro and N. Koichi, Fracture behavior and fracture toughness of particulate filled epoxy composites, Mater. Lett., 1996, 27, 21-25.

206 Q. Zhao and S. V. Hoa, Toughening Mechanism of Epoxy Resins with Micro/Nano Particles, Compos. Mater., 2007, 41(2), 201-219.

207 J. K. Chen, G. T. Wang, Z. Z. Yu, Z. Huang and Y. W. Mai, Critical particle size for interfacial debonding in polymer/ nanoparticle composites, Compos. Sci. Technol., 2010, 70(5), 861-872.

208 S. A. Meguid, J. M. Wernik and F. A. Jahwari, Toughening mechanisms in multiphase nanocomposites, Mech. Mater. Des. , 2013, 9(2), 115-125.

209 C. S. Li, D. Z. Wang, T. X. Liang, X. F. Wang, J. J. Wu, $\mathrm{X}$. Q. Hu and J. J. Liang, Oxidation of multiwalled carbon nanotubes by air: benefits for electric double layer capacitors, Powder Technol., 2004, 142(2-3), 175-179.

210 M. Shaffer and I. A. Kinloch, Prospects for nanotube and nanofibre composites, Compos. Sci. Technol., 2004, 64(15), 2281-2282.

211 J. N. Coleman, U. Khan, W. J. Blau and Y. K. Gun'ko, Small but strong: A review of the mechanical properties of carbon nanotube-polymer composites, Carbon, 2006, 44, 1624-1652.

212 S. Cui, I. A. Kinloch, R. J. Young, L. Noe and M. Monthioux, The effect of stress transfer within doublewalled carbon nanotubes upon their ability to reinforce composites, Adv. Mater., 2009, 21(35), 35913595.

213 H. Qian, E. S. Greenhalgh, M. S. P. Shaffer and A. Bismarck, Carbon nanotube-based hierarchical composites: a review, J. Mater. Chem., 2010, 20, 4751-4762.

214 M. R. Ayatollahi, S. Shadlou, M. M. Shokrieh and M. Chitsazzadeh, Effect of multi-walled carbon nanotube aspect ratio on mechanical and electrical properties of epoxy-based nanocomposites, Polym. Test., 2011, 30, 548556.

215 H. A. Perez, F. Aviles, M. A. Pat, V. A. Gonzalez, H. P. Franco and B. P. Perez, Effective properties of multiwalled carbon nanotube/epoxy composites using two different tubes, Compos. Sci. Technol., 2008, 68, 14221431.

216 D. Galpaya, M. Wang, M. Liu, N. Motta, E. Waclawik and C. Yan, Recent Advances in Fabrication and Characterization of Graphene-Polymer Nanocomposites, Sci. Res., 2012, 30-49.

217 D. R. Bortz, C. Merino and I. Martin-Gullon, Carbon nanofibers enhance the fracture toughness and fatigue performance of a structural epoxy system, Compos. Sci. Technol., 2011, 71, 31-38.

218 D. Bray, P. Dittanet, F. Guild, A. Kinloch, K. Masania, R. Pearson and A. Taylor, The modelling of the toughening of epoxy polymers via silica nanoparticles: The effects of volume fraction and particle size, Polymer, 2013, 54, 7022-7032. 